\title{
Catalytic Deoxygenation of Nitroarenes mediated by high-valent molybdenum(VI)-NHC complexes
}

Shenyu Liu, ${ }^{a}$ Jorge Ivan Amaro-Estrada, ${ }^{\mathrm{b}}$ Marc Baltrun, ${ }^{\mathrm{a}}$ Iskander Douair, ${ }^{\mathrm{b}}$ Roland Schoch, ${ }^{\mathrm{a}}$ Laurent Maron, ${ }^{\text {b* }}$ and Stephan Hohloch ${ }^{\mathrm{c}}$

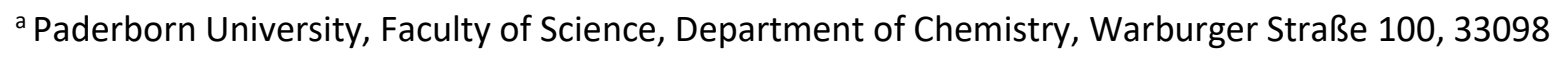
Paderborn, Germany.

${ }^{b}$ LPCNO, Université de Toulouse, INSA Toulouse, 135 Avenue de Rangueil, 31077 Toulouse, France

E-Mail: laurent.maron@irsamc.ups-tlse.fr

c University of Innsbruck, Faculty of Chemistry and Pharmacy, Institute of General, Inorganic and Theoretical Chemistry, Innrain 80-82, 6020 Innsbruck, Austria

E-Mail: Stephan.Hohloch@uibk.ac.at

Supporting Information

\section{Table of contents}

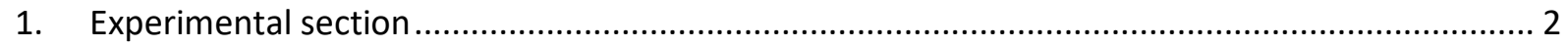

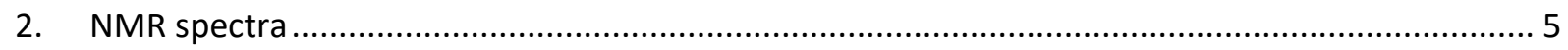

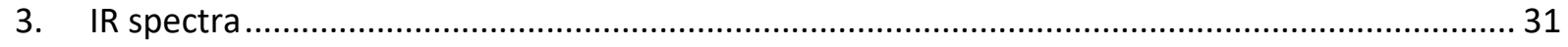

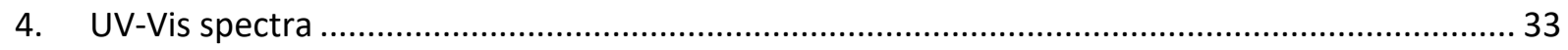

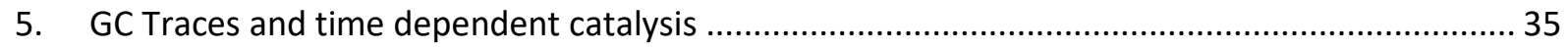

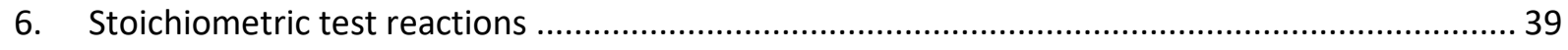

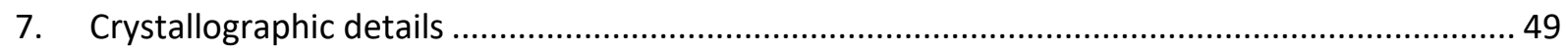

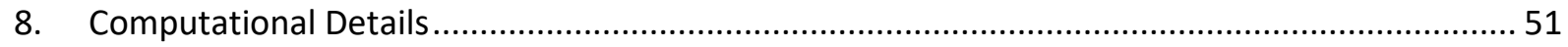

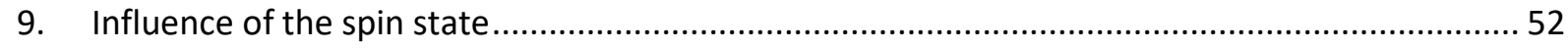

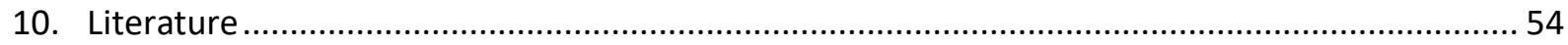




\section{Experimental section}

\section{General methods and instrumentation.}

If not otherwise mentioned, all transformations were carried out under inert conditions using the Schlenk technique or an argon filled glovebox. Solvents were dried by a MBraun SPS system and stored over activated molecular sieves ( $3 \AA$ ) for at least $24 \mathrm{~h}$. The deuterated solvents $C_{6} D_{6}$ were dried by storage over activated molecular sieves ( $3 \AA$ ) for at least $24 \mathrm{~h}$. IR spectra were recorded at room temperature under inert conditions using a Bruker Vertex 70 with ATR equipment. If not otherwise stated, the NMR spectra were collected at $298 \mathrm{~K}$ on a Bruker AV-500 or an Ascent 700 spectrometer using a J-Young NMR tube. All chemical shifts $(\delta)$ are reported in ppm. ${ }^{1} \mathrm{H}$ and ${ }^{13} \mathrm{C}$ chemical shifts were calibrated to residual solvent peaks. ${ }^{15} \mathrm{~N}$ chemical shifts were calibrated to liquid ammonia $\left(\mathrm{NH}_{3}\right)$ and were determined using ${ }^{1} \mathrm{H}_{-}{ }^{15} \mathrm{~N}$ HMBC NMR. ${ }^{31} \mathrm{P}$ chemical shifts were calibrated to phosphoric acid $\left(\mathrm{H}_{3} \mathrm{PO}_{4}, 85 \%\right.$ in water). Elemental analyses were performed using an Elementar vario microcube instrument at the University of Paderborn. Magnetic moments have been obtained using the Evans method at room temperature. ${ }^{[1]}$

GC analysis was carried out using an Agilent 6890 headspace instrument with a DB-5ms column ( $30 \mathrm{~m}$ $\times 0.25 \mathrm{~mm} \times 0.25 \mu \mathrm{m})$ by J\&W Scientific and an FID detector. Samples were analyzed using the following method: Injection Temp: $60^{\circ} \mathrm{C}$, Heating rate $15^{\circ} \mathrm{C} / \mathrm{min}$. End temperature: $300{ }^{\circ} \mathrm{C}$.

$\mathrm{MoO}_{2} \mathrm{Cl}_{2}(\mathrm{DME})^{[2]} \mathrm{MoO}\left(\mathrm{N}^{\mathrm{t} B u}\right) \mathrm{Cl}_{2} \mathrm{DME}{ }^{[3]}$ complexes $\mathbf{1}$ and $\mathbf{2}^{[4]}$ and the proligand $\left[\mathrm{H}_{3} \mathrm{~L}\right] \mathrm{Cl}^{[5]}$ were obtained following literature known procedures.

\section{X-ray crystallography.}

Single crystals for X-ray diffraction experiments were measured at the analytical facility of the University of Paderborn, the University of Duisburg-Essen, and the Bruker Training Center in Karlsruhe. All crystals were kept at 130(2) or 100(2) K throughout data collection. Data was collected using either the Smart or the APEXIII software package. Data refinement and reduction were performed with Bruker Saint (V8.34A). All structures were solved with SHELXT and refined using the OLEX 2 software package. ${ }^{[6,7]}$ Strongly disordered solvent molecules were removed using the SQUEEZE operation. ${ }^{\left[{ }^{[8]}\right.}$ All non-hydrogen atoms were refined anisotropically, and hydrogen atoms were included at the geometrically calculated positions and refined using a riding model. All structures have been submitted to the CCDC and can be obtained under the numbers presented in Table S1. For further crystallographic details regarding crystal measurements, please check Tables S1 and S2 in the Supporting Information.

For complex 5 we have not been able to grow high-quality crystals. Problems occurred due to strong twinning and/or low diffraction $\left(2 \Theta=33^{\circ}\right.$ resolution max) of the crystals. The model as such cannot be considered reliable, however it matches well with other analytical data, so that at least the connectivity and overall configuration of the molecule are correctly described.

\section{Computational details.}

Please see section 7 for further details. 


\section{Synthetic procedures:}

Complex 4: In an argon filled glovebox a $10 \mathrm{~mL}$ J-Young Schlenk flask was loaded with complex 1 (1 eq, $0.2 \mathrm{mmol}, 138 \mathrm{mg}$ ) and dissolved in toluene $(3 \mathrm{~mL})$. To this solution was added dropwise a solution of triethylphosphine (10 eq, $2 \mathrm{mmol}, 237 \mathrm{mg}$ ) in toluene $(3 \mathrm{~mL}$ ). The flask was capped and brought outside of the glovebox and was stirred for $24 \mathrm{~h}$ at $100{ }^{\circ} \mathrm{C}$. Afterwards, toluene was evaporated under high vacuum leaving behind a reddish brown residue, which was washed with hexane $(2 \times 5 \mathrm{~mL})$ to give the desired product as a reddish brown powder in a yield of $56 \% .76 \mathrm{mg}, 0.06 \mathrm{mmol}) .{ }^{1} \mathrm{H}$ NMR $\left(\mathrm{C}_{6} \mathrm{D}_{6}, 700\right.$ $\left.\mathrm{MHz}, 25^{\circ} \mathrm{C}\right): \delta(\mathrm{ppm}) 10.26(\mathrm{~s}, 2 \mathrm{H}$, Aryl-H), $9.92(\mathrm{~s}, 2 \mathrm{H}$, Aryl-H), $7.90(\mathrm{~d}, J=7.9 \mathrm{~Hz}, 2 \mathrm{H}$, Aryl-H), 7.85 (t, J $=7.6 \mathrm{~Hz}, 2 \mathrm{H}$, Aryl-H), $7.60(\mathrm{t}, J=7.6 \mathrm{~Hz}, 2 \mathrm{H}$, Aryl-H), $7.54(\mathrm{~d}, J=7.9 \mathrm{~Hz}, 2 \mathrm{H}$, Aryl-H), $5.48(\mathrm{~s}, 2 \mathrm{H}$, Aryl-H), $4.80\left(\mathrm{~s}, 2 \mathrm{H}\right.$, Aryl-H), $3.52\left(\mathrm{~s}, 18 \mathrm{H}, \mathrm{C}\left(\mathrm{CH}_{3}\right)_{3}\right), 2.16\left(\mathrm{~s}, 18 \mathrm{H}, \mathrm{C}\left(\mathrm{CH}_{3}\right)_{3}\right), 1.40\left(\mathrm{~s}, 18 \mathrm{H}, \mathrm{C}\left(\mathrm{CH}_{3}\right)_{3}\right), 1.30(\mathrm{~s}, 18 \mathrm{H}$, $\left.\mathrm{C}\left(\mathrm{CH}_{3}\right)_{3}\right) ;{ }^{13} \mathrm{C} \mathrm{NMR}\left(\mathrm{C}_{6} \mathrm{D}_{6}, 175 \mathrm{MHz}, 25^{\circ} \mathrm{C}\right): \delta$ (ppm) 184.1 (Aryl-CH), 183.2 (Aryl-CH), 180.9 (Aryl-C), 173.1 (Aryl-C), 145.9 (Aryl-C), 134.2 (Aryl-C), 131.8 (Aryl-C), 131.7 (Aryl-C), 130.2 (Aryl-C), 129.7 (Aryl-C), 129.3 (Aryl-CH), 128.6 (Aryl-CH), 126.1 (Aryl-CH), 122.2 (Aryl-CH), 121.2 (Aryl-CH), 121.0 (Aryl-C), 58.9 $\left.\left(\mathrm{C}\left(\mathrm{CH}_{3}\right)_{3}\right), 53.8\left(\mathrm{C}_{(\mathrm{CH}}\right)_{3}\right), 40.4\left(\mathrm{C}\left(\mathrm{CH}_{3}\right)_{3}\right), 38.2\left(\mathrm{C}\left(\mathrm{CH}_{3}\right)_{3}\right), 36.9\left(\mathrm{C}\left(\mathrm{CH}_{3}\right)_{3}\right), 36.7\left(\mathrm{C}\left(\mathrm{CH}_{3}\right)_{3}\right), 30.2\left(\mathrm{C}\left(\mathrm{CH}_{3}\right)_{3}\right)$; Carbene- $\mathrm{C}$ not obtained, Aryl- $\mathrm{CH}$ hidden underneath solvent signal Elemental analysis calcd.(\%) for $\mathrm{C}_{70} \mathrm{H}_{88} \mathrm{~N}_{4} \mathrm{O}_{7} \mathrm{Mo}_{2} \quad \mathrm{O}_{1} \mathrm{P}_{1}\left(\mathrm{C}_{2} \mathrm{H}_{5}\right)_{3} \mathrm{C} 64.12$ H 7.29 N 3.94. Found C $64.34 \mathrm{H}$ 7.48 N 3.65.

Complex 5: In an argon filled glovebox a $10 \mathrm{~mL}$ J-Young Schlenk flask was loaded with complex 2 (1 eq, $0.3 \mathrm{mmol}, 228 \mathrm{mg}$ ) and dissolved in toluene ( $3 \mathrm{~mL}$ ). To this solution was added dropwise a solution of triethylphosphine (10 eq, $3 \mathrm{mmol}, 355 \mathrm{mg}$ ) in toluene $(3 \mathrm{~mL}$ ). The flask was capped and brought outside of the glovebox and was stirred for $24 \mathrm{~h}$ at $100{ }^{\circ} \mathrm{C}$. Afterwards, toluene was evaporated under high vacuum leaving behind a highly air sensitive dark green residue, which was washed with hexane $(4 \times 5 \mathrm{~mL})$ to give the desired product as a green powder in a yield of $81 \% .(0.128 \mathrm{mmol}, 179 \mathrm{mg}) .{ }^{1} \mathrm{H}$ $\operatorname{NMR}\left(\mathrm{C}_{6} \mathrm{D}_{6}, 700 \mathrm{MHz}, 25^{\circ} \mathrm{C}\right): \delta(\mathrm{ppm}) 8.50(\mathrm{~s}, 2 \mathrm{H}, \operatorname{Aryl}-\mathrm{H}), 8.37(\mathrm{~s}, 2 \mathrm{H}, \operatorname{Aryl}-\mathrm{H}), 7.96(\mathrm{~d}, J=8.6 \mathrm{~Hz}, 2 \mathrm{H}$, Aryl-H), $7.71(\mathrm{~d}, J=8.6 \mathrm{~Hz}, 2 \mathrm{H}$, Aryl-H), $7.57(\mathrm{t}, J=7.2 \mathrm{~Hz}, 2 \mathrm{H}, \operatorname{Aryl}-H), 7.25(\mathrm{t}, J=7.2 \mathrm{~Hz}, 2 \mathrm{H}$, Aryl-H), $6.96(\mathrm{~s}, 2 \mathrm{H}, \mathrm{Aryl}-\mathrm{H}), 6.48(\mathrm{~s}, 2 \mathrm{H}, \operatorname{Aryl}-\mathrm{H}), 2.85\left(\mathrm{~s}, 18 \mathrm{H}, \mathrm{C}\left(\mathrm{CH}_{3}\right)_{3}\right), 1.45\left(\mathrm{~s}, 36 \mathrm{H}, \mathrm{C}\left(\mathrm{CH}_{3}\right)_{3}, \mathrm{Mo}=\mathrm{NC}\left(\mathrm{CH}_{3}\right)_{3}\right), 1.30$ $\left(\mathrm{s}, 18 \mathrm{H}, \mathrm{C}\left(\mathrm{CH}_{3}\right)_{3}\right),-1.11\left(\mathrm{~s}, 18 \mathrm{H}, \mathrm{C}\left(\mathrm{CH}_{3}\right)_{3}\right) ;{ }^{13} \mathrm{C} \mathrm{NMR}\left(\mathrm{C}_{6} \mathrm{D}_{6}, 175 \mathrm{MHz}, 25^{\circ} \mathrm{C}\right): \delta$ (ppm) 392.3 (Carbene- $\left.\mathrm{C}\right)$, 391.5 (Carbene-C), 170.0 (Aryl-C), 159.6 (Aryl-C), 158.6 (Aryl-C), 158.5 (Aryl-CH), 156.0 (Aryl-C), 155.9 (Aryl-C), 151.8 (Aryl-CH), 137.0 (Aryl-C), 134.9 (Aryl-C), 133.8 (Aryl-C), 129.6 (Aryl-C), 128.1 (Aryl-CH), 126.4 (Aryl-CH), 126.1 (Aryl-CH), 125.0 (Aryl-CH), 124.0 (Aryl-CH), 123.9 (Aryl-C), $48.6\left(\mathrm{Mo}=\mathrm{N} \mathrm{C}\left(\mathrm{CH}_{3}\right)_{3}\right)$,

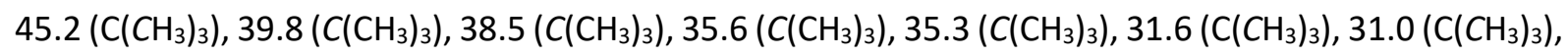

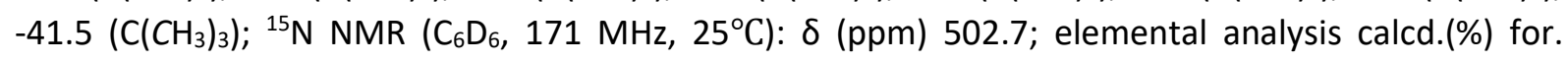
$\mathrm{C}_{78} \mathrm{H}_{106} \mathrm{~N}_{6} \mathrm{O}_{5} \mathrm{Mo}_{2} \mathrm{C} 66.94 \mathrm{H} 7.63 \mathrm{~N}$ 6.00. Found C $67.23 \mathrm{H} 7.53 \mathrm{~N} 6.24$.

Complex 6: Route A: In an argon filled glovebox, complex 1 (1 eq, $0.1 \mathrm{mmol}, 65 \mathrm{mg}$ ) and pinacol (1.5 eq, $0.15 \mathrm{mmol}, 17.9 \mathrm{mg}$ ) were suspended in acetonitrile $(3 \mathrm{~mL})$ in a $10 \mathrm{~mL}$ J-Young Schlenk flask. The suspension was vigorously stirred overnight at room temperature, during which a fine pale yellow precipitate formed. The resulting solid was collected and washed with hexane, to remove excess of pinacol, until the washings were colorless. The title compound was obtained in yield of $96 \%$ (0.1 mmol, $74.1 \mathrm{mg}$ ).

Route $B$ : In an argon filled glovebox, complex 1 (1 eq, $0.1 \mathrm{mmol}, 65 \mathrm{mg}$ ) and pinacol (1.5 eq, $0.15 \mathrm{mmol}$, $17.9 \mathrm{mg}$ ) were dissolved in benzene $(5 \mathrm{~mL})$ in a $20 \mathrm{~mL}$ scintillation vial. The mixture was shaken three times to guarantee good mixing of the reactants and the left to stand over the weekend at room temperature. This afforded pale yellow (X-ray quality) crystals of 6 . The reddish benzene solution was decanted and the yellow crystals were washed wit $2 \times 5 \mathrm{~mL}$ hexanes and dried in the glovebox atmosphere for $4 \mathrm{~h}$. This affords crystalline complex 6 in a yield of $78 \%(0.078 \mathrm{mmol}, 60 \mathrm{mg})$. ${ }^{1} \mathrm{H} \mathrm{NMR}\left(\mathrm{CD}_{2} \mathrm{Cl}_{2}, 700 \mathrm{MHz}, 25^{\circ} \mathrm{C}\right): \delta(\mathrm{ppm}) 8.87(\mathrm{~s}, 1 \mathrm{H}$, Benzimidazolium- $2 \mathrm{H}), 8.25(\mathrm{~s}, 1 \mathrm{H}, \mathrm{OH}), 7.82(\mathrm{~d}, J$ $=7.9 \mathrm{~Hz}$, Aryl-H), $7.71(\mathrm{~m}, 1 \mathrm{H}$, Aryl-H), $7.67(\mathrm{~m}, 1 \mathrm{H}$, Aryl-H), $7.61(\mathrm{~d}, J=2.3 \mathrm{~Hz}, \operatorname{Aryl}-H), 7.57(\mathrm{~d}, J=2.3$ $\mathrm{Hz}, \operatorname{Aryl}-H), 7.49$ (d, J = 7.9 Hz, Aryl-H), $7.32(\mathrm{~d}, J=2.3 \mathrm{~Hz}$, Aryl-H), 7.09 (d, J = 2.3 Hz, Aryl-H), 1.51 (s, 
$\left.9 \mathrm{H}, \mathrm{C}\left(\mathrm{CH}_{3}\right)_{3}\right), 1.46\left(\mathrm{~s}, 9 \mathrm{H}, \mathrm{C}\left(\mathrm{CH}_{3}\right)_{3}\right), 1.38\left(\mathrm{~s}, 9 \mathrm{H}, \mathrm{C}\left(\mathrm{CH}_{3}\right)_{3}\right), 1.31\left(\mathrm{~s}, 9 \mathrm{H}, \mathrm{C}\left(\mathrm{CH}_{3}\right)_{3}\right), 1.11$ (s, 3H, pinacol- $\left.\mathrm{CH}_{3}\right)$, $0.93\left(\mathrm{~s}, 3 \mathrm{H}\right.$, pinacol- $\left.\mathrm{CH}_{3}\right), 0.85\left(\mathrm{~s}, 3 \mathrm{H}\right.$, pinacol- $\left.\mathrm{CH}_{3}\right), 0.50\left(\mathrm{~s}, 3 \mathrm{H}\right.$, pinacol- $\left.\mathrm{CH}_{3}\right) ;{ }^{13} \mathrm{C} \mathrm{NMR}\left(\mathrm{C}_{6} \mathrm{D}_{6}, 175 \mathrm{MHz}\right.$, 25으): $\delta$ (ppm) 155.5 (Aryl-C-O-Mo), 149.7 (Aryl-C-OH), 144.1 (Aryl-C), 144.0 (Aryl-C), 143.5 (Benzimidazolium-2C), 142.6 (Aryl-C), 141.8 (Aryl-C), 133.1 (Aryl-C), 132.6 (Aryl-C), 128.7 (Aryl-C), 128.0 (Aryl-CH), 127.89 (Aryl-CH), 127.7 (Aryl-CH), 126.2 (Aryl-CH), 125.8 (Aryl-C), 125.1 (Aryl-C), 121.9 (Aryl$\mathrm{CH}$ ), 121.8 (Aryl-C), 119.9 (Aryl-CH), 115.4 (Aryl-CH), 114.8 (Aryl-CH), 96.7 (pinacol-C), 91.5 (pinacol-C),

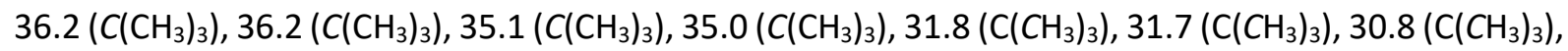
$29.9\left(\mathrm{C}_{\left.\left(\mathrm{CH}_{3}\right)_{3}\right),} 27.5\right.$ (pinacol- $\left.\mathrm{CH}_{3}\right), 26.9$ (pinacol- $\mathrm{CH}_{3}$ ), 25.1 (pinacol- $\mathrm{CH}_{3}$ ), 24.1 (pinacol- $\mathrm{CH}_{3}$ ). elemental analysis calcd.(\%) for. $\mathrm{C}_{41} \mathrm{H}_{58} \mathrm{~N}_{2} \mathrm{O}_{6} \mathrm{Mo}_{1} \mathrm{C} 63.88 \mathrm{H} 7.58 \mathrm{~N}$ 3.63. Found $\mathrm{C} 63.63 \mathrm{H} 7.24 \mathrm{~N} 3.75$.

Complex 7: In an argon filled glovebox complex 1 (1 eq, $0.02 \mathrm{mmol}, 13,8 \mathrm{mg}$ ) was dissolved in $0.5 \mathrm{~mL}$ of benzene and stirred for 5 minutes. To this solution was added triethylphosphine oxide ( 1 eq, 0.02 $\mathrm{mmol}, 3 \mathrm{mg}$ ) dissolved in $0.5 \mathrm{~mL}$ of benzene. The reaction was stirred for $1 \mathrm{~h}$ at room temperature. Afterwards the benzene was evaporated under high vacuum leaving behind analytically pure complex 7 as a pale yellow solid in quantitative yields. $0.02 \mathrm{mmol}, 16 \mathrm{mg}){ }^{1} \mathrm{H} N \mathrm{NMR}\left(\mathrm{C}_{6} \mathrm{D}_{6}, 700 \mathrm{MHz}, 25^{\circ} \mathrm{C}\right): \delta$ (ppm) $8.05(\mathrm{~m}, 2 \mathrm{H}, \operatorname{Aryl}-\mathrm{H}), 7.80(\mathrm{~d}, J=2.4 \mathrm{~Hz}, 2 \mathrm{H}, \operatorname{Aryl}-\mathrm{H}), 7.60(\mathrm{~d}, J=2.4 \mathrm{~Hz}, 2 \mathrm{H}, \operatorname{Aryl}-\mathrm{H}), 7.07(\mathrm{~m}, 2 \mathrm{H}$, Aryl-H), $1.79\left(\mathrm{~s}, 18 \mathrm{H}, \mathrm{C}\left(\mathrm{CH}_{3}\right)_{3}\right), 1.38\left(\mathrm{~s}, 18 \mathrm{H}, \mathrm{C}\left(\mathrm{CH}_{3}\right)_{3}\right), 1.11\left(\mathrm{~m}, 6 \mathrm{H}, \mathrm{OP}\left(\mathrm{CH}_{2} \mathrm{CH}_{3}\right)_{3}\right), 0.50(\mathrm{~m}, 9 \mathrm{H}$, $\left.\mathrm{OP}\left(\mathrm{CH}_{2} \mathrm{CH}_{3}\right)_{3}\right) ;{ }^{13} \mathrm{C} \mathrm{NMR}\left(\mathrm{C}_{6} \mathrm{D}_{6}, 175 \mathrm{MHz}, 25^{\circ} \mathrm{C}\right): \delta$ (ppm) 194.5 (Carbene-C), 154.1 (Aryl-C), 141.5 (ArylC), 140.7 (Aryl-C), 133.9 (Aryl-C), 133.9 (Aryl-C), 124.7 (Aryl-CH), 122.8 (Aryl-CH), 116.4 (Aryl-CH), 114.6

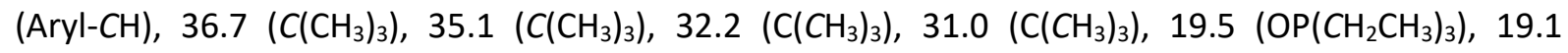
$\left(\mathrm{OP}\left(\mathrm{CH}_{2} \mathrm{CH}_{3}\right)_{3}\right), 5.8\left(\mathrm{OP}\left(\mathrm{CH}_{2} \mathrm{CH}_{3}\right)_{3}\right), 5.8\left(\mathrm{OP}\left(\mathrm{CH}_{2} \mathrm{CH}_{3}\right)_{3}\right) ;{ }^{31} \mathrm{P} \mathrm{NMR}\left(\mathrm{C}_{6} \mathrm{D}_{6}, 283 \mathrm{MHz}, 25^{\circ} \mathrm{C}\right): \delta(\mathrm{ppm}) 55.7$; $\mathrm{C}_{41} \mathrm{H}_{59} \mathrm{~N}_{2} \mathrm{O}_{5} \mathrm{P}_{1} \mathrm{Mo} \mathrm{C} 62.58 \mathrm{H} 7.56 \mathrm{~N}$ 3.56. Found C 62.31 H 7.45 N 3.43.

Stoichiometric test reaction: In an argon filled glovebox, complexes 4, 5 or 6 ( 1 eq, $0.025 \mathrm{mmol}$ ) were mixed with stoichiometric amounts (1 eq) of either $o$-nitrotoluene, $o$-nitrosotoluene or azobenzene in a J-Young NMR tube in $\mathrm{C}_{6} \mathrm{D}_{6}(0.8 \mathrm{~mL})$ at room temperature. The reaction progress was followed by ${ }^{1} \mathrm{H}$ NMR spectroscopy. The results are summarized in Figures S35 - S44.

Time dependent catalytic deoxygenations and condition optimization: In an argon filled glove box, the corresponding amount ( $1 \mathrm{~mol} \%, 0.5 \mathrm{~mol} \%, 0.25 \mathrm{~mol} \%$ ) of complex 1 or 2 were dissolved in $4 \mathrm{~mL}$ of toluene. To this solution was added pinacol ( $4 \mathrm{eq}, 4 \mathrm{mmol}, 473 \mathrm{mg}$ ), o-nitrotoluene ( $1 \mathrm{eq}, 1 \mathrm{mmol}, 137$ $\mathrm{mg}$ ) and mesitylene $(0.5 \mathrm{eq}, 0.5 \mathrm{mmol}, 60 \mathrm{mg})$ as an internal standard. The reaction was capped and stirred at the corresponding temperature $\left(110^{\circ} \mathrm{C}\right.$ or $\left.130^{\circ} \mathrm{C}\right)$ for the assigned amount of time. In case of the time-dependent analysis, small aliquots of the reaction mixture were taken at the assigned times and analyzed via GC.

Catalytic deoxygenation reactions: In an argon filled glovebox, complex 1 (1 mol\%, $6.8 \mathrm{mg}$ ) was dissolved in toluene $(4 \mathrm{~mL}$ ). To this solution was added pinacol (4 eq, $4 \mathrm{mmol}, 437 \mathrm{mg}$ ) the corresponding substrates $(1 \mathrm{mmol})$ and mesitylene $(0.5 \mathrm{eq}, 0.5 \mathrm{mmol}, 60 \mathrm{mg})$ as an internal standard. The reaction mixtures were capped and heated to $130{ }^{\circ} \mathrm{C}$ for $24 \mathrm{~h}$. The yields were determined by GC using mesitylene as an internal standard. To determine isolated yields, the crude reaction mixtures were treated with $0.5 \mathrm{M} \mathrm{NaOH}$ solutions and extracted with diethyl ether. The organic layer was washed with brine and dried over magnesium sulfate and evaporated to give the desired anilines in pure form. For entries I the product was additionally purified using silica gel column chromatography using hexane/ethyl acetate/triethylamine (95:4:1) as an eluent. 


\section{NMR spectra}

ஸ़̃
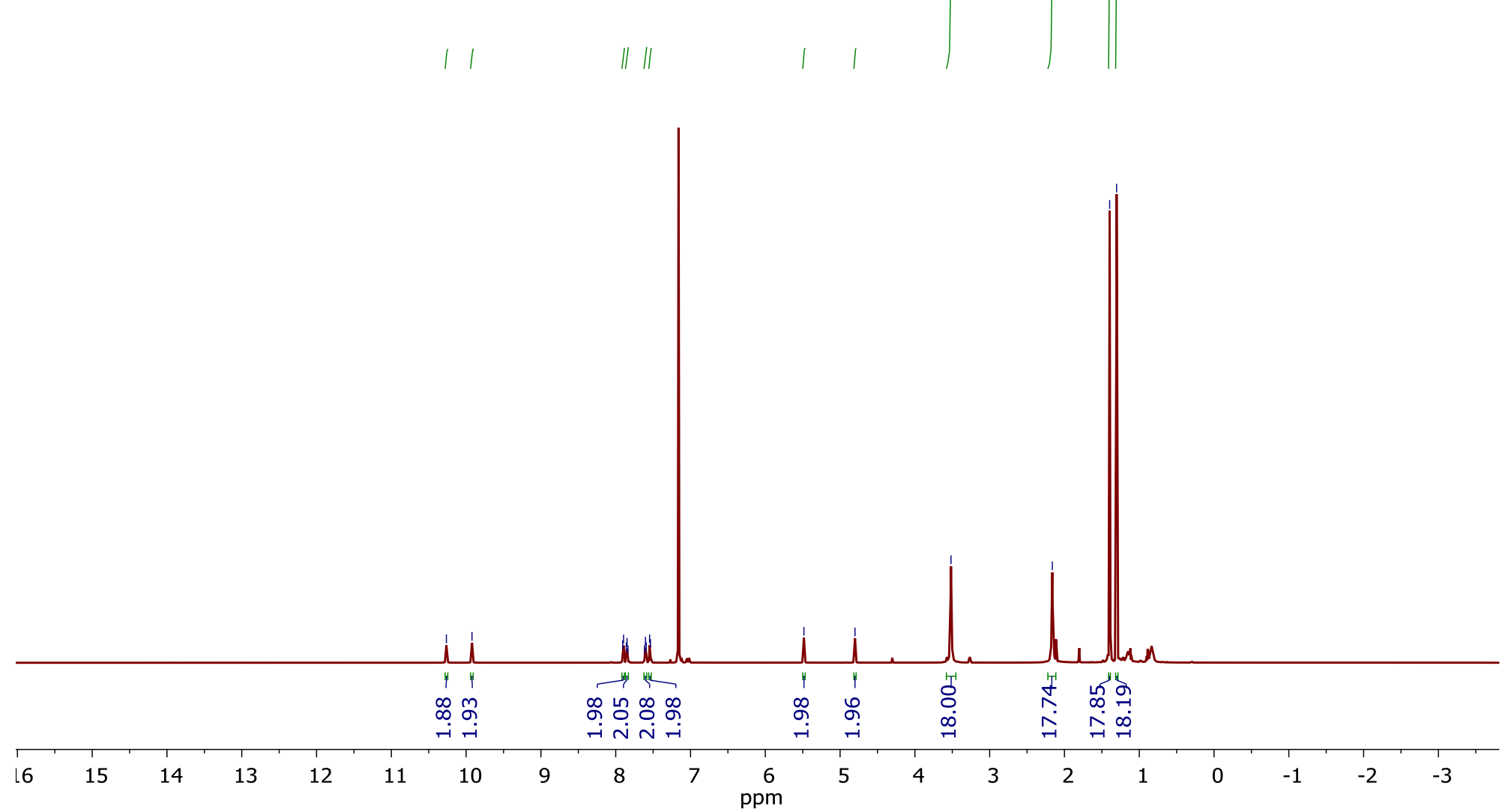

Figure S1: $\quad{ }^{1} \mathrm{H}$ NMR of 4 in $\mathrm{C}_{6} \mathrm{D}_{6}$ at $298 \mathrm{~K}$.

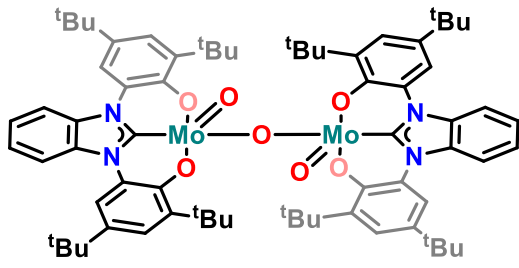

${ }_{\mathrm{t}}^{\mathrm{Bu}}$ 

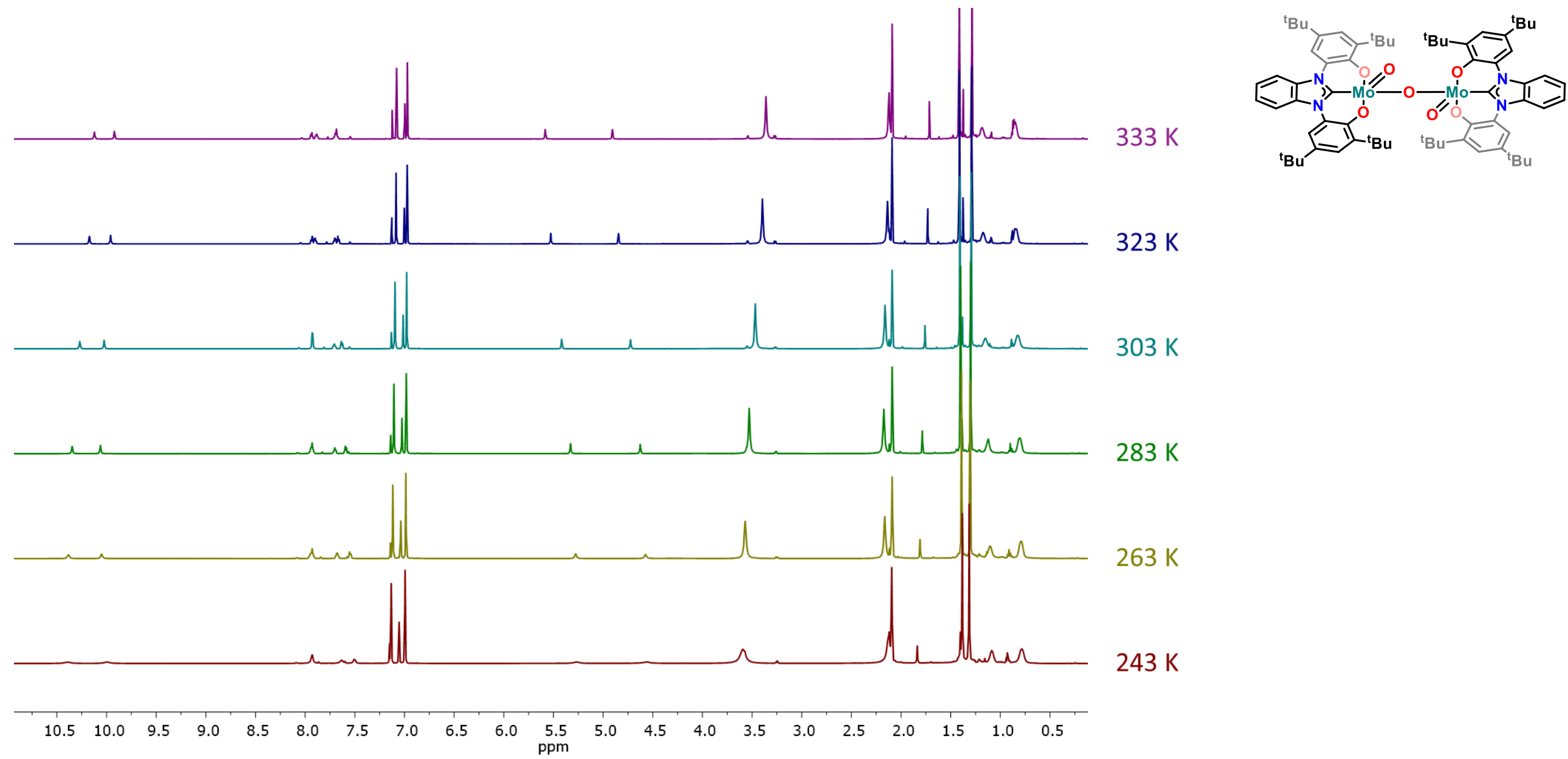

Figure S2: $\quad$ Variable temperature ${ }^{1} \mathrm{H}-\mathrm{NMR}$ of $\mathbf{4}$ in $\mathrm{C}_{7} \mathrm{D}_{8}$. 

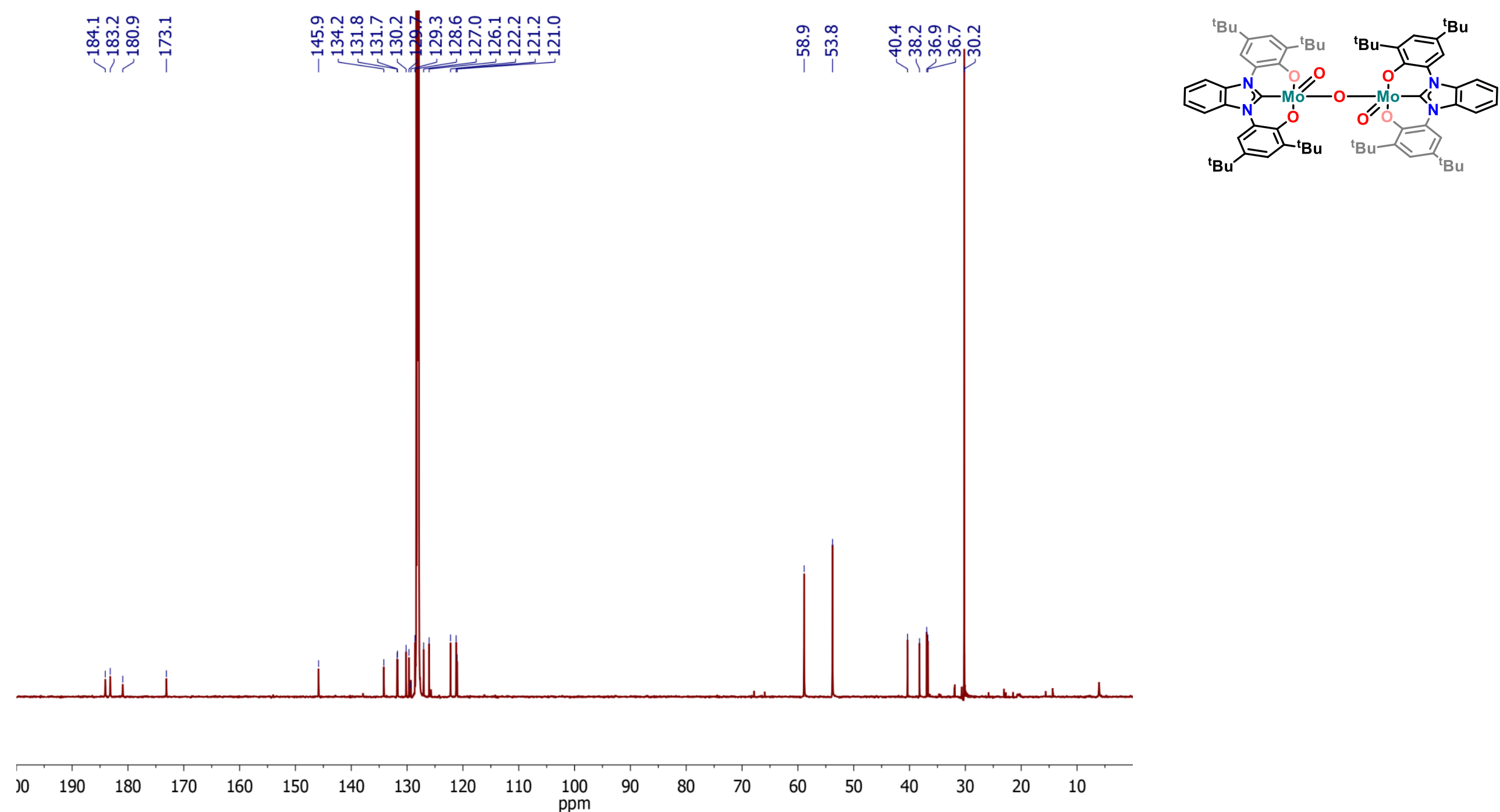

Figure S3: $\quad{ }^{13} \mathrm{C}\left\{{ }^{1} \mathrm{H}\right\}-\mathrm{NMR}$ of 4 in $\mathrm{C}_{6} \mathrm{D}_{6}$ at $298 \mathrm{~K}$. 


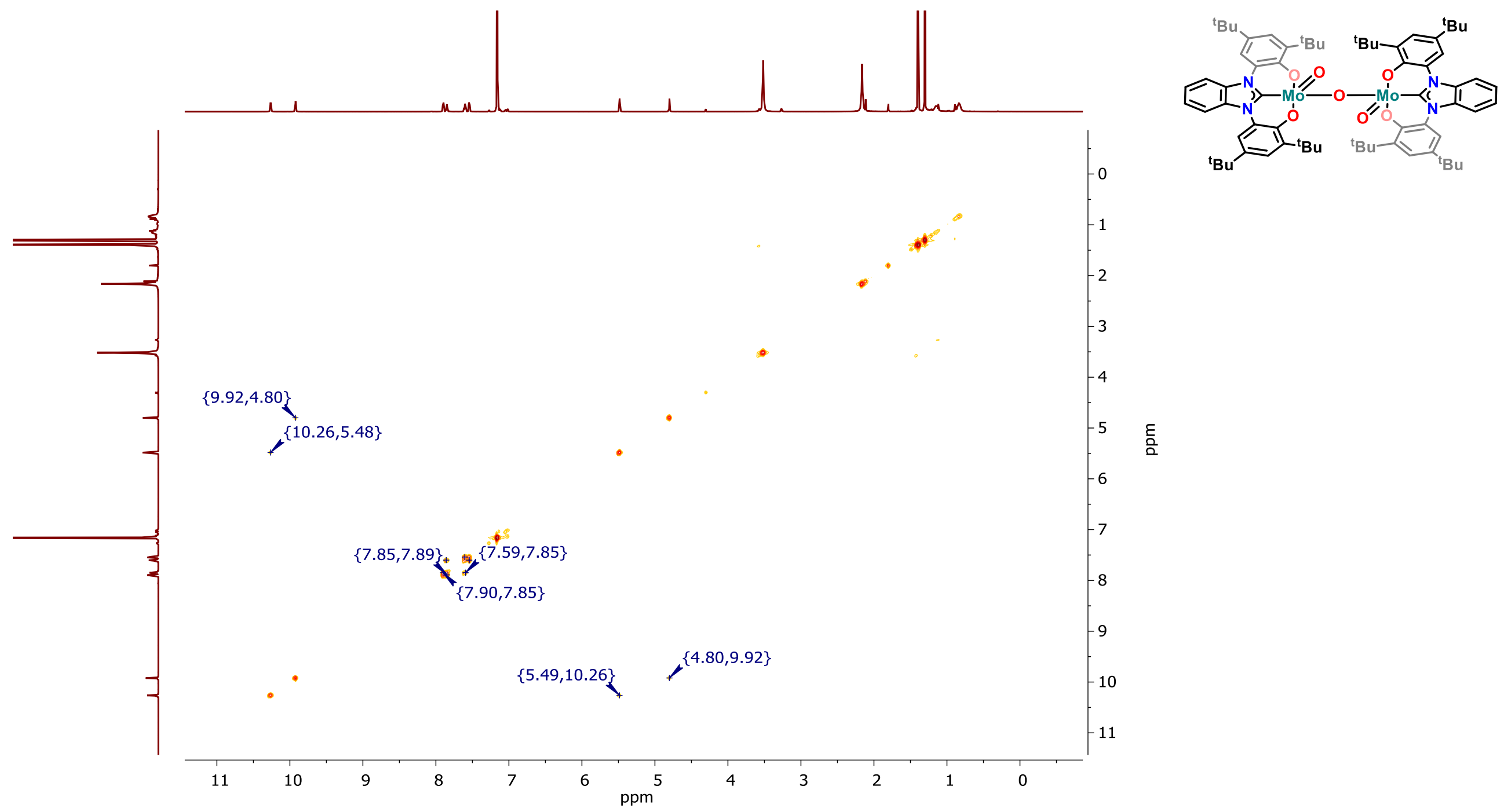

Figure S4: $\quad{ }^{1} \mathrm{H}-{ }^{1} \mathrm{H}$ COSY of 4 in $\mathrm{C}_{6} \mathrm{D}_{6}$ at $298 \mathrm{~K}$. 


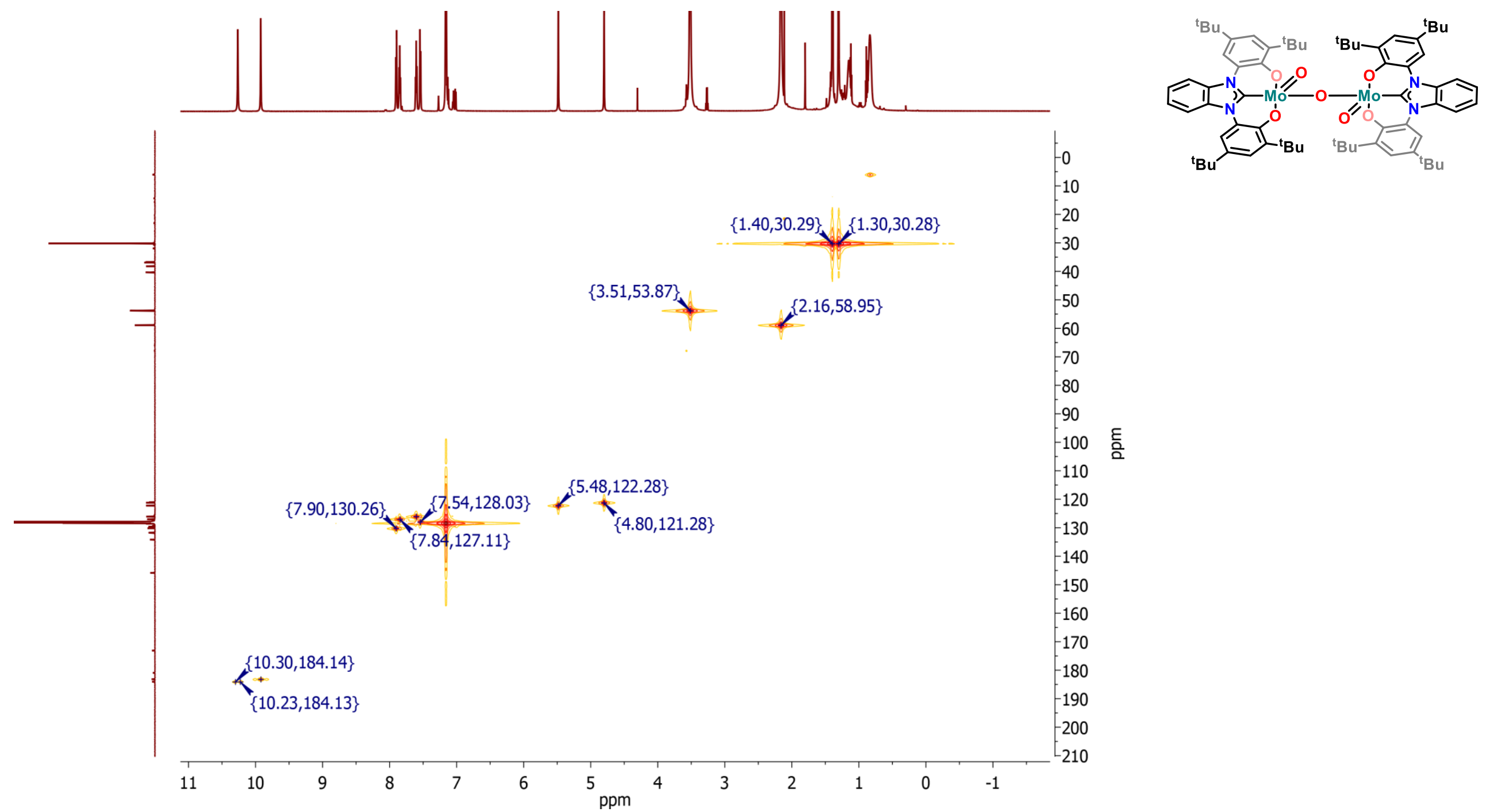

Figure S5: $\quad{ }^{1} \mathrm{H}_{-}{ }^{13} \mathrm{C}$ HSQC of 4 in $\mathrm{C}_{6} \mathrm{D}_{6}$ at $298 \mathrm{~K}$. 


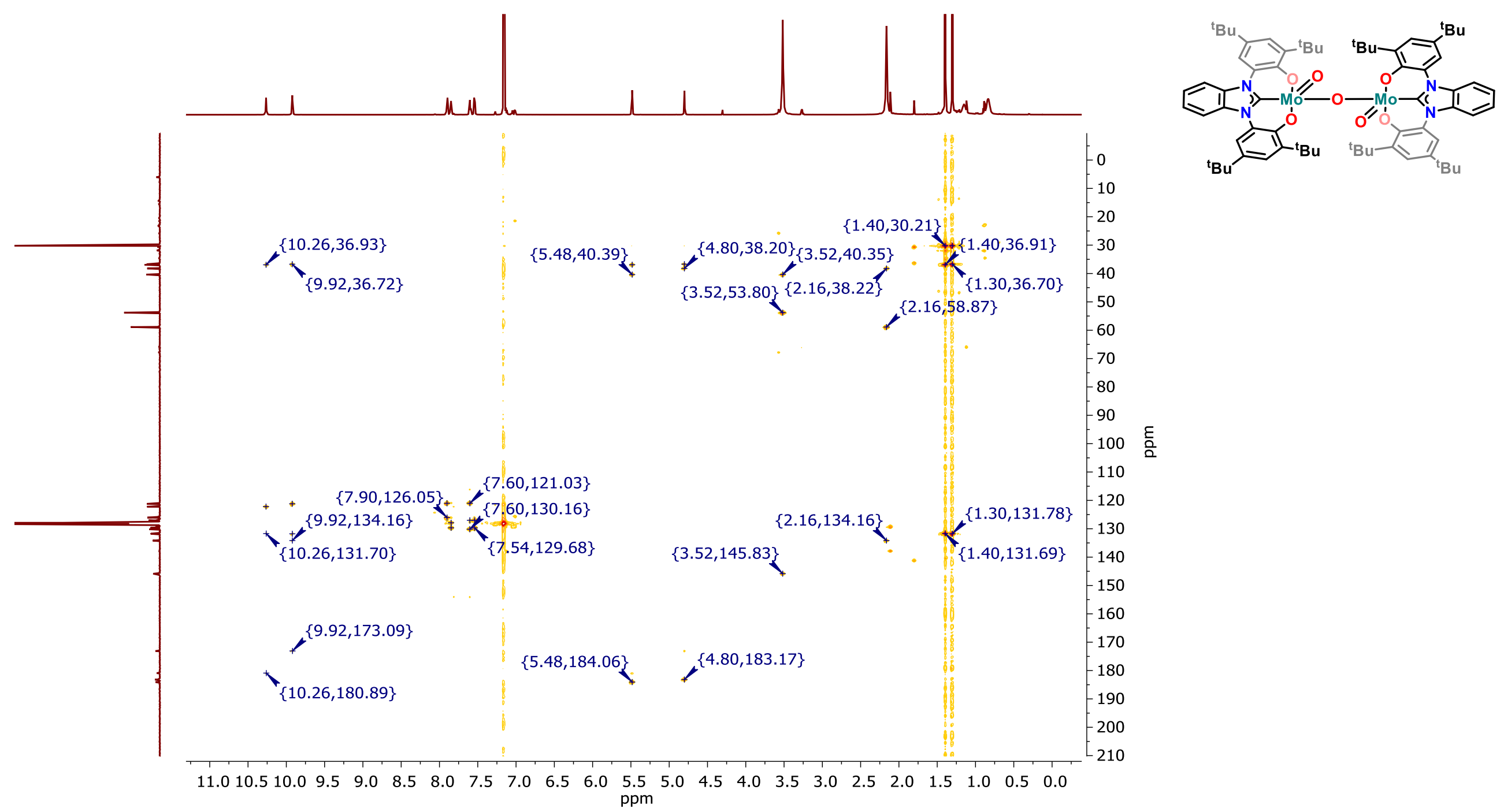

Figure S6: $\quad{ }^{1} \mathrm{H}_{-}{ }^{13} \mathrm{C} H M B C$ of 4 in $\mathrm{C}_{6} \mathrm{D}_{6}$ at $298 \mathrm{~K}$. 


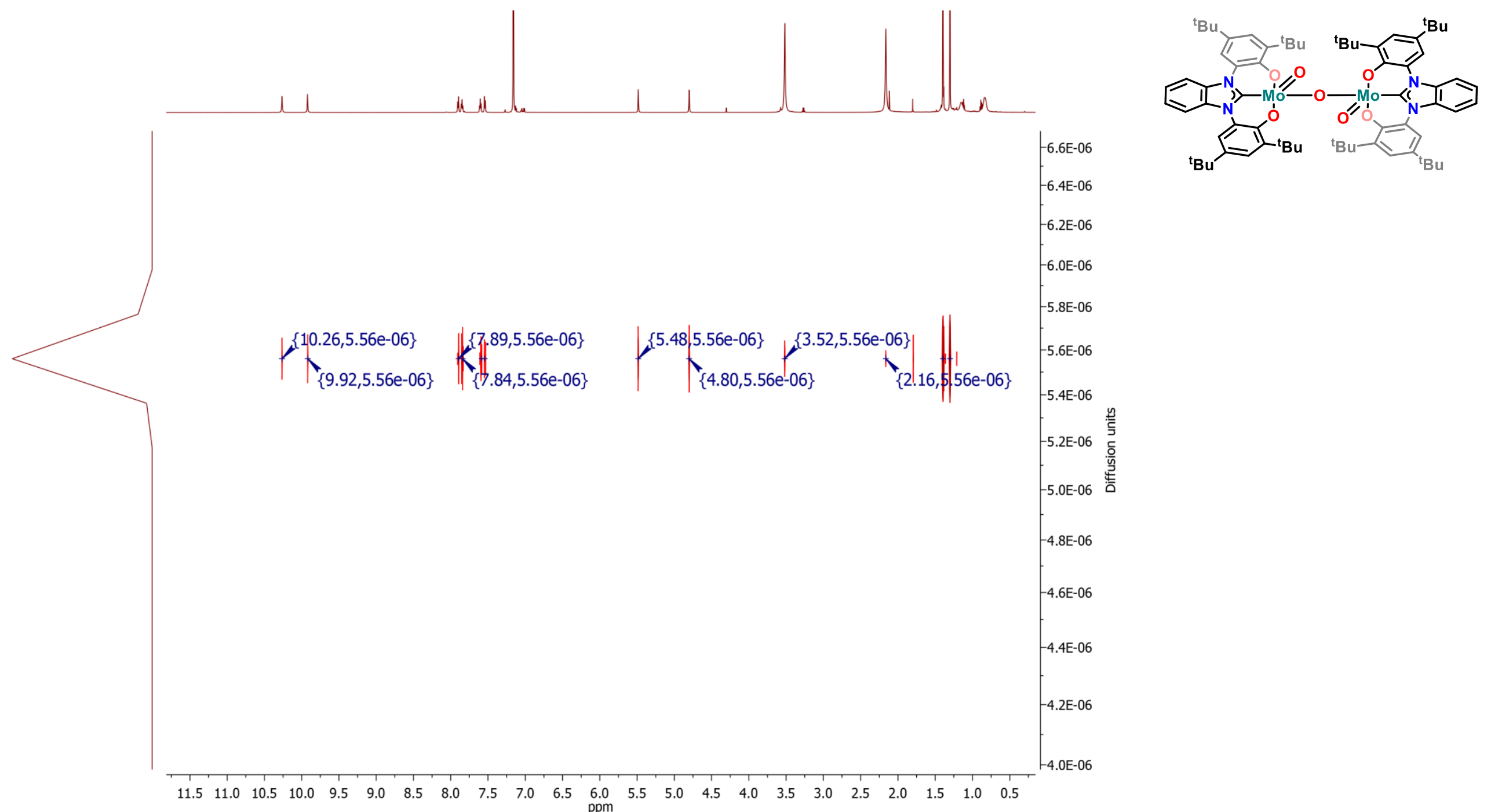

Figure S7: $\quad{ }^{1} \mathrm{H}$ DOSY of 4 in $\mathrm{C}_{6} \mathrm{D}_{6}$ at $298 \mathrm{~K}$. 


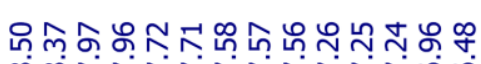

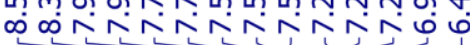
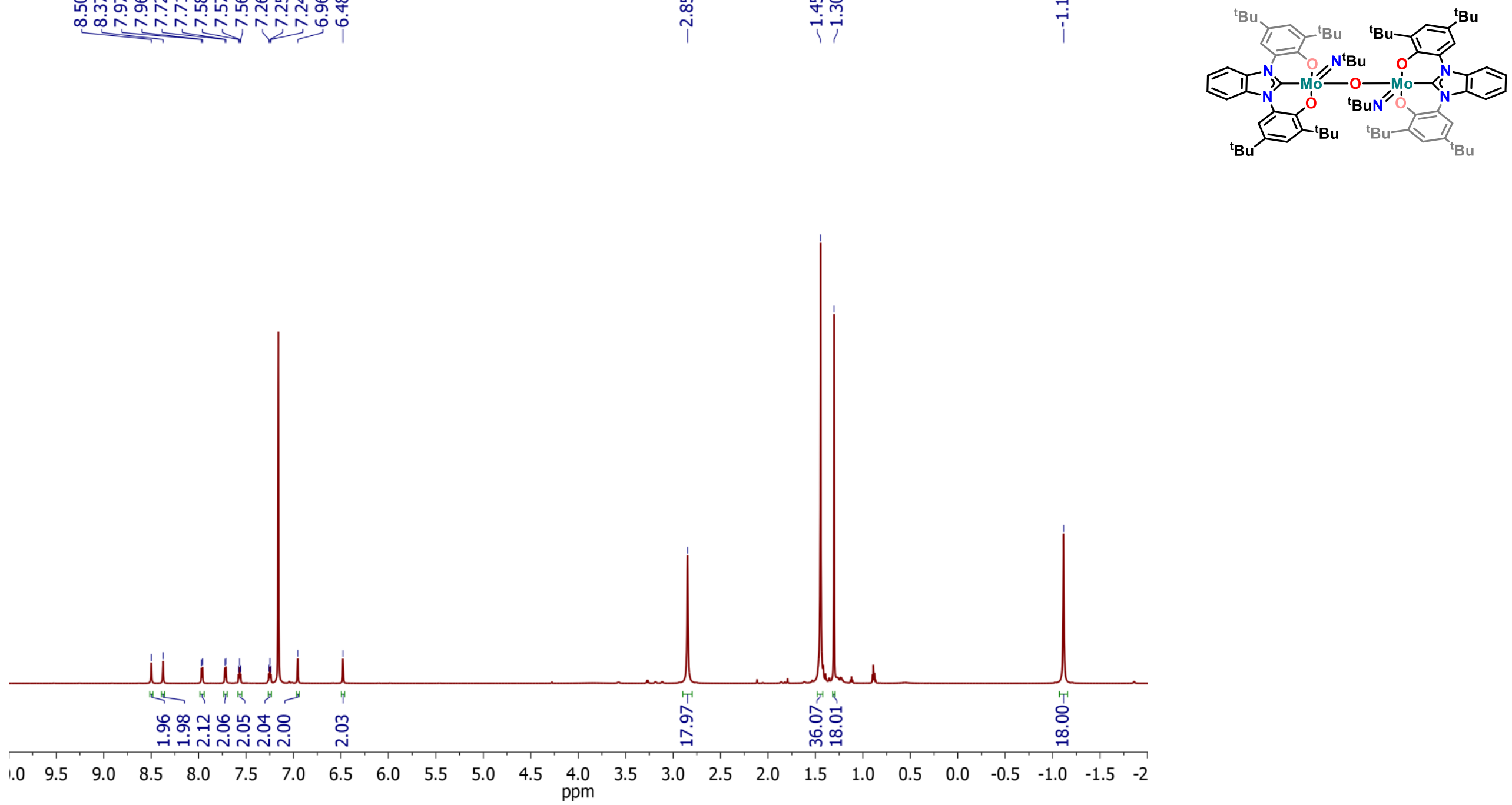

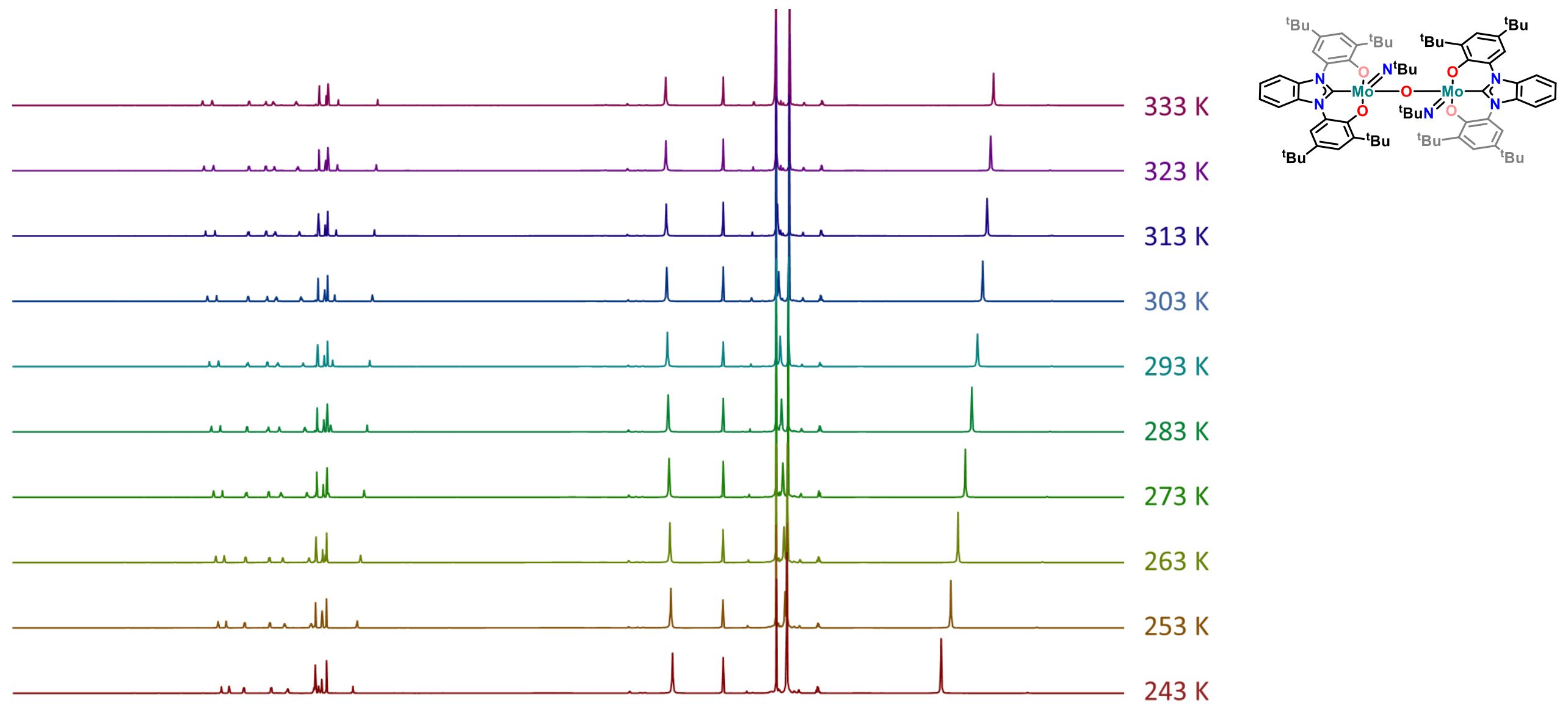

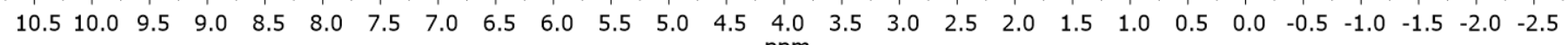

$\mathrm{ppm}$

Figure S9: $\quad$ Variable temperature ${ }^{1} \mathrm{H}$ NMR of 5 in $C_{7} D_{8}$ 

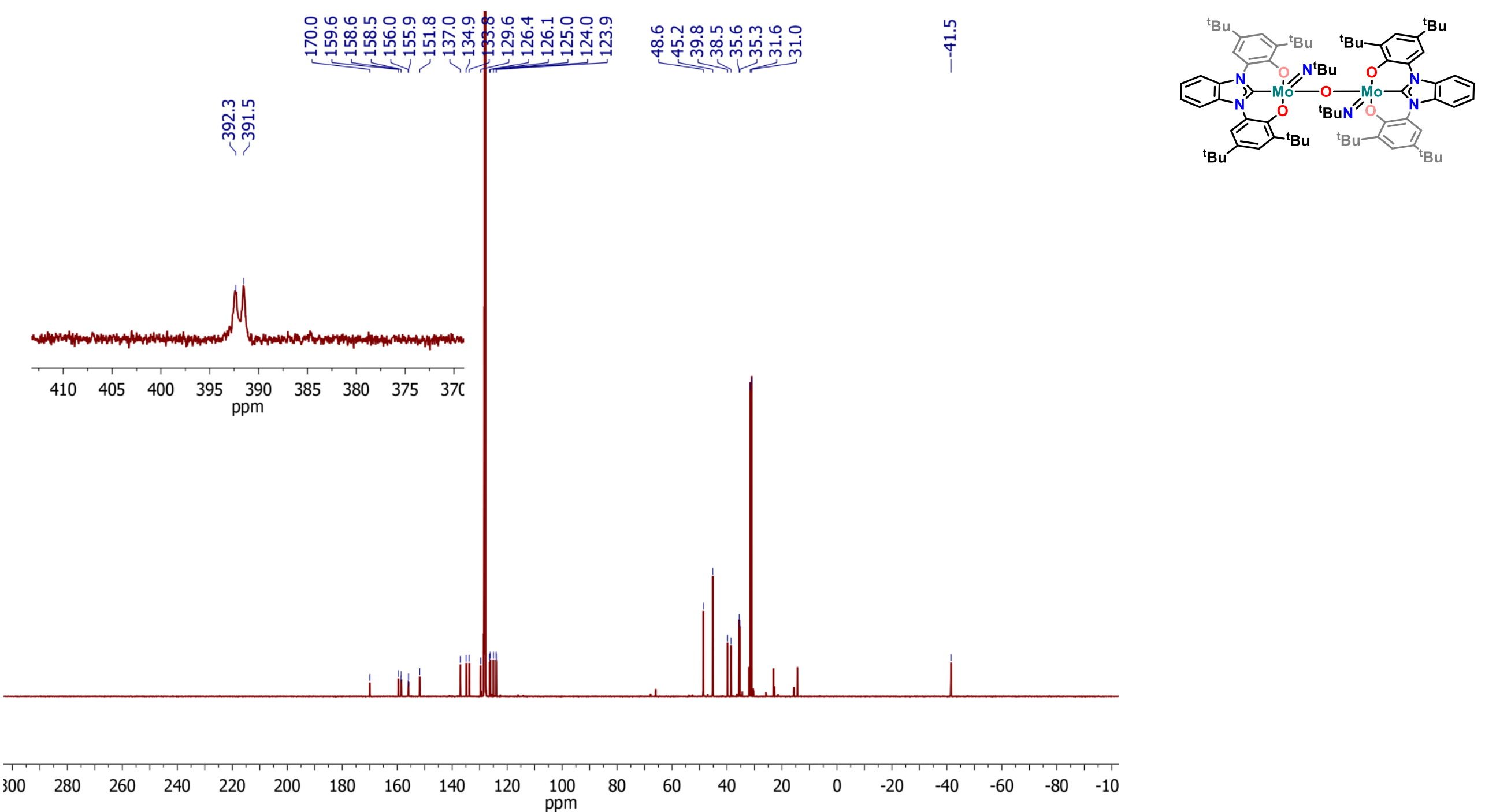

Figure S10: $\quad{ }^{13} \mathrm{C}\left\{{ }^{1} \mathrm{H}\right\}$ NMR of 5 in $\mathrm{C}_{6} \mathrm{D}_{6}$ at $298 \mathrm{~K}$. Please note that small impurities of hexane are present at 14 and $22 \mathrm{ppm}$. 


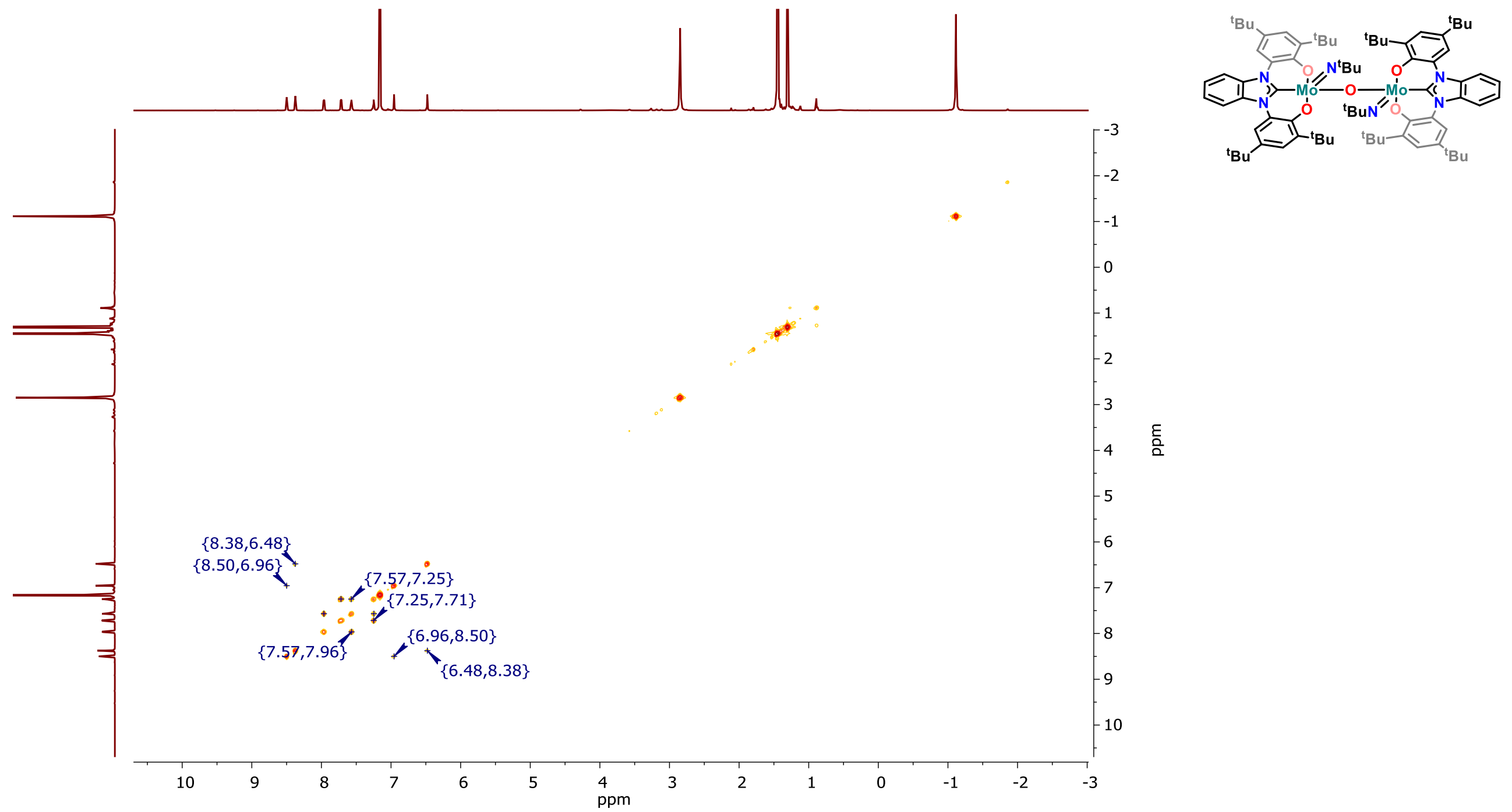

Figure S11: $\quad{ }^{1} \mathrm{H}-{ }^{1} \mathrm{H}$ COSY of 5 in $\mathrm{C}_{6} \mathrm{D}_{6}$ at $298 \mathrm{~K}$. 

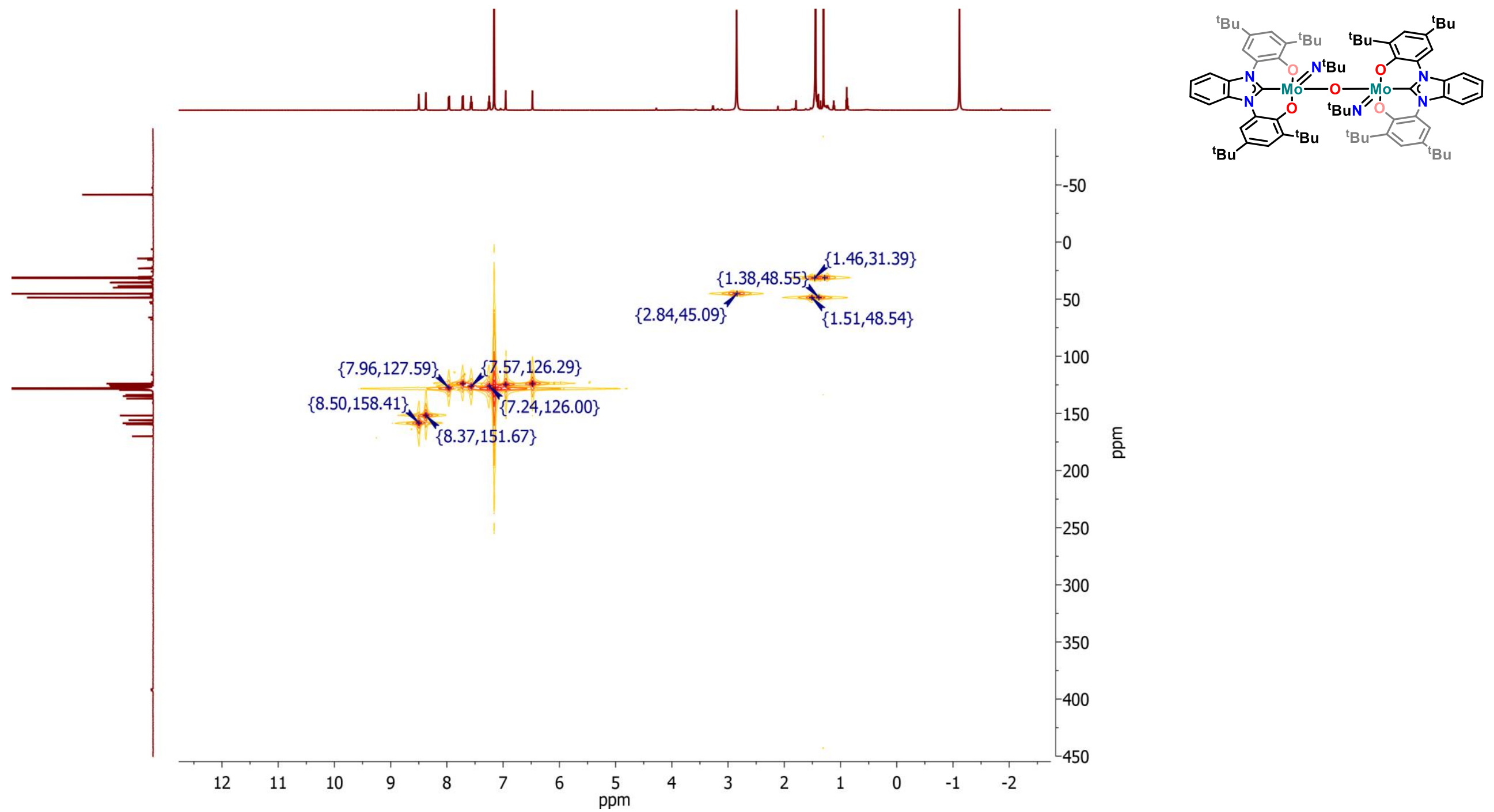

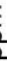

Figure S12: $\quad{ }^{1} \mathrm{H}_{-13}{ }^{13} \mathrm{C}$ HSQC of 5 in $\mathrm{C}_{6} \mathrm{D}_{6}$ at $298 \mathrm{~K}$. 

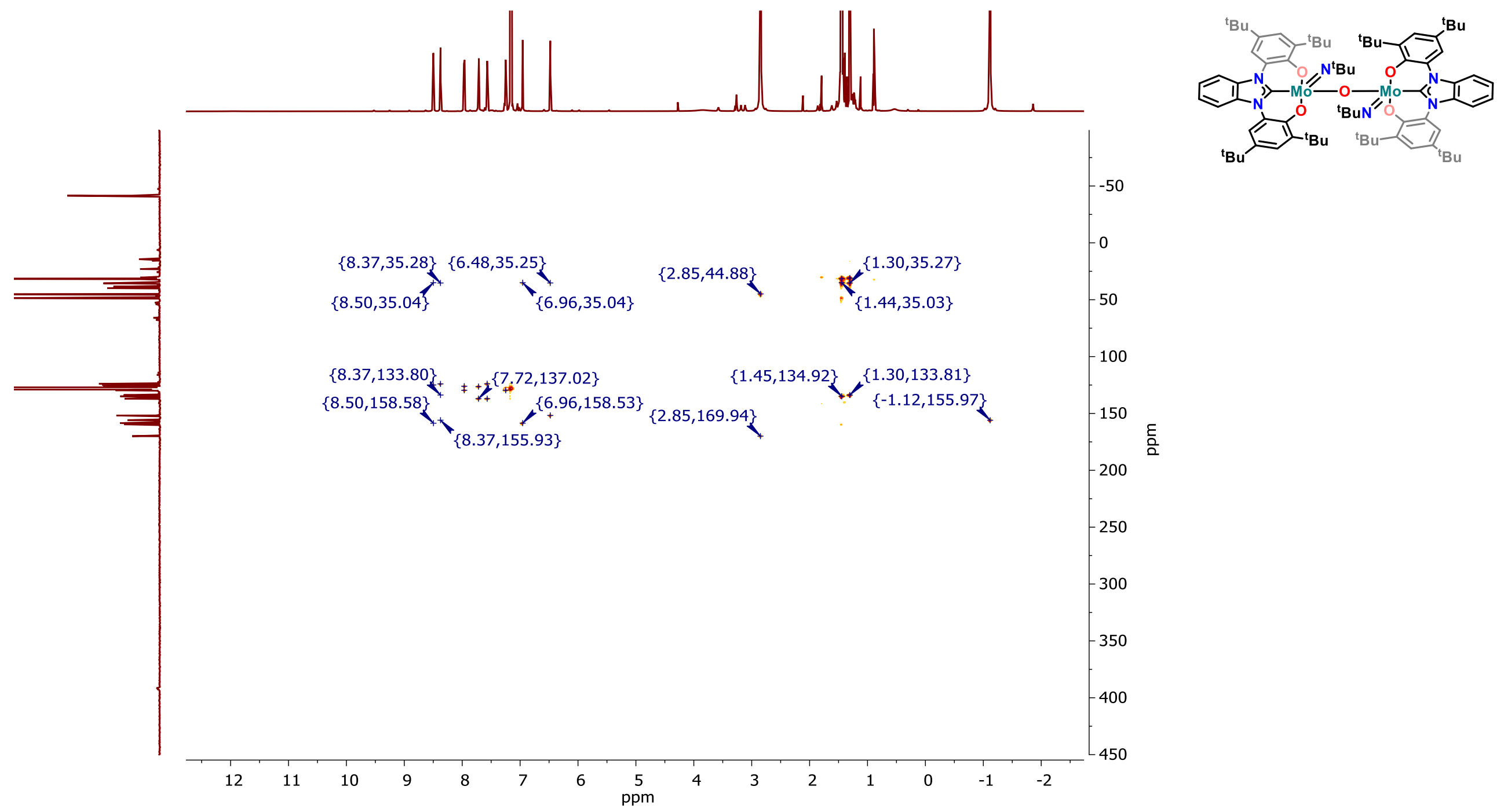

Figure S13: $\quad{ }^{1} \mathrm{H}-{ }^{13} \mathrm{C} H M B C$ of 5 in $\mathrm{C}_{6} \mathrm{D}_{6}$ at $298 \mathrm{~K}$. 

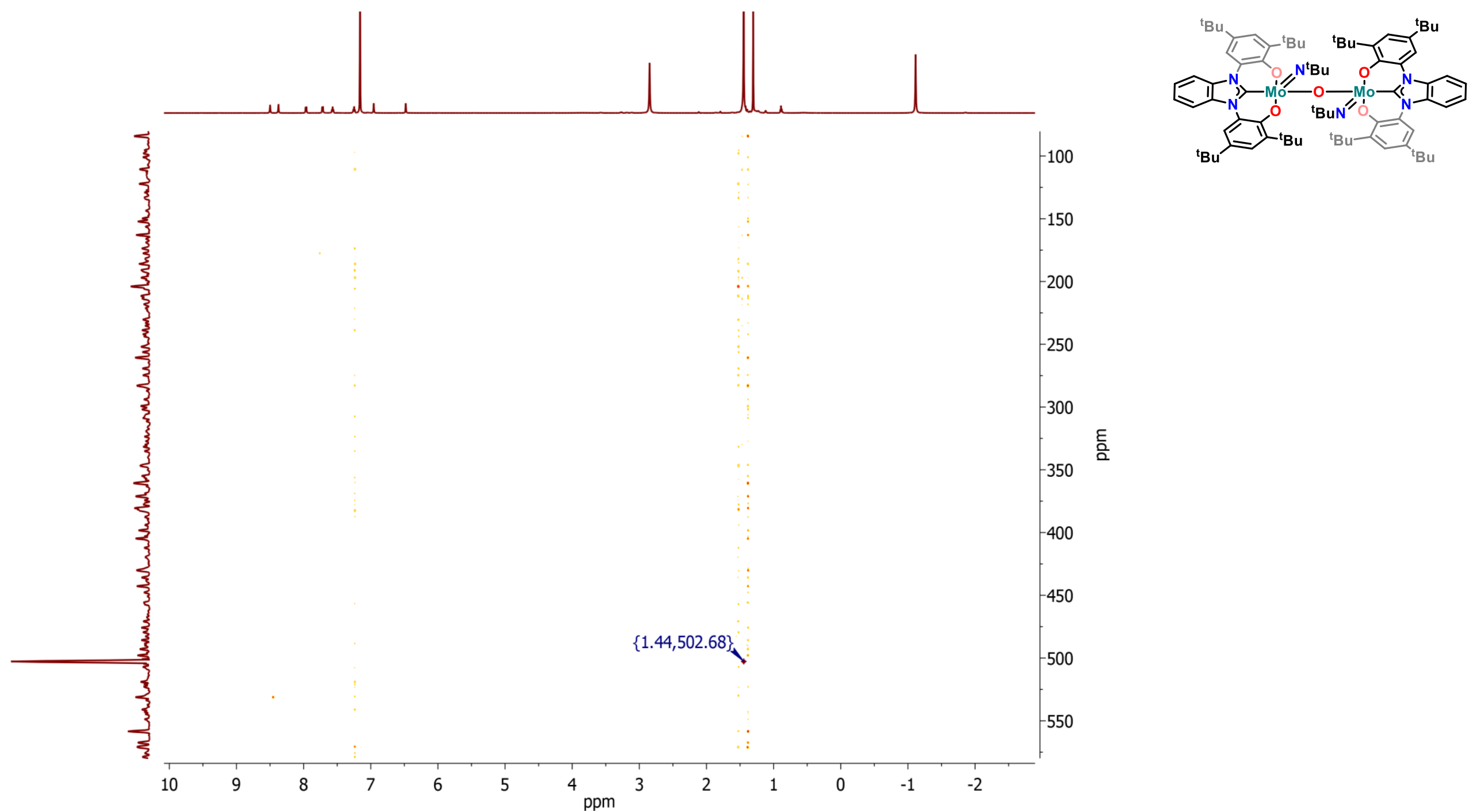

Figure S14: $\quad{ }^{1} \mathrm{H}_{-}{ }^{15} \mathrm{~N}$ HMBC of 5 in $\mathrm{C}_{6} \mathrm{D}_{6}$ at $298 \mathrm{~K}$. 

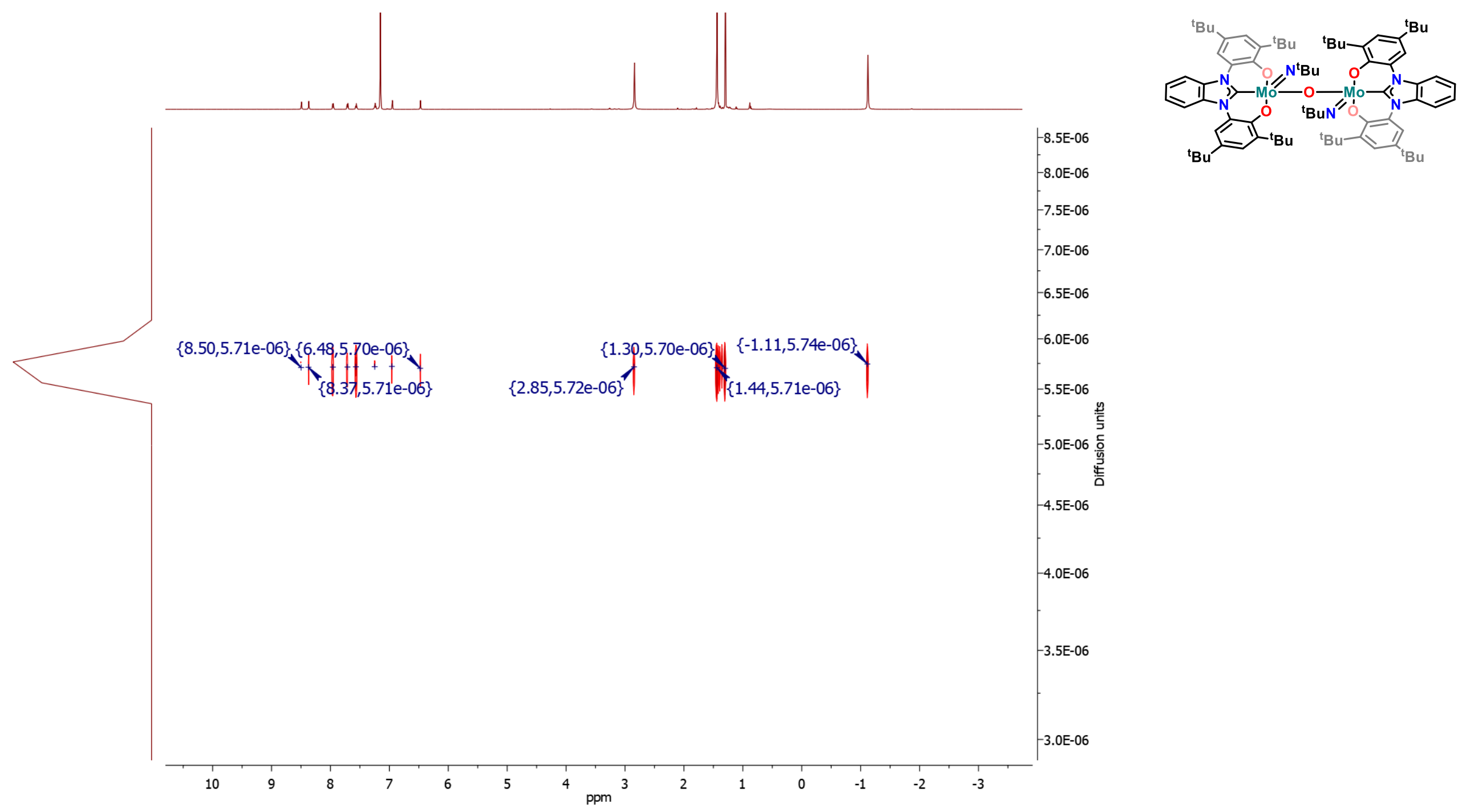

Figure S15: $\quad{ }^{1} \mathrm{H}$ DOSY of 5 in $\mathrm{C}_{6} \mathrm{D}_{6}$ at $298 \mathrm{~K}$. 

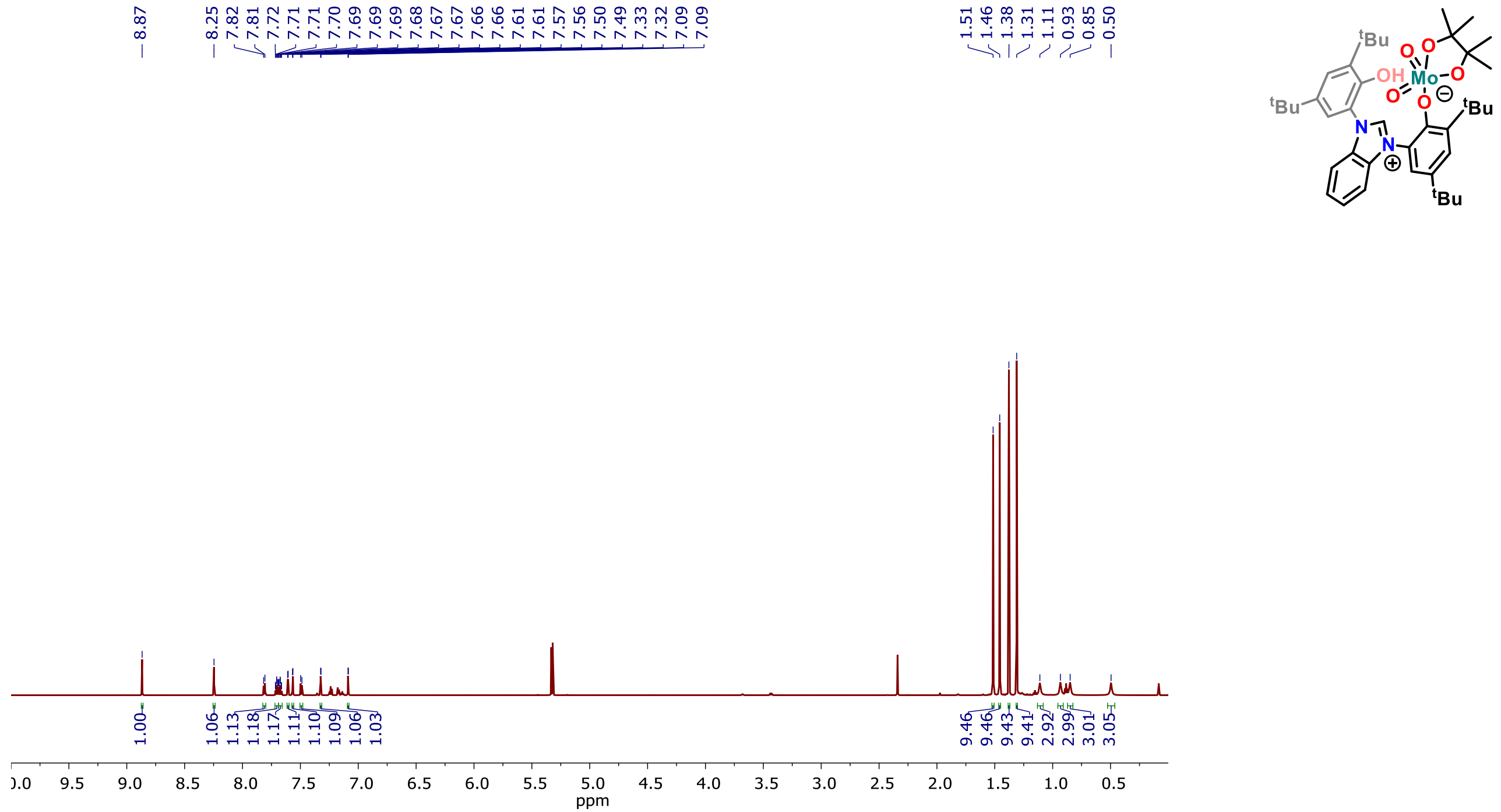

Figure S16: $\quad{ }^{1} \mathrm{H}$ NMR of 6 in $\mathrm{CD}_{2} \mathrm{Cl}_{2}$ at $298 \mathrm{~K}$. Note an impurity of toluene at $2.36 \mathrm{ppm}$ 


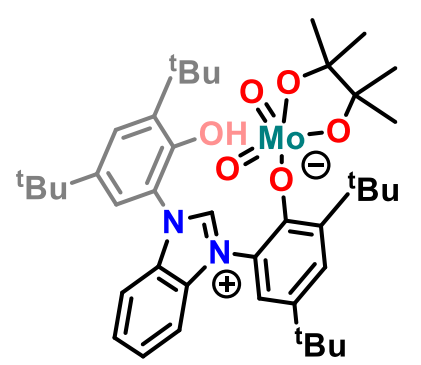

$\begin{array}{llll}190 & 180 & 170 & 160\end{array}$

150 140

Figure S17: $\quad{ }^{13} \mathrm{C}\left\{{ }^{1} \mathrm{H}\right\} \mathrm{NMR}$ of 6 in $\mathrm{CD}_{2} \mathrm{Cl}_{2}$ at $298 \mathrm{~K}$. 

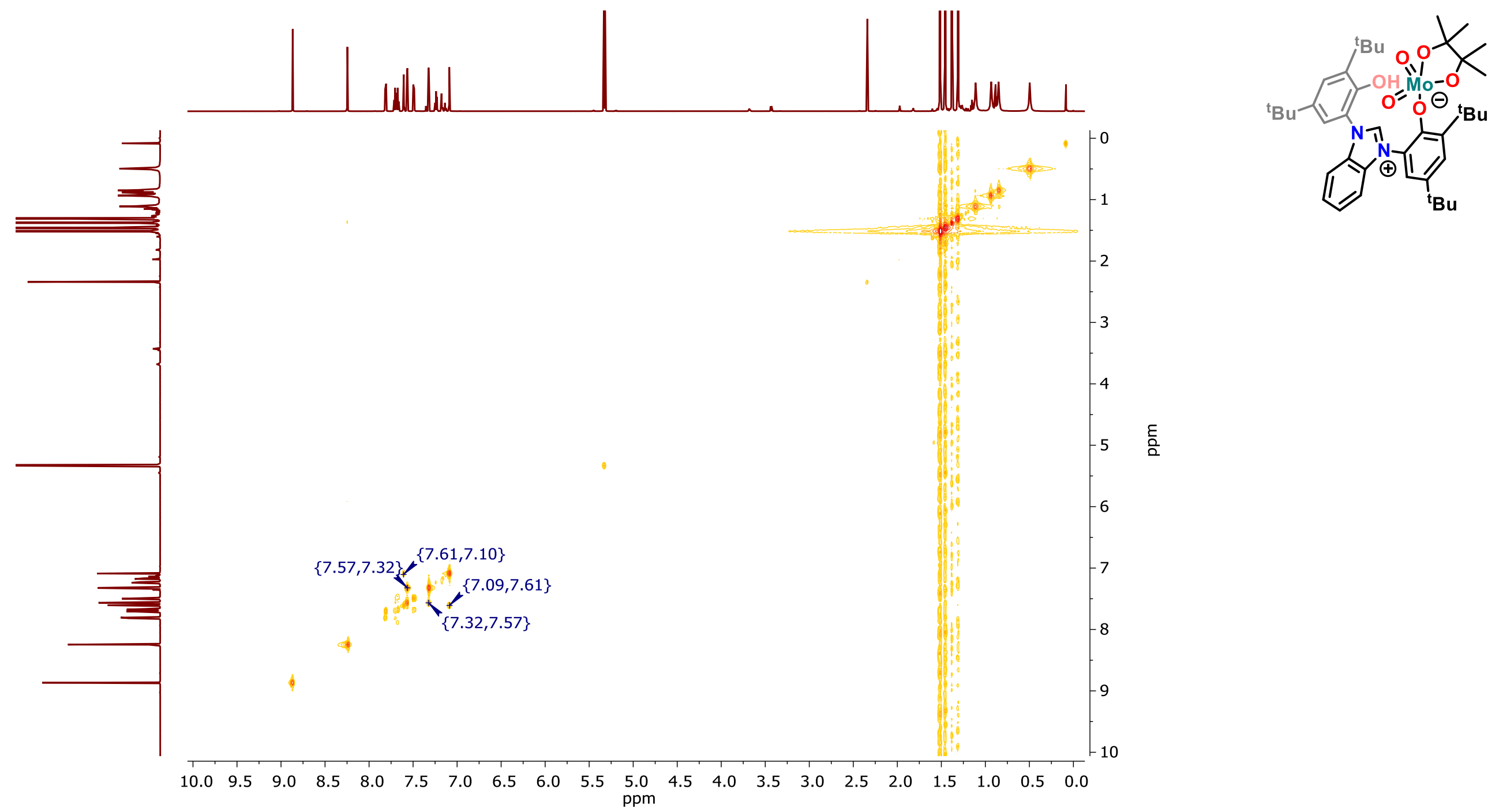

Figure S18: $\quad{ }^{1} \mathrm{H}-{ }^{1} \mathrm{H}$ COSY of 6 in $\mathrm{CD}_{2} \mathrm{Cl}_{2}$ at $298 \mathrm{~K}$. 


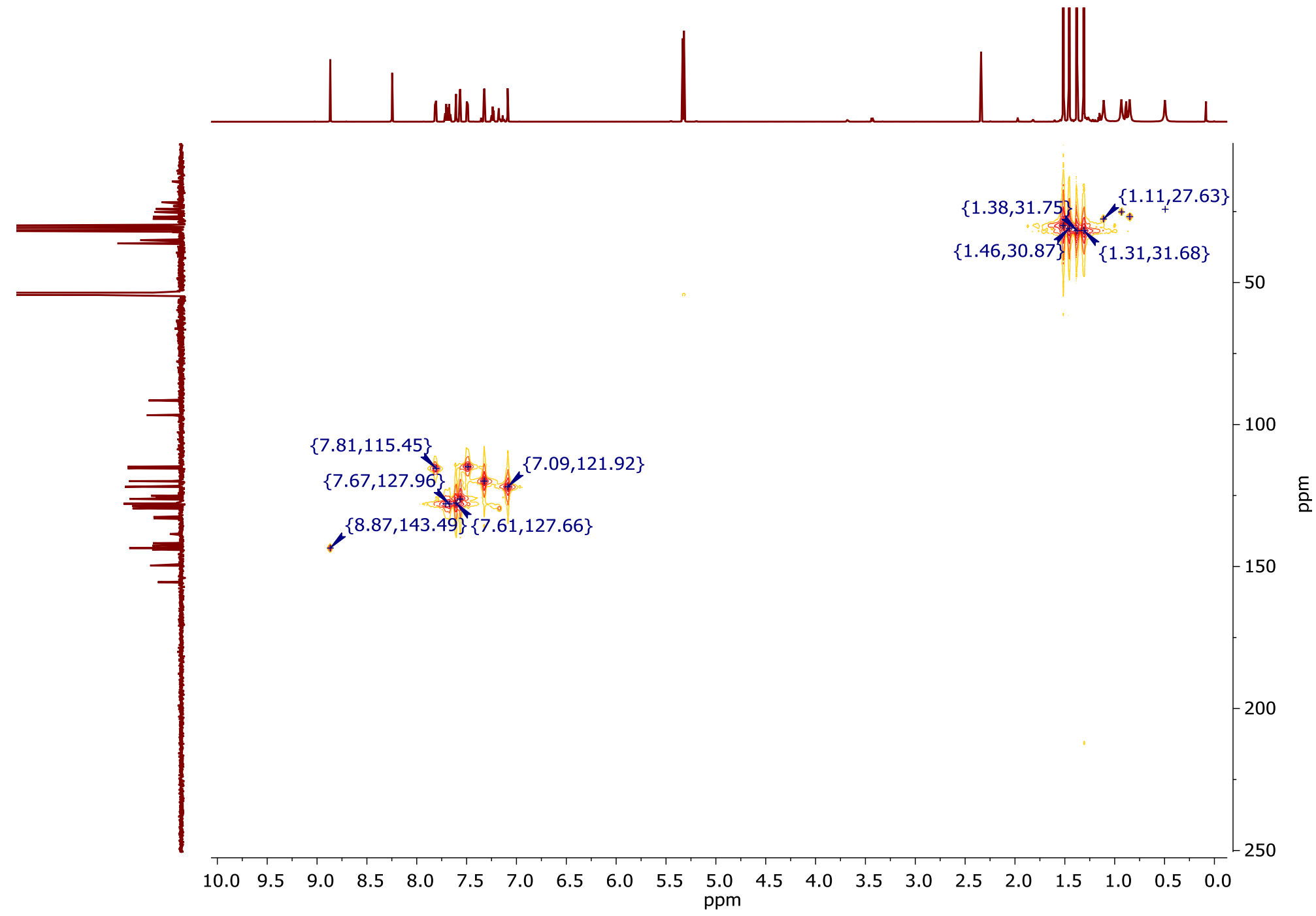

Figure S19: $\quad{ }^{1} \mathrm{H}_{-}{ }^{13} \mathrm{C} \mathrm{HSQC}$ of 6 in $\mathrm{CD}_{2} \mathrm{Cl}_{2}$ at $298 \mathrm{~K}$. 

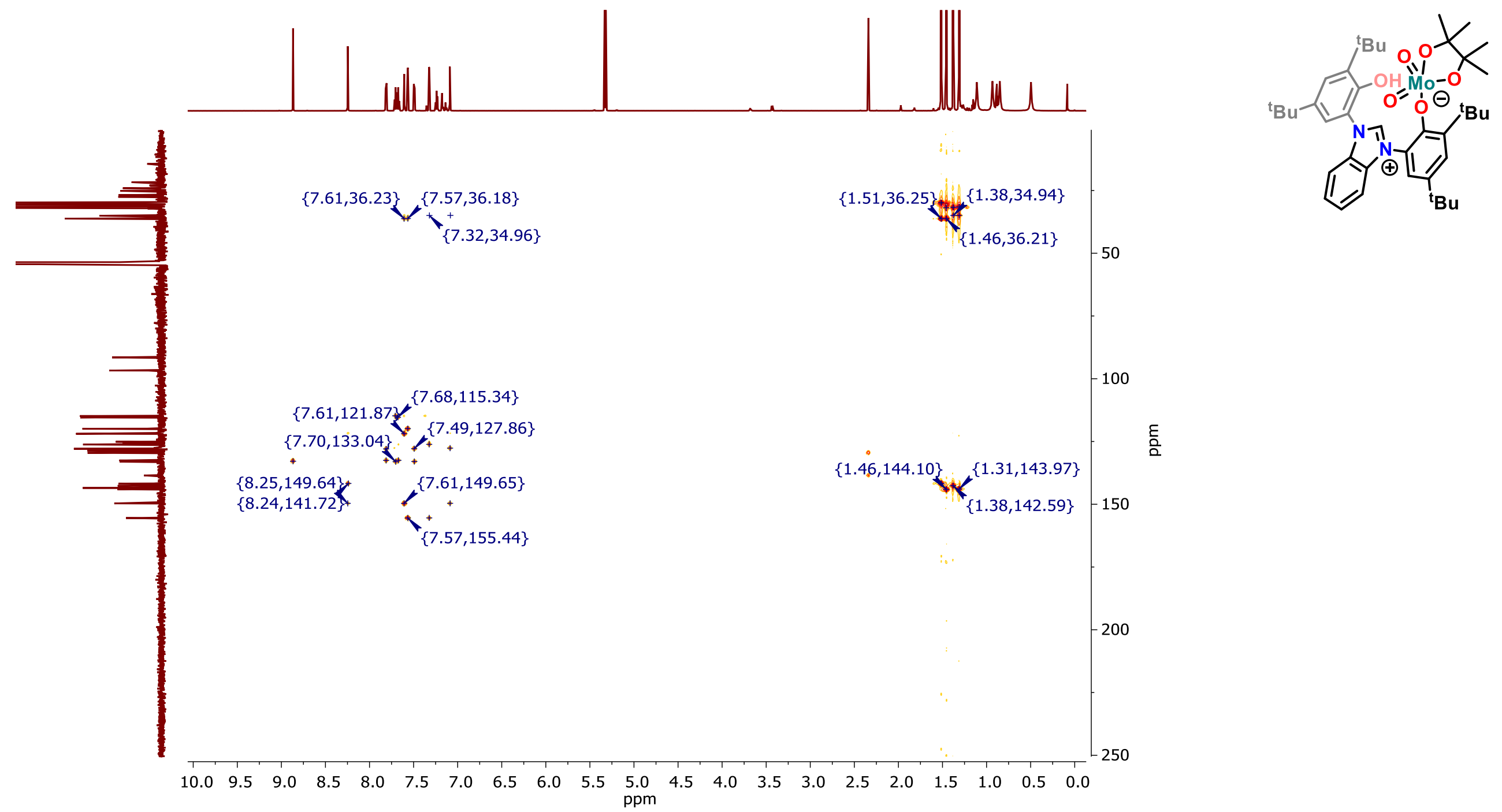

Figure S20: $\quad{ }^{1} \mathrm{H}_{-}{ }^{13} \mathrm{C} \mathrm{HMBC}$ of 6 in $\mathrm{CD}_{2} \mathrm{Cl}_{2}$ at $298 \mathrm{~K}$. 


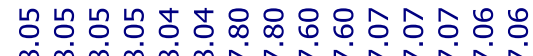

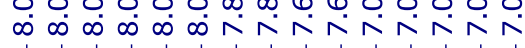
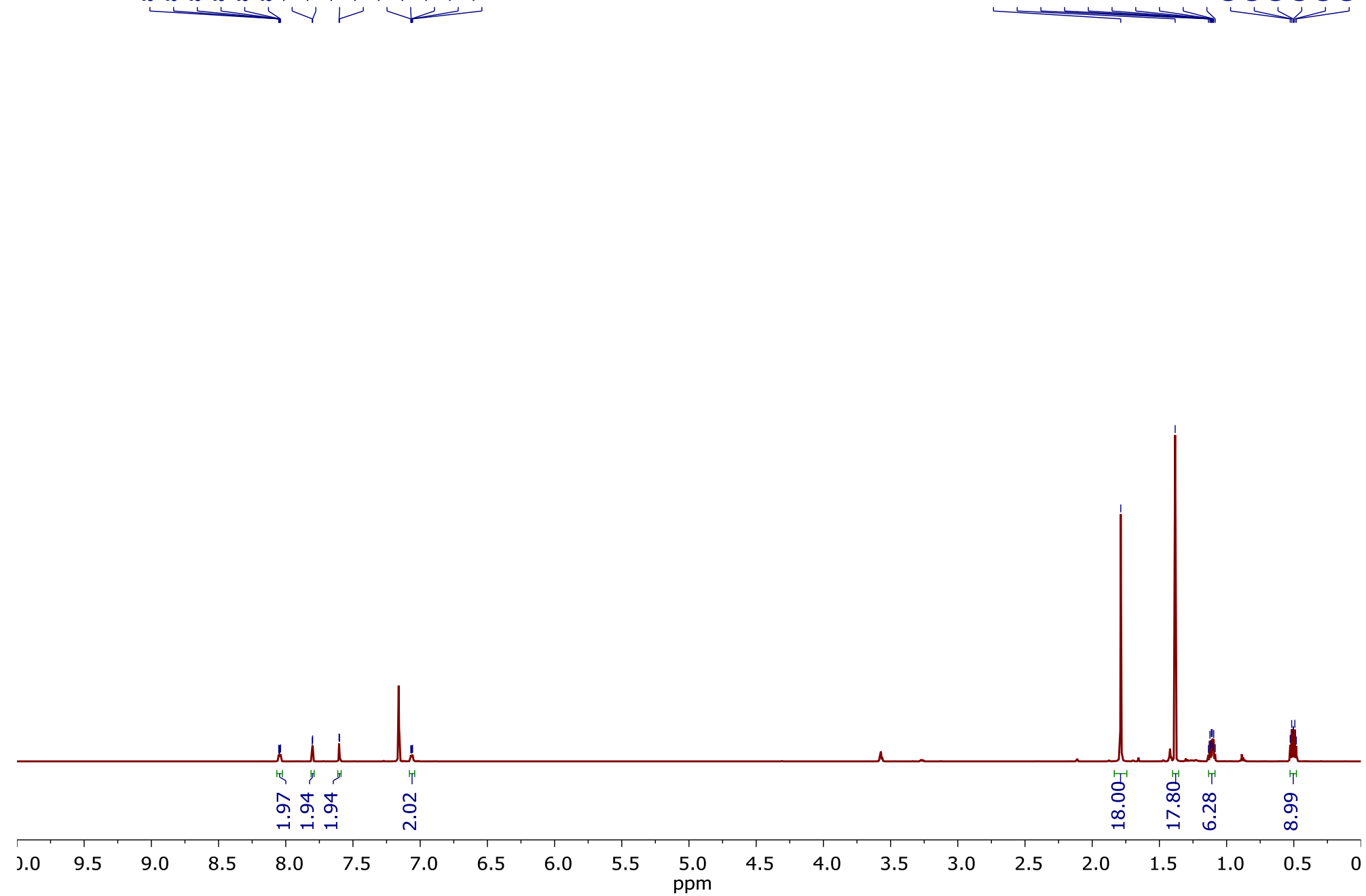

Figure S21: $\quad{ }^{1} \mathrm{H}$ NMR of 7 in $\mathrm{C}_{6} \mathrm{D}_{6}$ at $298 \mathrm{~K}$. 

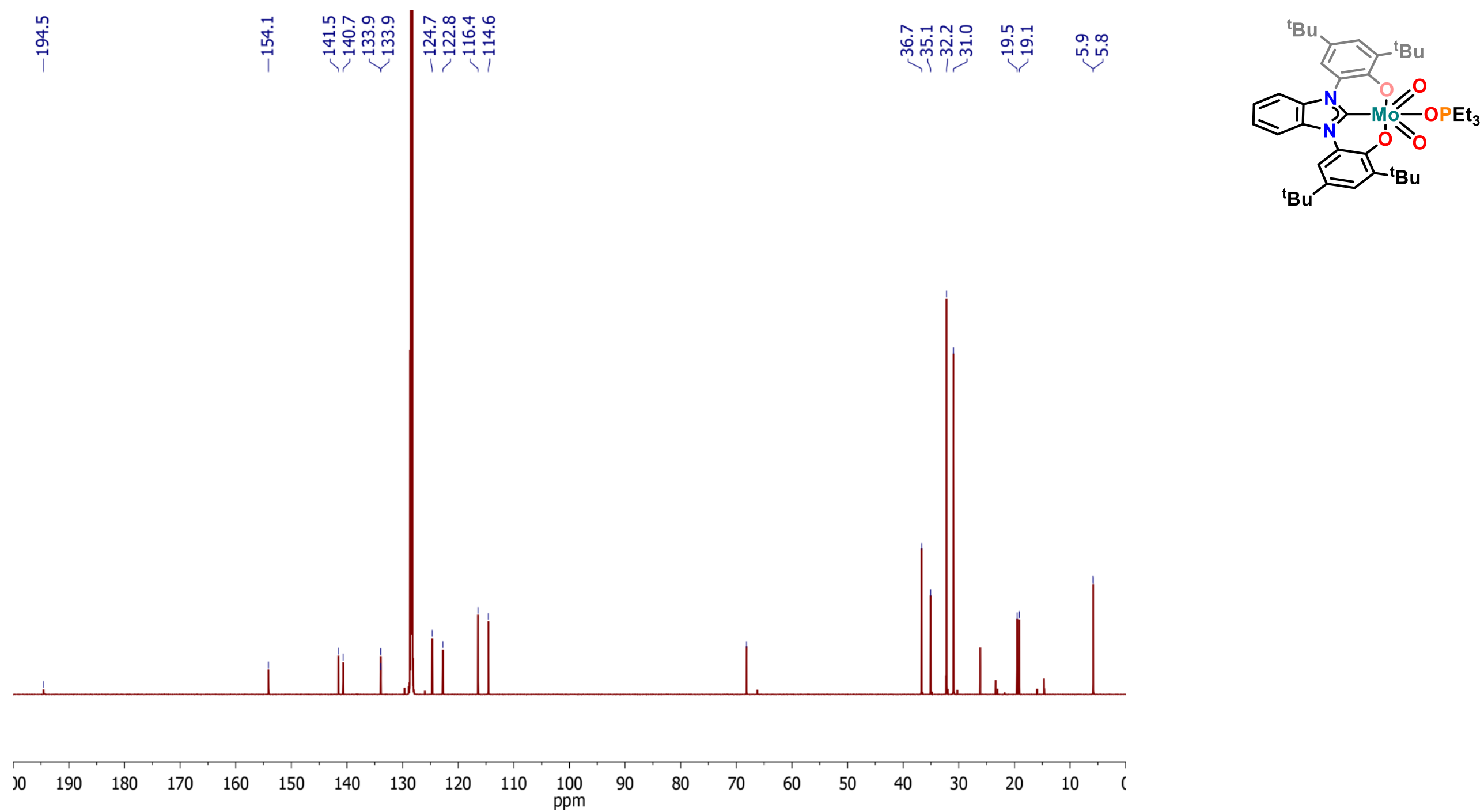

Figure S22: $\quad{ }^{13} \mathrm{C}\left\{{ }^{1} \mathrm{H}\right\}$ NMR of 7 in $\mathrm{C}_{6} \mathrm{D}_{6}$ at $298 \mathrm{~K}$. (impurities of THF are present at 68 and $28 \mathrm{ppm}$ ) 

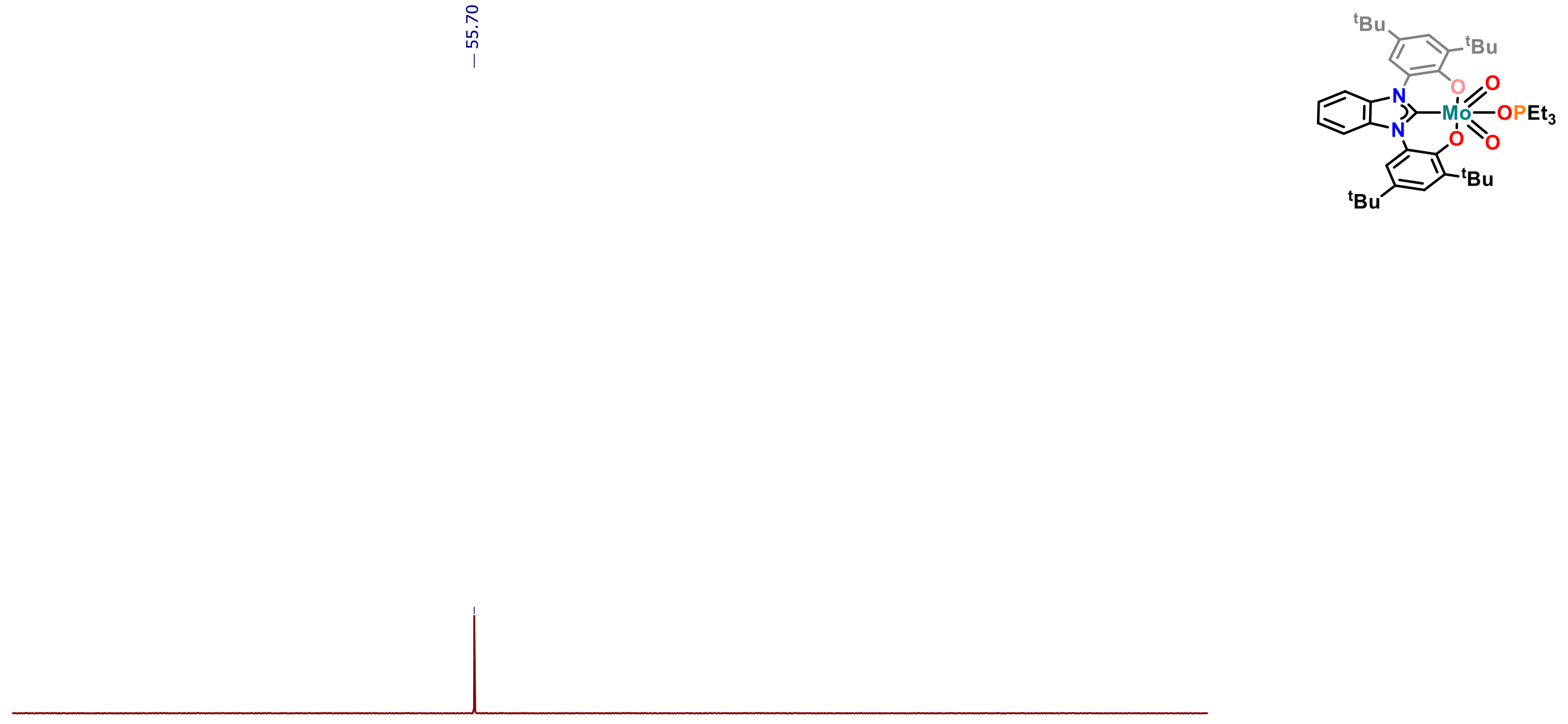

$\begin{array}{llllllllllllllllllllllllllllll}240 & 220 & 200 & 180 & 160 & 140 & 120 & 100 & 80 & 60 & 40 & 20 & 0 & 0 & -20 & -40 & -60 & -80 & -100 & -120 & -140 & -160 & -180 & -200 & -220 & -24\end{array}$

Figure S23: $\quad{ }^{31} \mathrm{P}\left\{{ }^{1} \mathrm{H}\right\}$ NMR of 7 in $\mathrm{C}_{6} \mathrm{D}_{6}$ at $298 \mathrm{~K}$. 

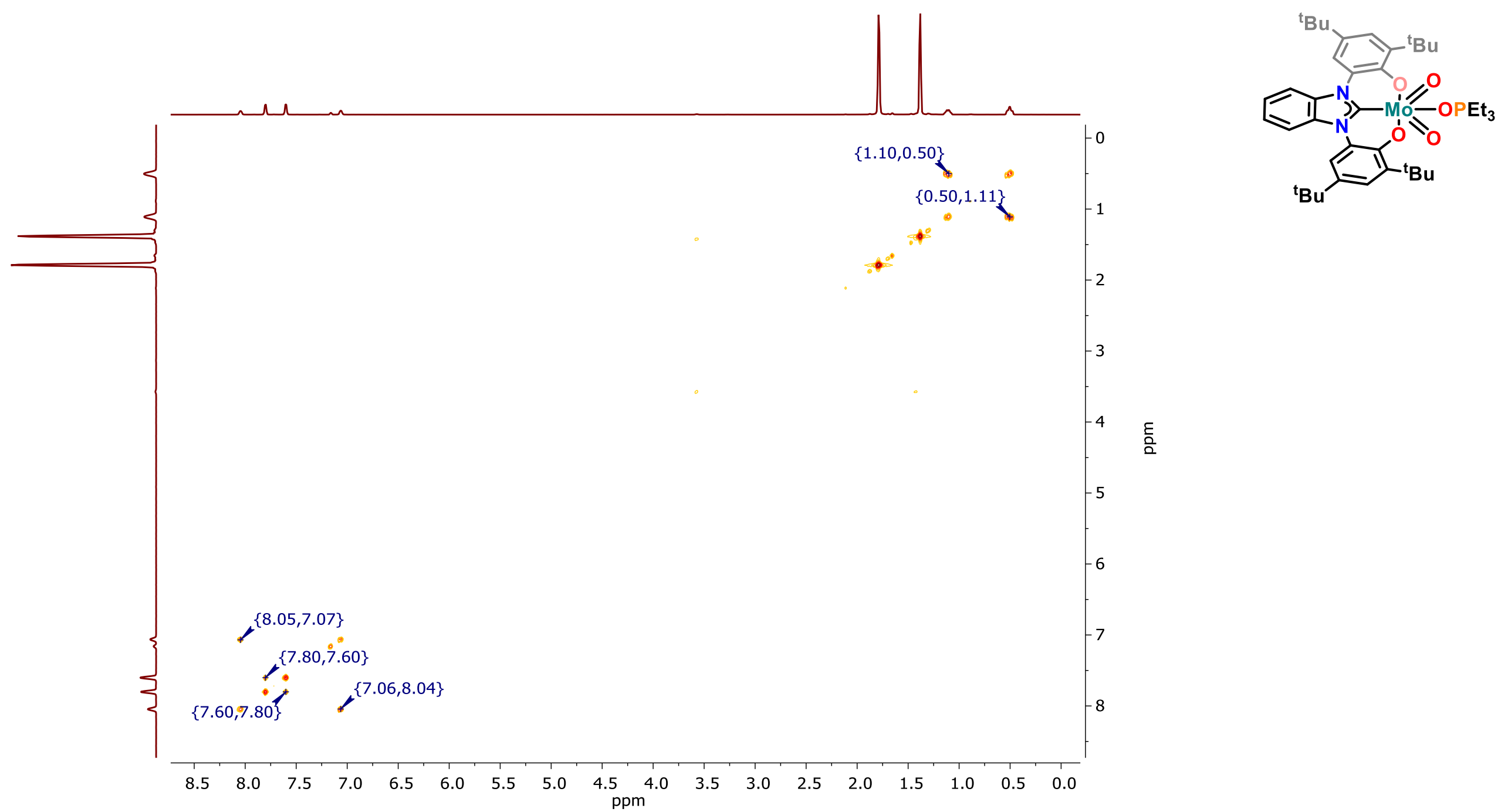

Figure S24: $\quad{ }^{1} \mathrm{H}_{-}{ }^{1} \mathrm{H}$ COSY of 7 in $\mathrm{C}_{6} \mathrm{D}_{6}$ at $298 \mathrm{~K}$. 

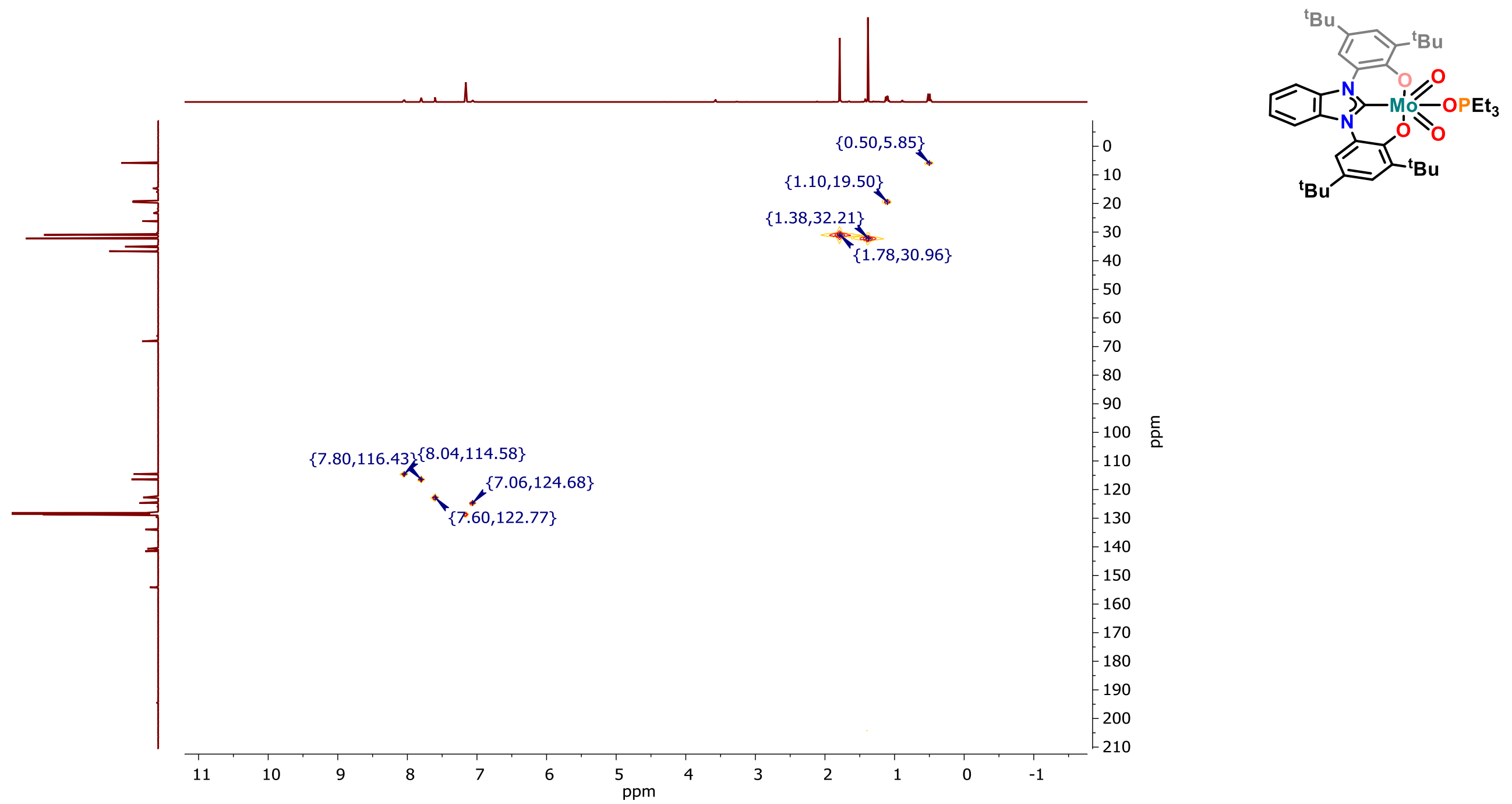

Figure S25: $\quad{ }^{1} \mathrm{H}^{-13} \mathrm{C}$ HSQC of 7 in $\mathrm{C}_{6} \mathrm{D}_{6}$ at $298 \mathrm{~K}$. 

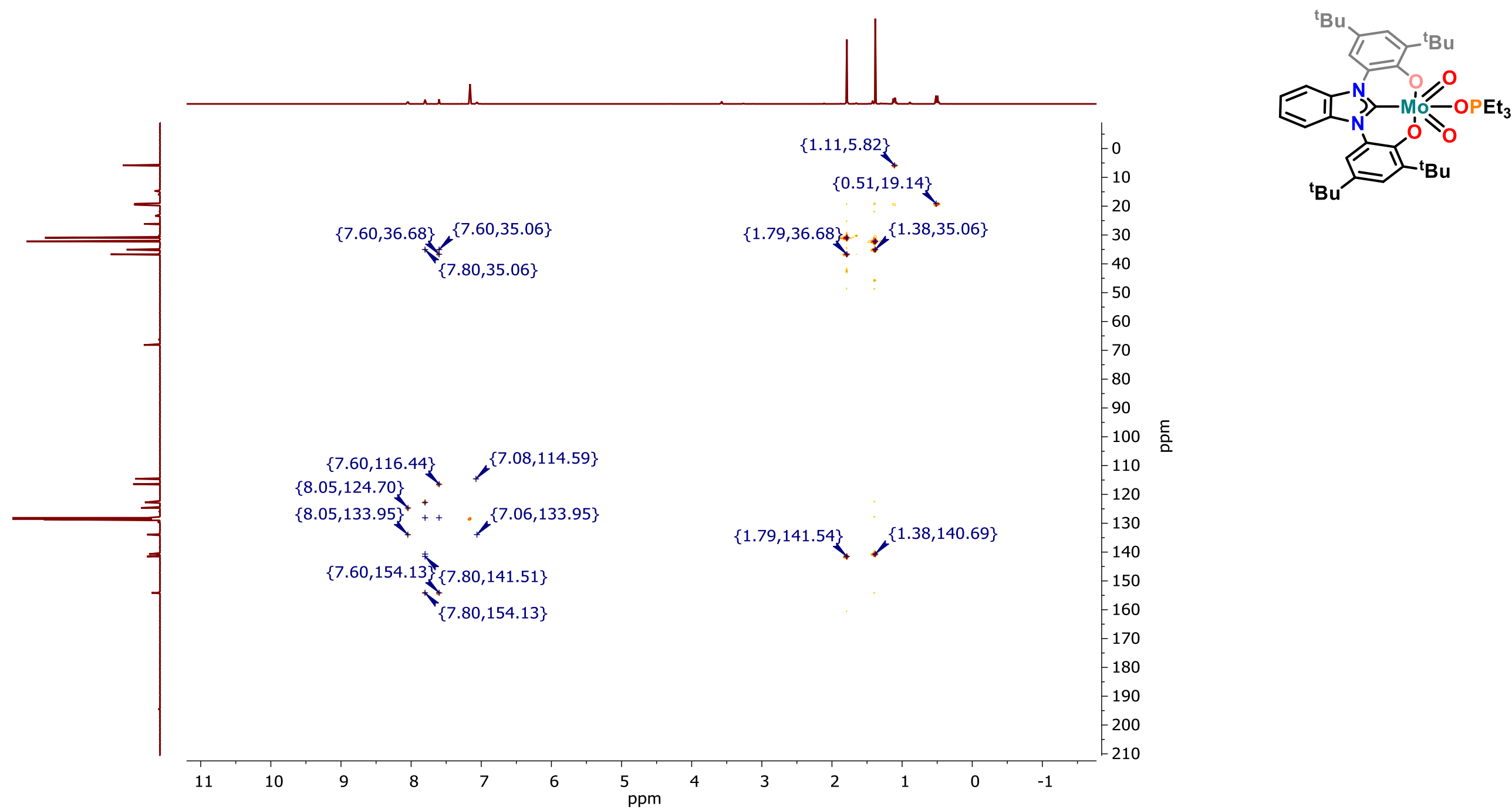

Figure S26: $\quad{ }^{1} \mathrm{H}_{-}{ }^{13} \mathrm{C} H M B C$ of 7 in $\mathrm{C}_{6} \mathrm{D}_{6}$ at $298 \mathrm{~K}$. 


\section{IR spectra}
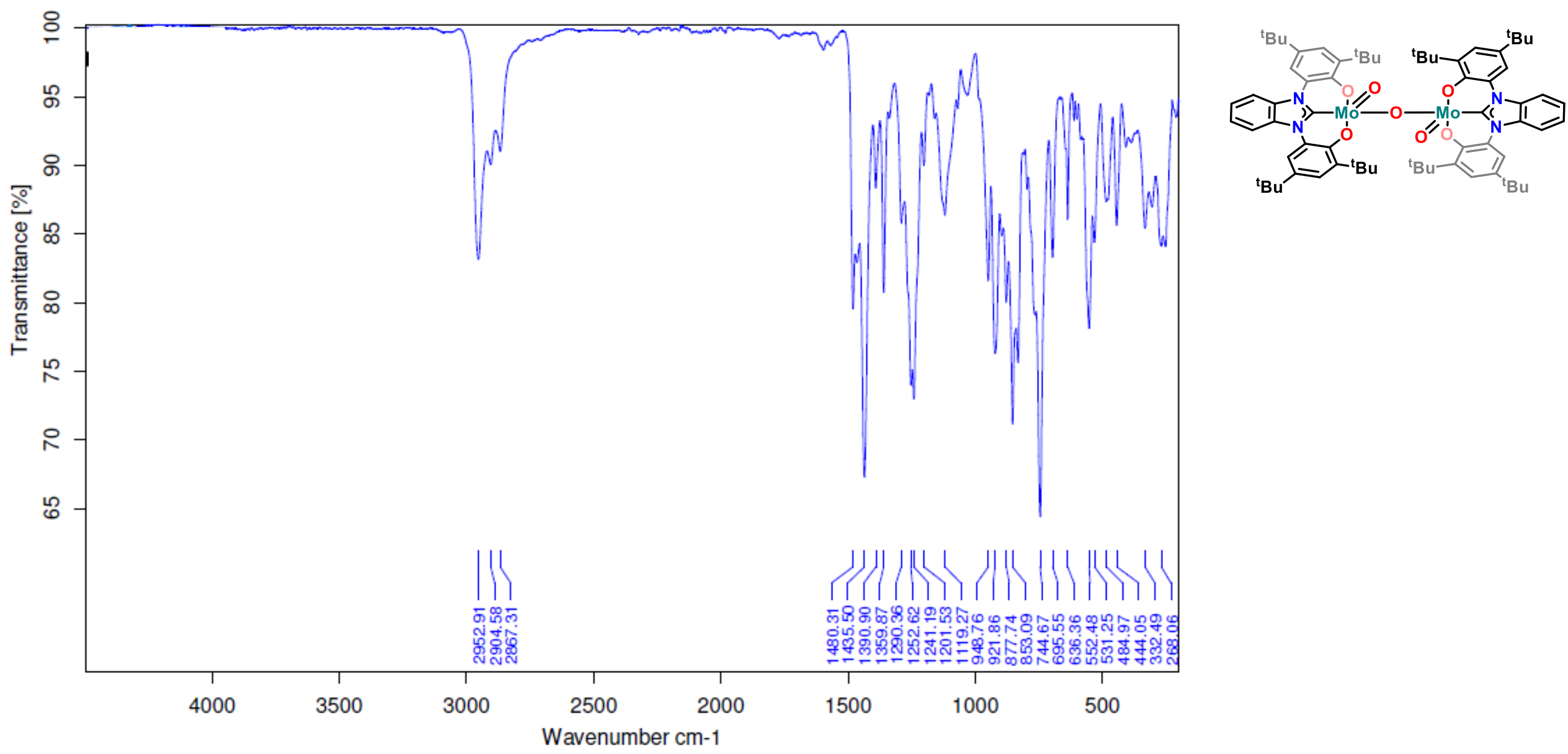

Figure S27: $\quad$ FT-IR (ATR) of 4 at $298 \mathrm{~K}$. 

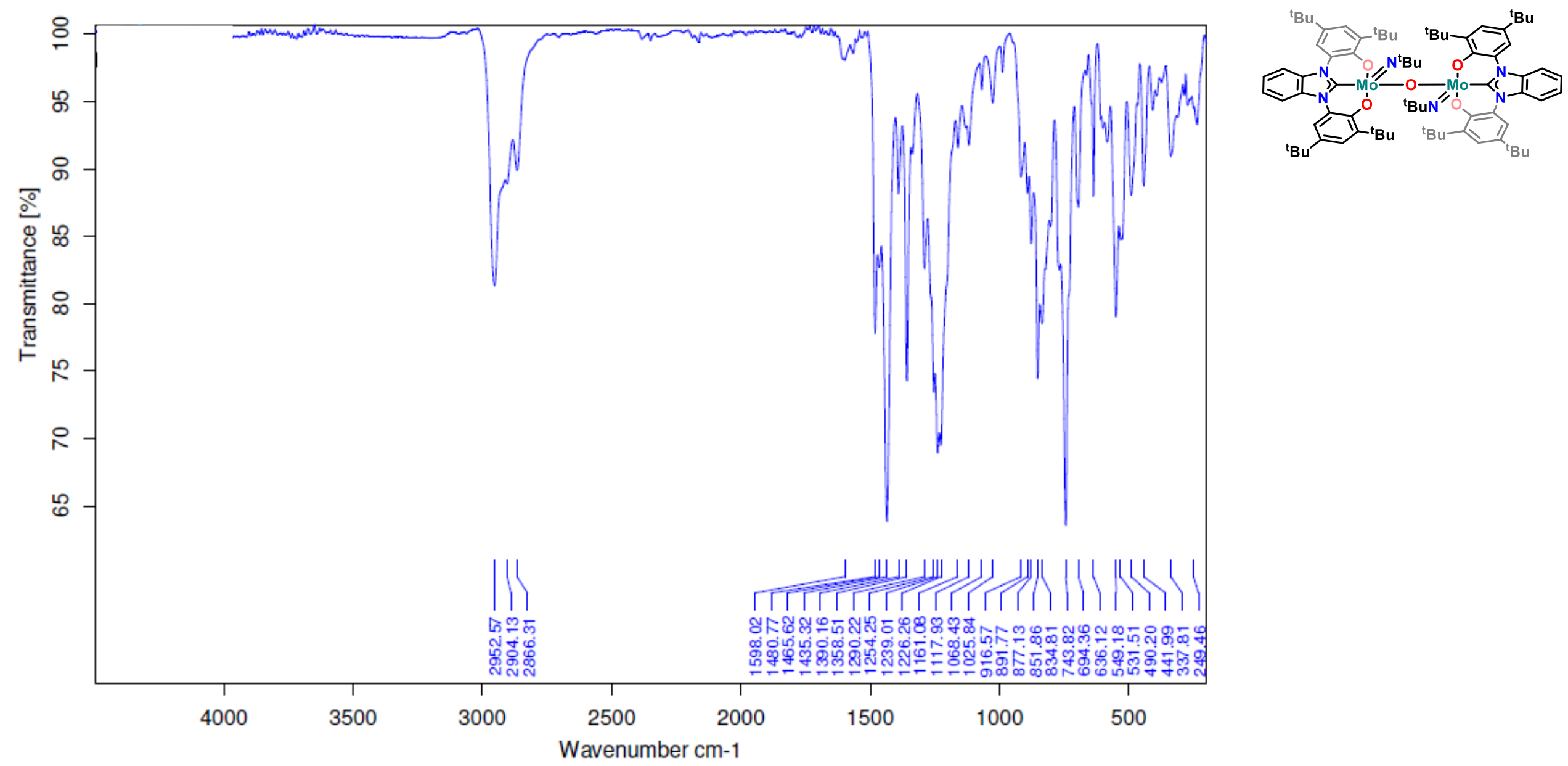

Figure S28: $\quad$ FT-IR (ATR) of 5 at $298 \mathrm{~K}$ 
4. UV-Vis spectra

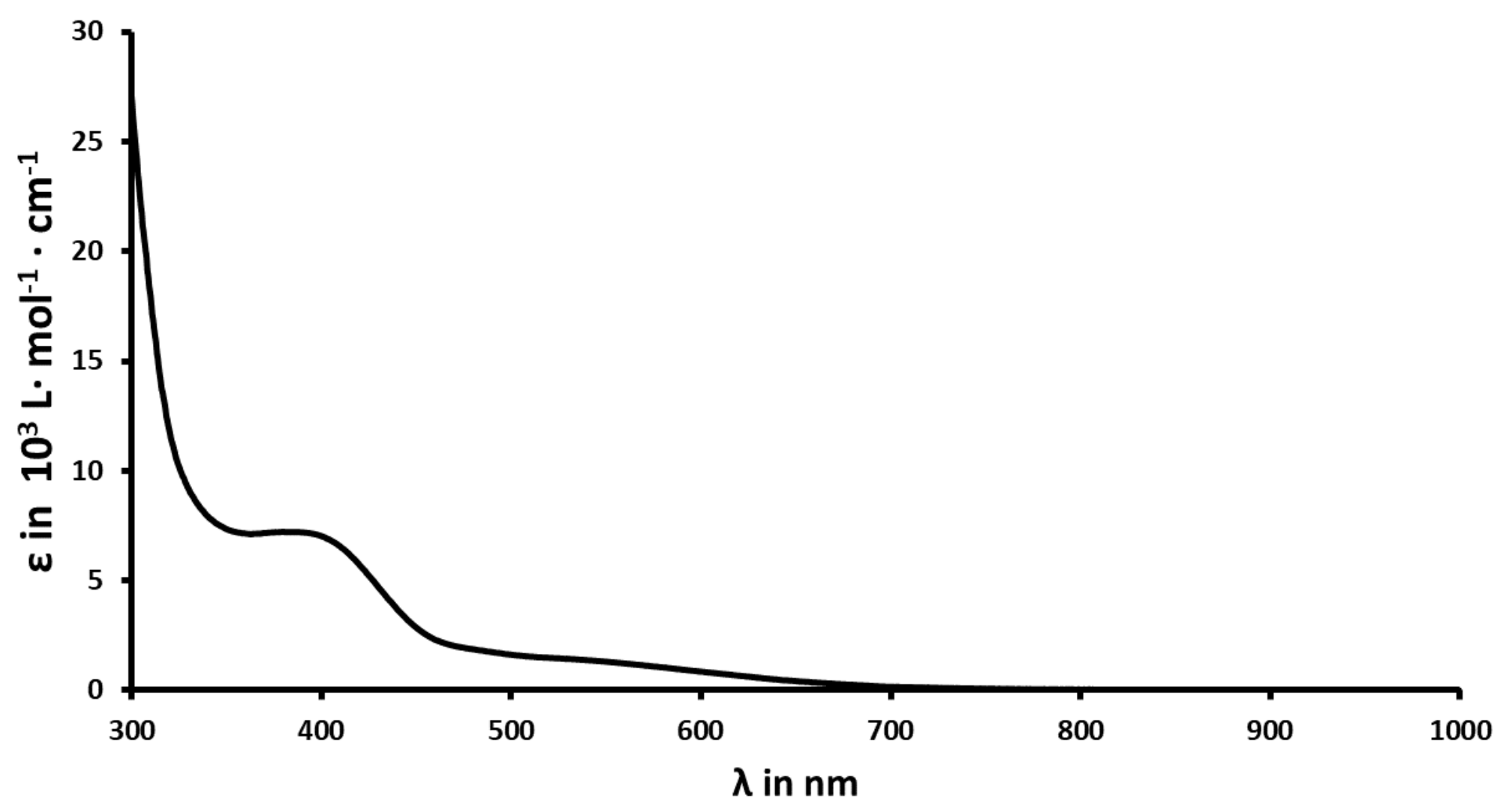

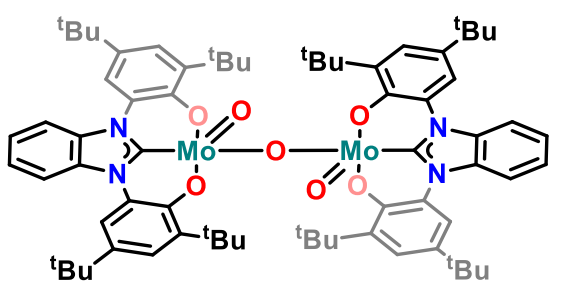

Figure S29: $\quad$ UV-Vis spectrum of complex 4 in dichloromethane at $298 \mathrm{~K}$. 

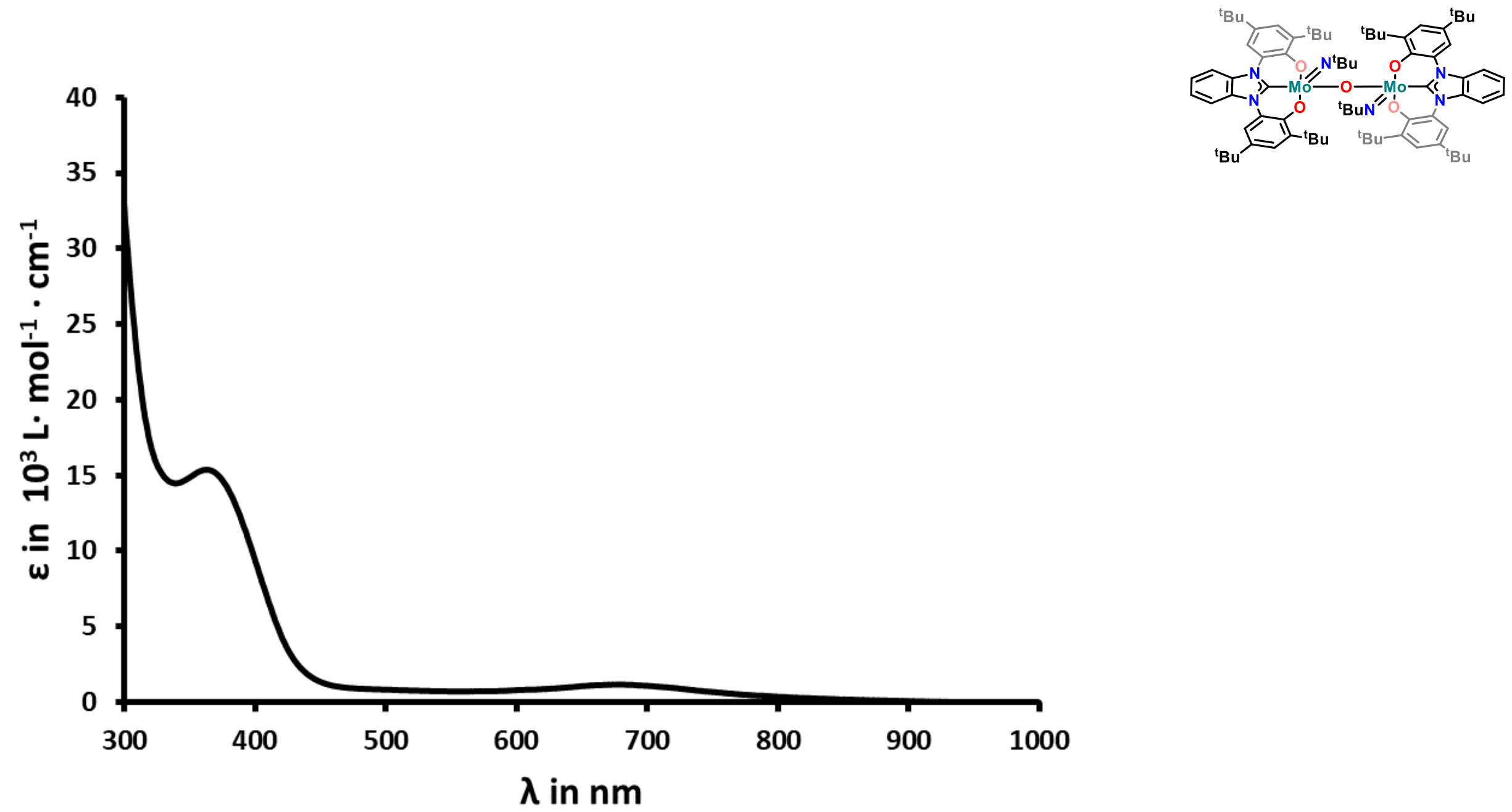

Figure S30: UV-Vis spectrum of complex 5 in dichloromethane at $298 \mathrm{~K}$. 
5. GC Traces and time dependent catalysis
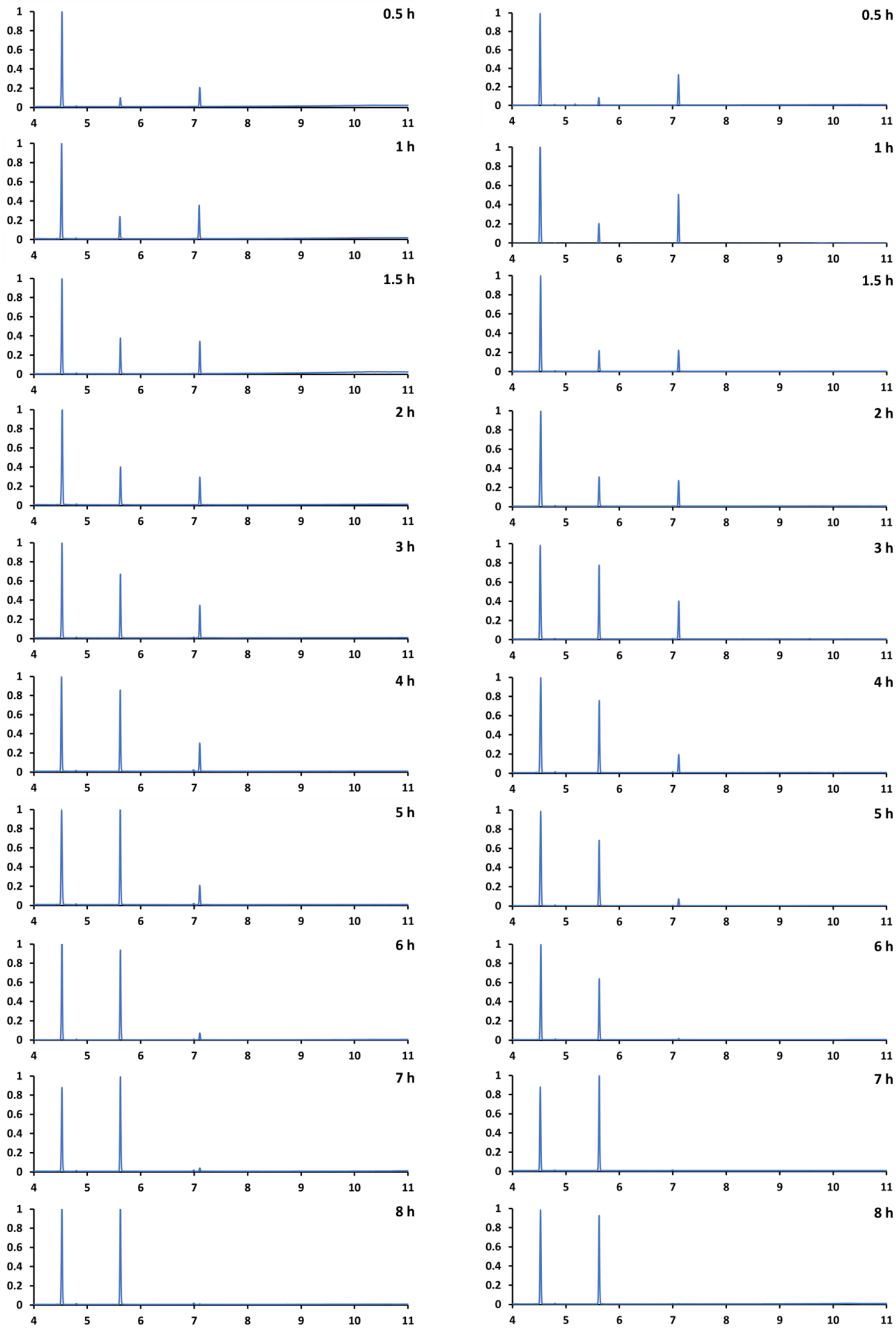

Figure S31: $\quad$ Normalized GC Traces of time dependent catalysis monitoring with 1 mol\% of 1 (left) and 0.5 mol\% of 1 (right). Peaks list as following: mesitylene (4.55 $\mathrm{min}), p$-Toluidine (5.6 $\mathrm{min}$ ) and $p$-Nitrotoluene (7.11 $\mathrm{min})$. 

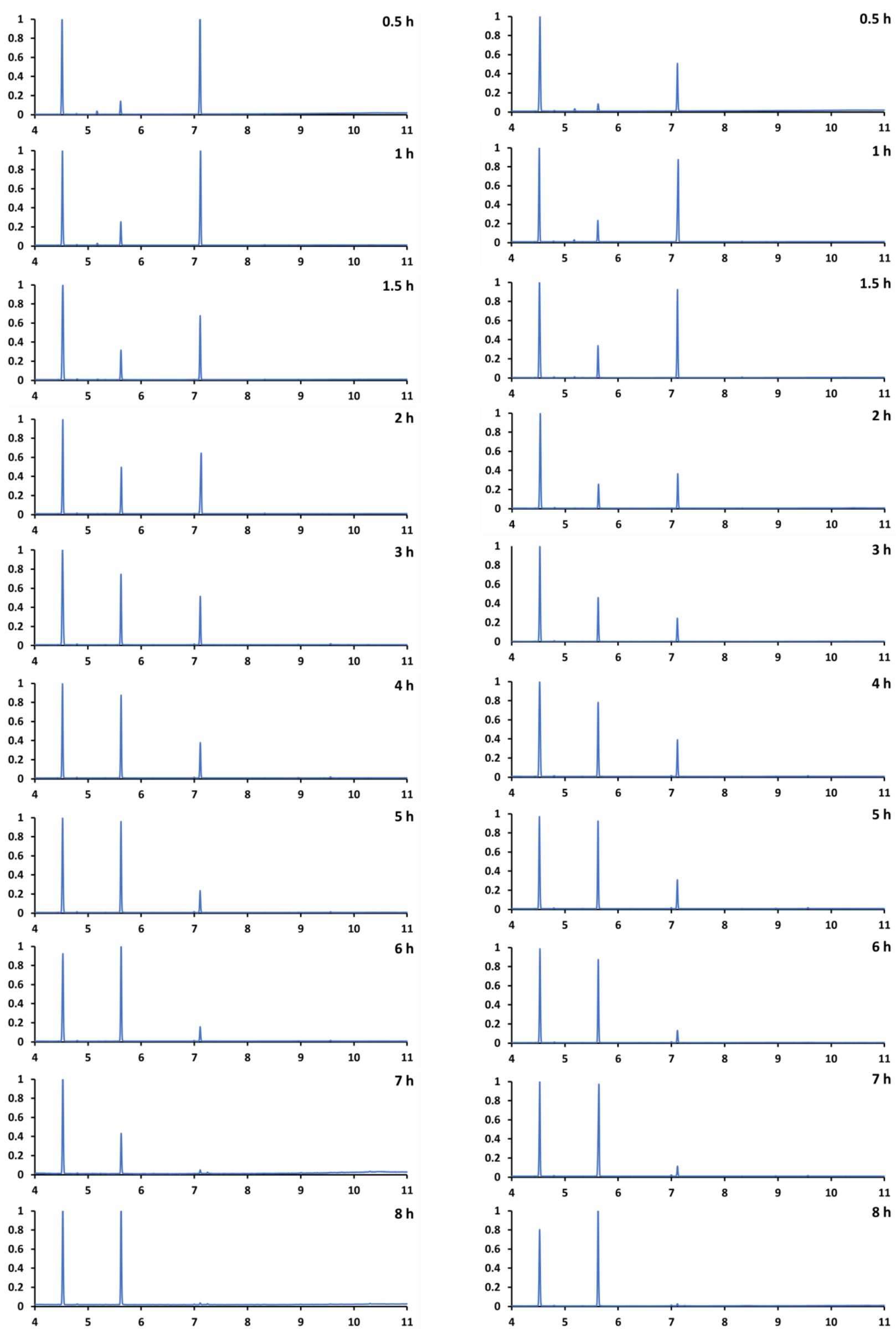

Figure S32: $\quad$ Normalized GC Traces of time dependent catalysis monitoring with 0.25 mol\% of 1 (left) and 0.25 mol\% of 2 (right). Peaks list as following: mesitylene (4.55 $\mathrm{min}), p$-Toluidine $(5.6 \mathrm{~min})$ and $p$ Nitrotoluene (7.11 $\mathrm{min})$. 

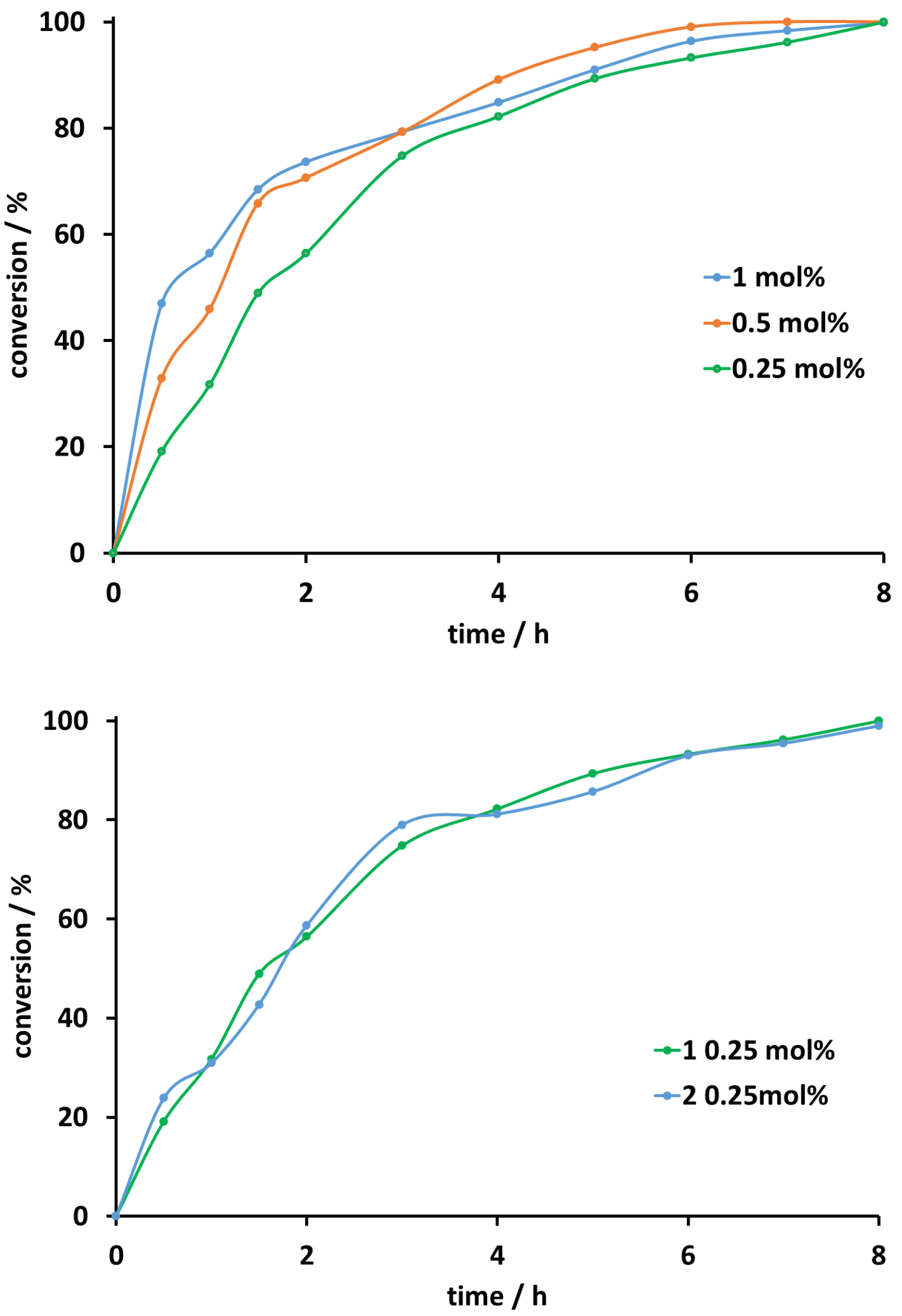

Figure S33: Time-conversion plot of the catalytic deoxygenation of 4-nitrotoluene using 4 equiv of pinacol as a sacrificial oxygen atom acceptor at $130^{\circ} \mathrm{C}$ in toluene and variable catalysts loadings of complex $\mathbf{1}$ (top). Comparison of the catalytic activities of complexes $\mathbf{1}$ and $\mathbf{2}$ at 0.25 mol\% (bottom). 


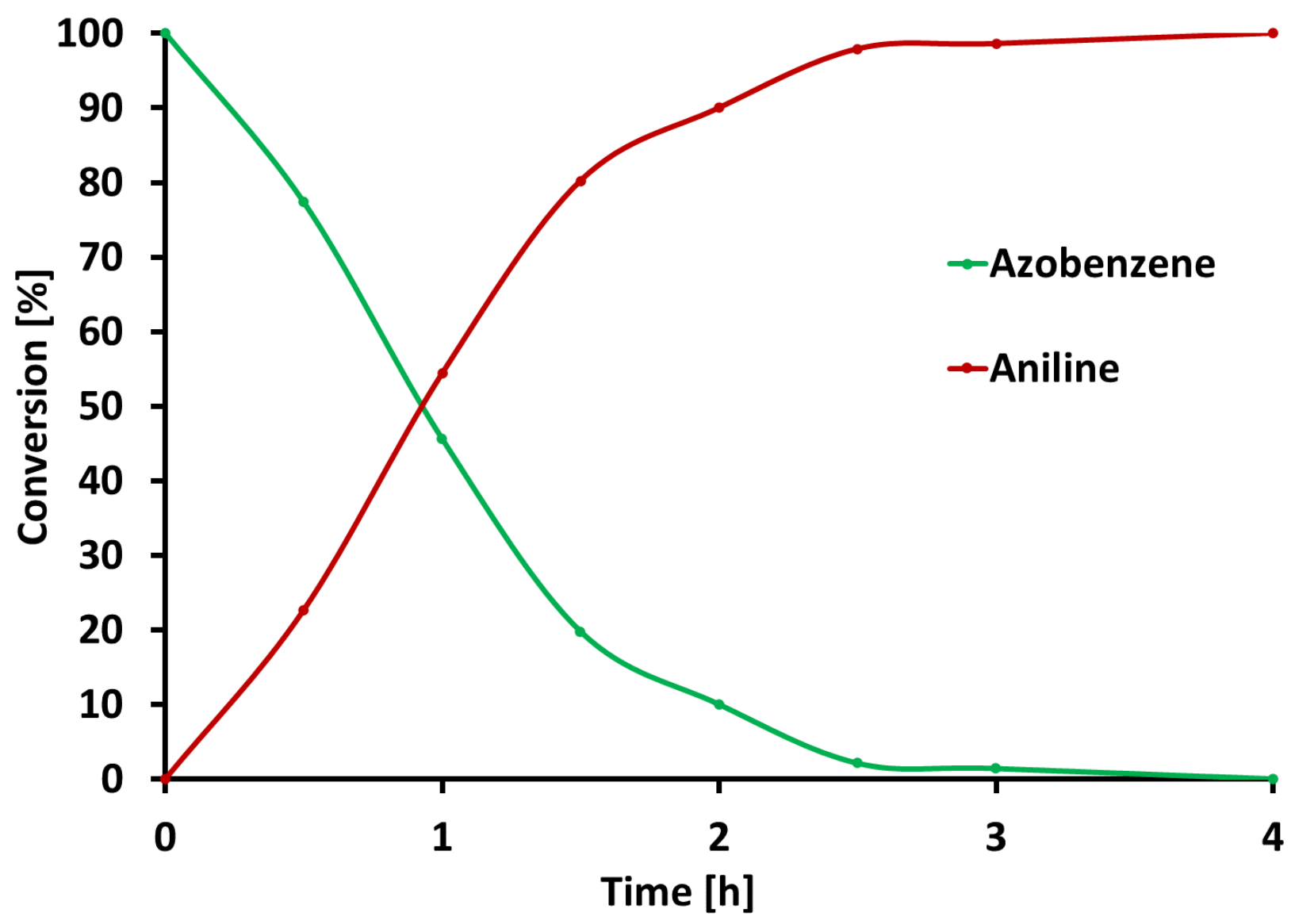

Figure S34: Time-conversion plot of the catalytic reduction of azobenzene using 1 mol\% of 1, 4 equivalents of pinacol as a sacrificial reductant at $130^{\circ} \mathrm{C}$ in toluene. 
6. Stoichiometric test reactions

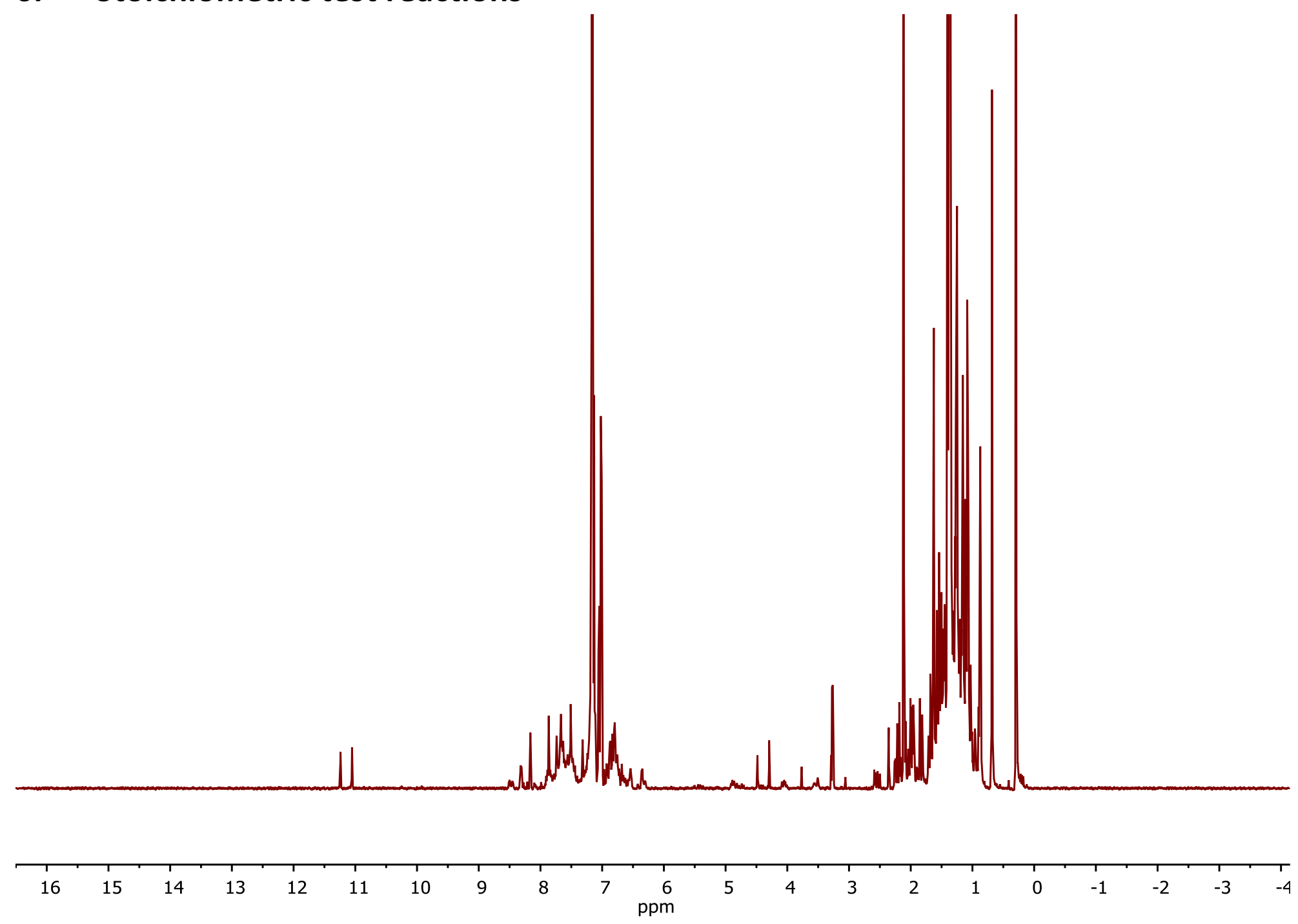

Figure S35: $\quad$ NMR of complex 6 after heating in $\mathrm{C}_{6} \mathrm{D}_{6}$. 


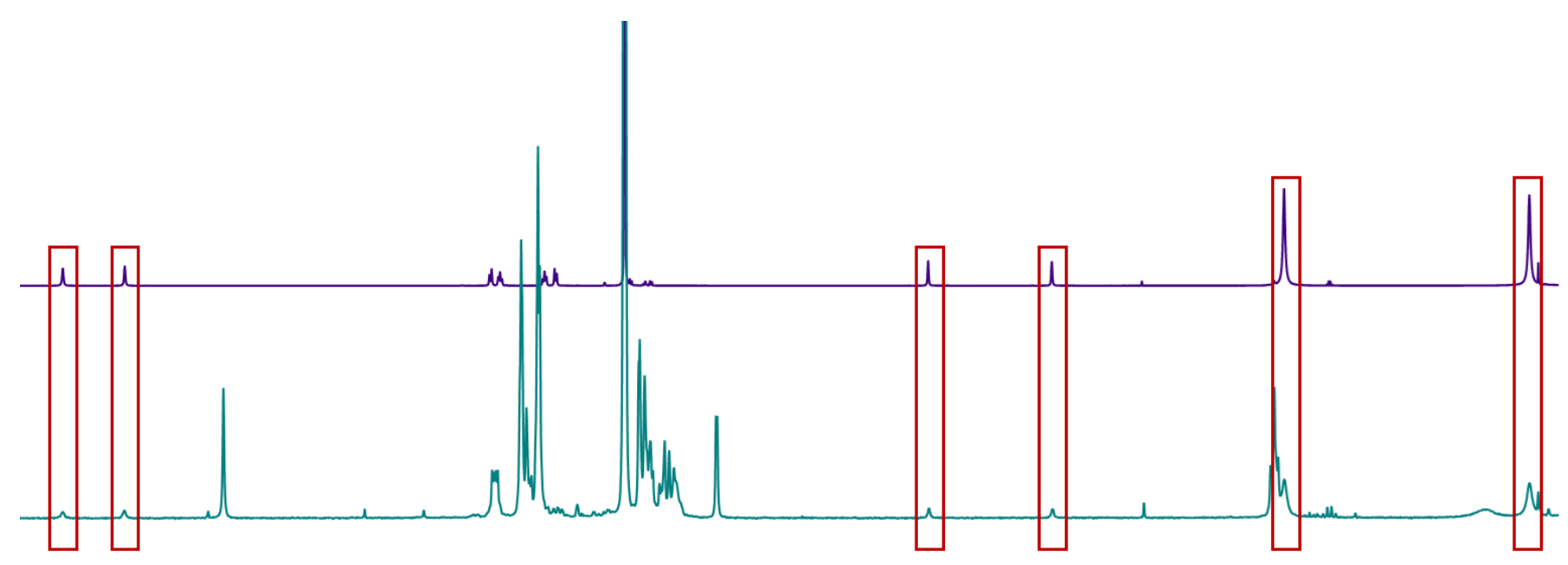

Isolated complex 4

In-situ NMR of 6 heated to $100^{\circ} \mathrm{C}$ for $24 \mathrm{~h}$ in the presence of 1 eq complex 1

\section{Isolated complex 6}

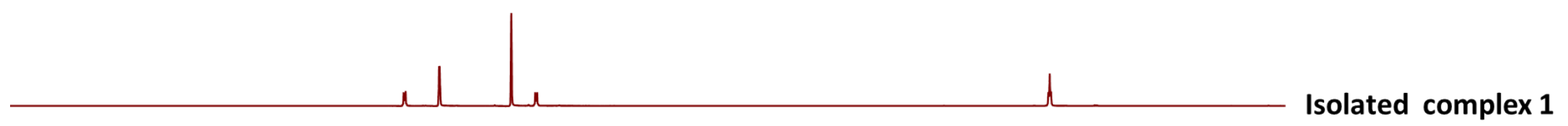

.5 10.0 9.5 9.0 8.5 8.0 $7.5 \quad 7.0$ 6.5 ppm

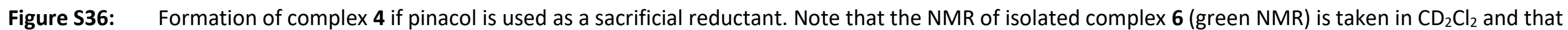
samples of $\mathbf{6}$ used for mechanistic studies were slightly contaminated with toluene from previous solution attempts. All other NMR experiments are reported in $\mathrm{C}_{6} \mathrm{D}_{6}$. 

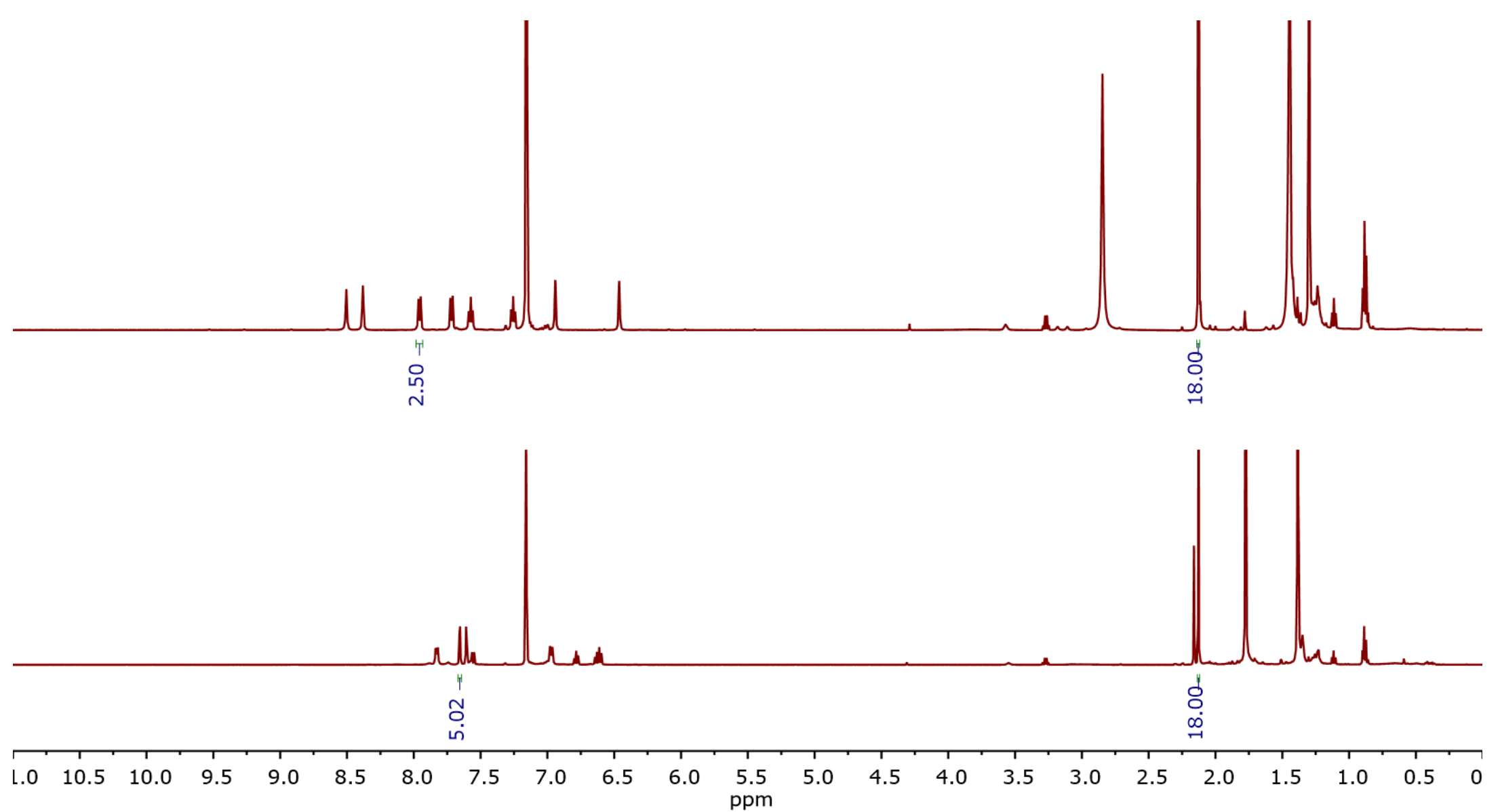

Figure S37: Mechanistic test reaction between 5 and $o$-nitrotoluene in $\mathrm{C}_{6} \mathrm{D}_{6}$ at room temperature with $\mathrm{C}_{6} \mathrm{Me}_{6}$ as an internal standard. Top spectrum shows initial relative integration of $\mathrm{C}_{6} \mathrm{Me}_{6}$ with one proton of the catecholate units. Bottom spectrum shows the same relative integrations. Doubling of the integral confirms that 2 eq of $\mathbf{2}$ have been formed during the reaction. 


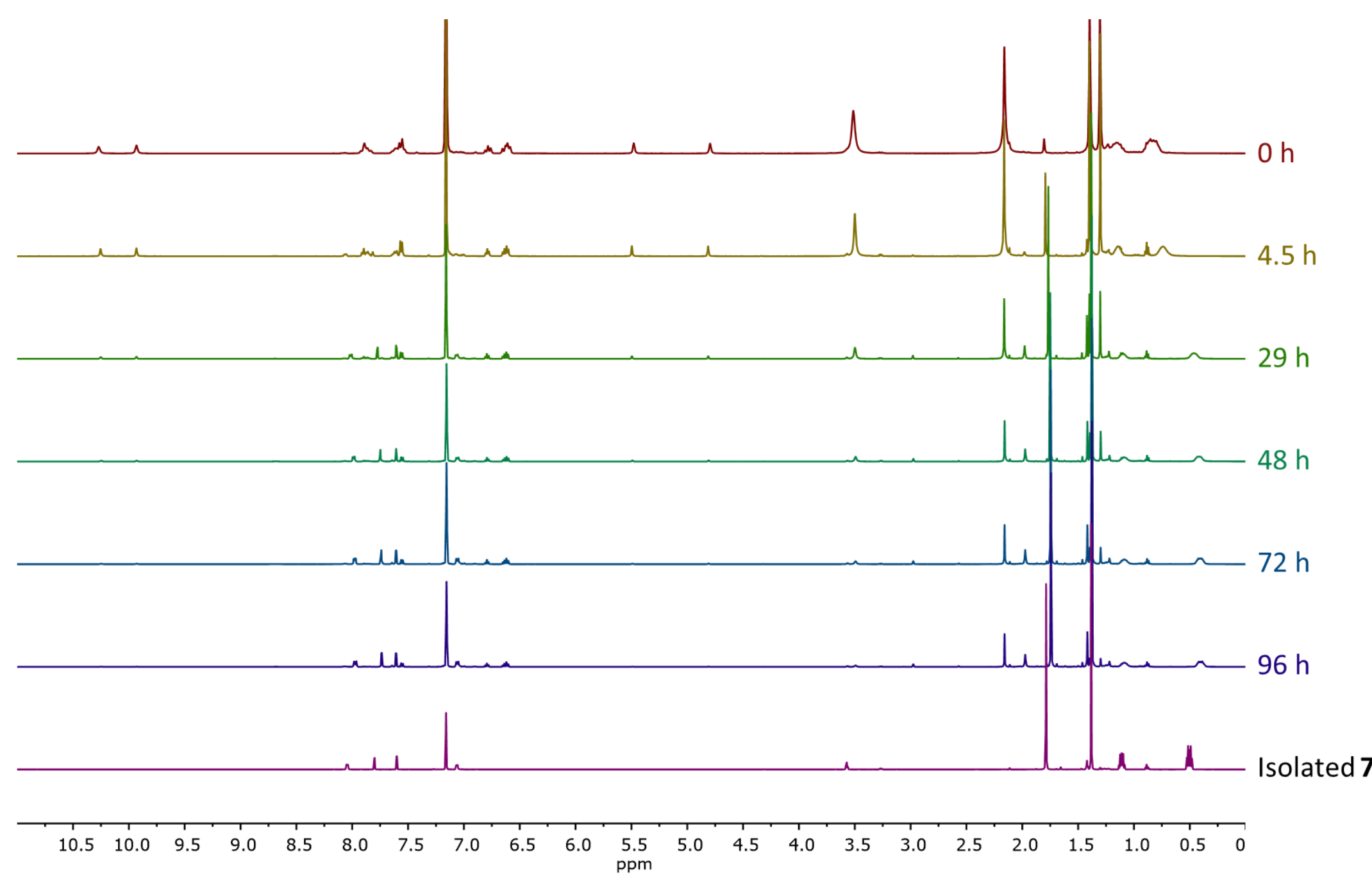

Figure S38: Reaction between $\mathbf{4}$ and $o$-nitrotoluene at room temperature monitored for $96 \mathrm{~h}+$ isolated $\mathbf{7}$ as the final product of the deoxygenation reaction. 


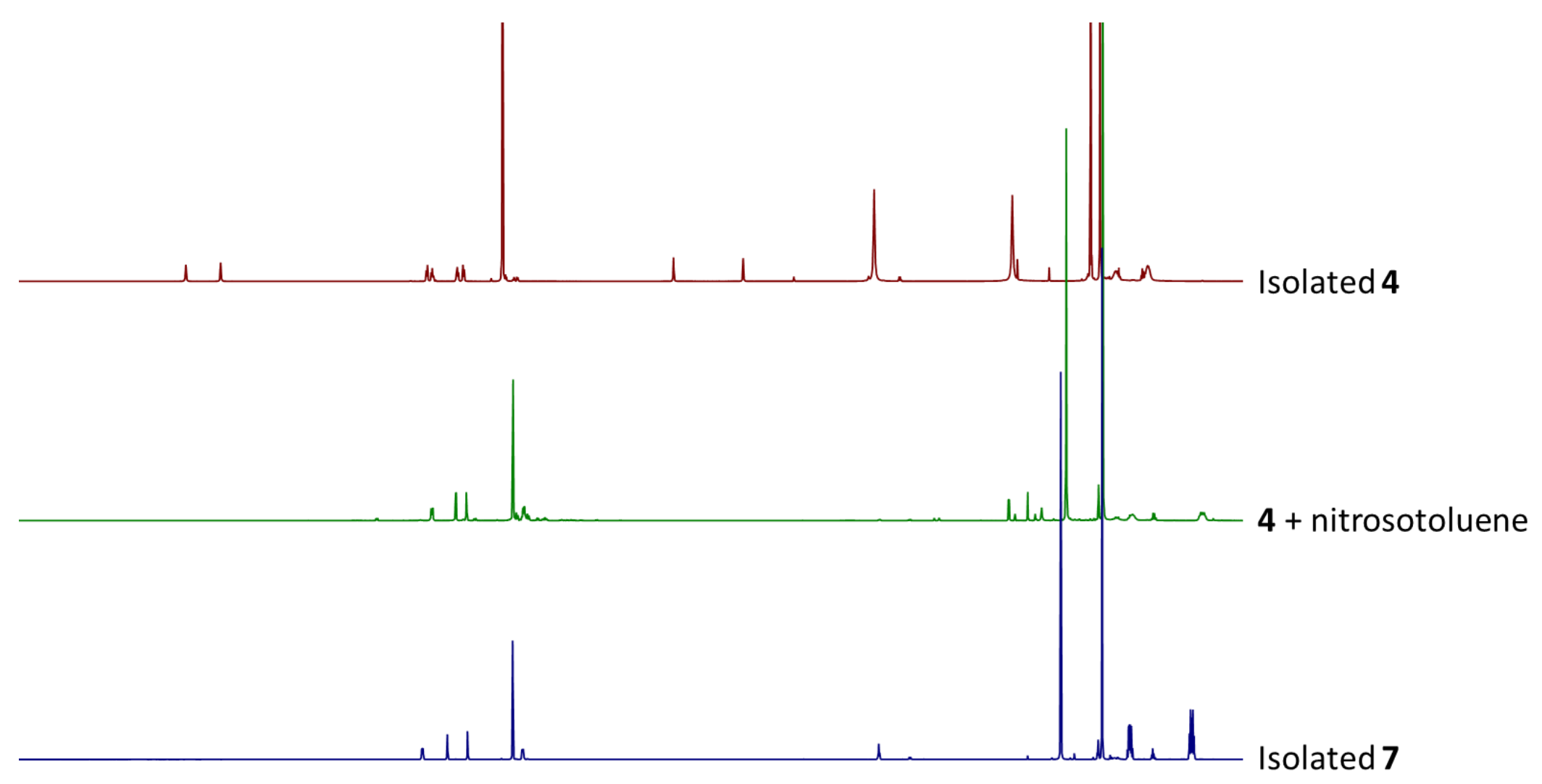

$\begin{array}{lllllllllllllllllllllllll}1.0 & 11.5 & 11.0 & 10.5 & 10.0 & 9.5 & 9.0 & 8.5 & 8.0 & 7.5 & 7.0 & 6.5 & 6.0 & 5.5 & 5.0 & 4.5 & 4.0 & 3.5 & 3.0 & 2.5 & 2.0 & 1.5 & 1.0 & 0.5 & 0\end{array}$

Figure S39: Reaction between 4 and o-nitrosotoluene at room temperature and isolated 7 as the final product of the deoxygenation reaction. 


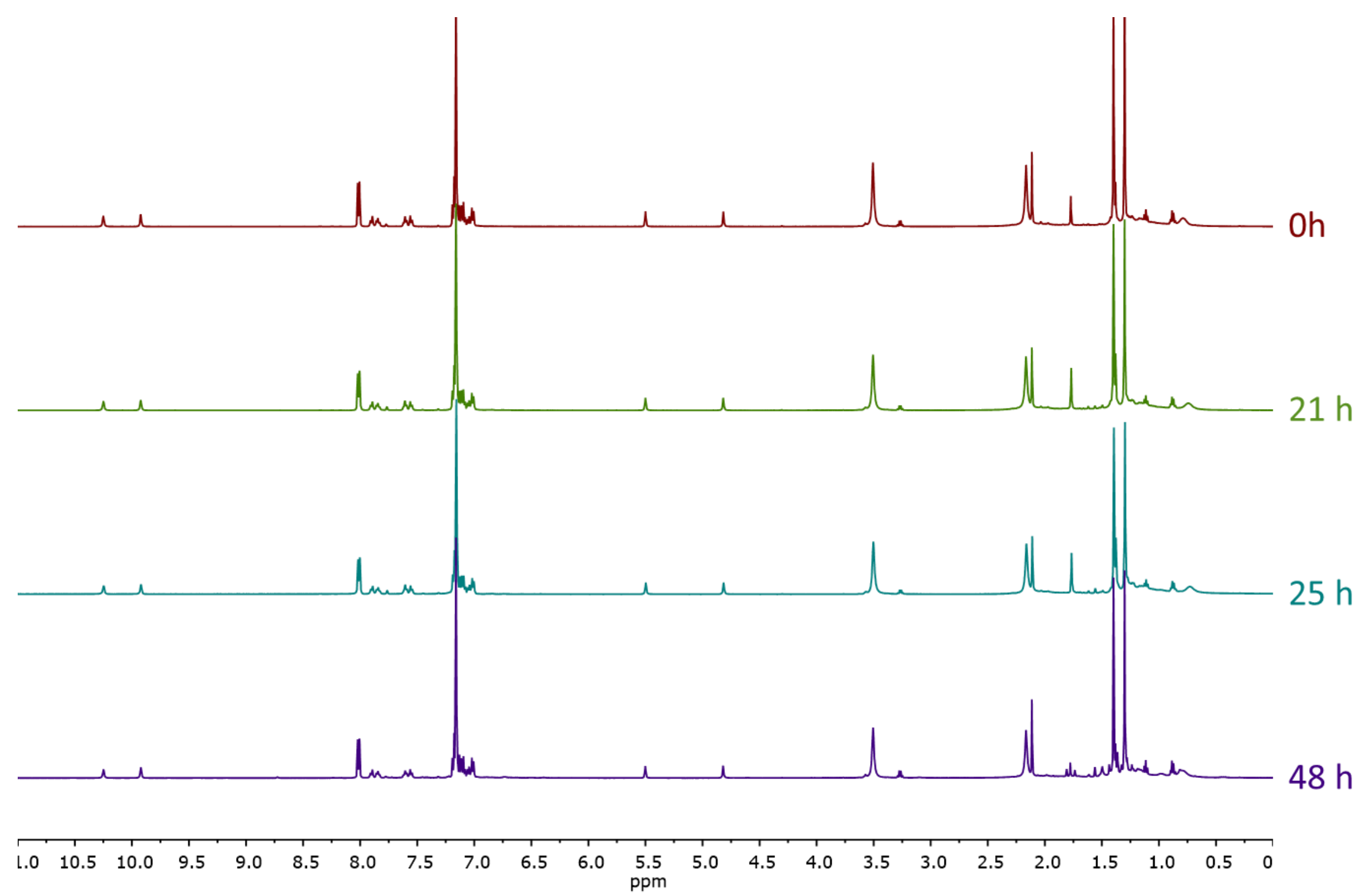

Figure S40: $\quad$ Reaction between 4 and azobenzene at $130{ }^{\circ} \mathrm{C}$ for $48 \mathrm{~h}$. 


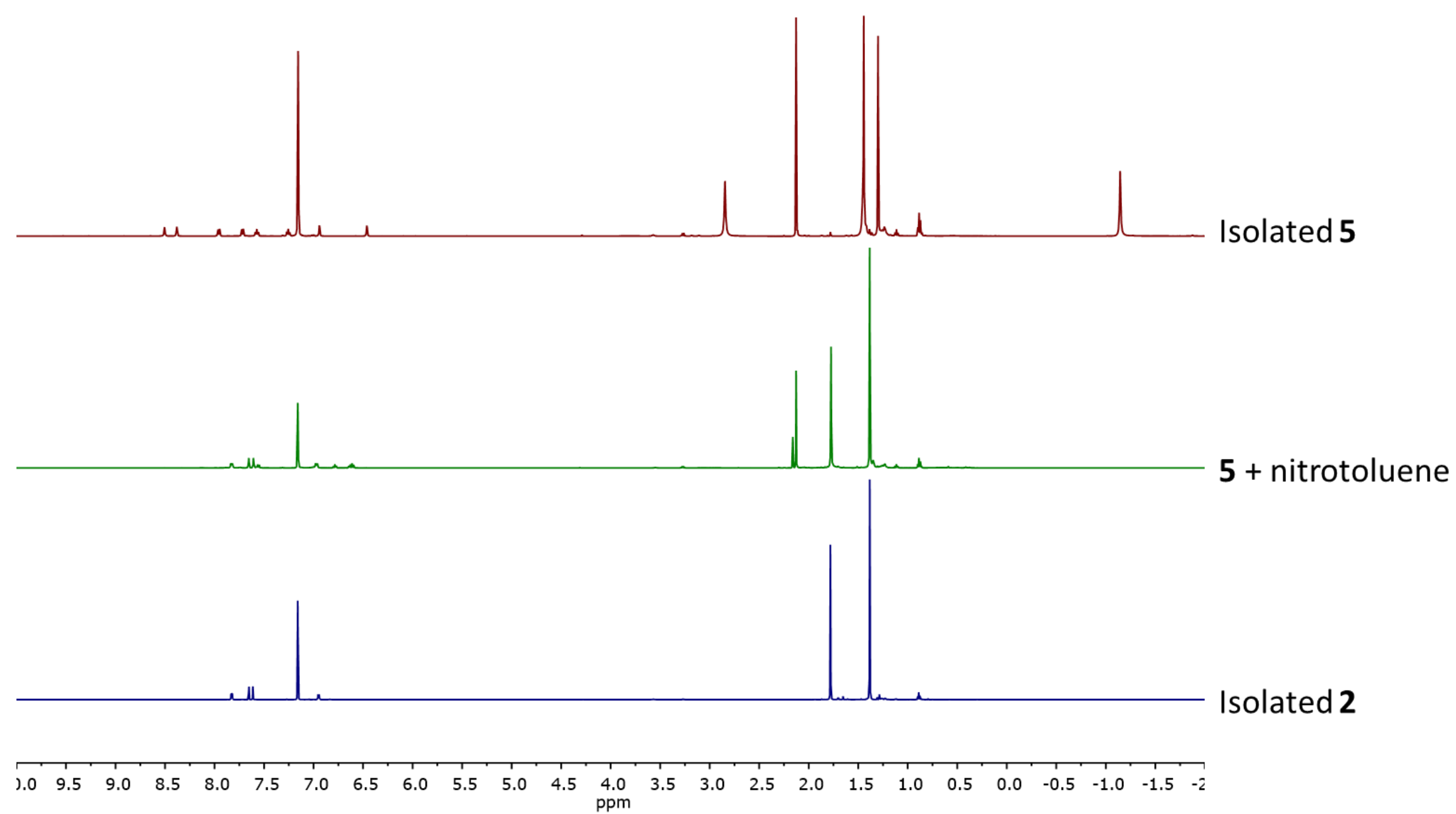

Figure S41: Reaction between $\mathbf{5}$ and $o$-nitrotoluene at room temperature and isolated $\mathbf{2}$ as the final product of the deoxygenation reaction. Signal at 2.13 belongs to hexamethylbenzene as an internal standard. 


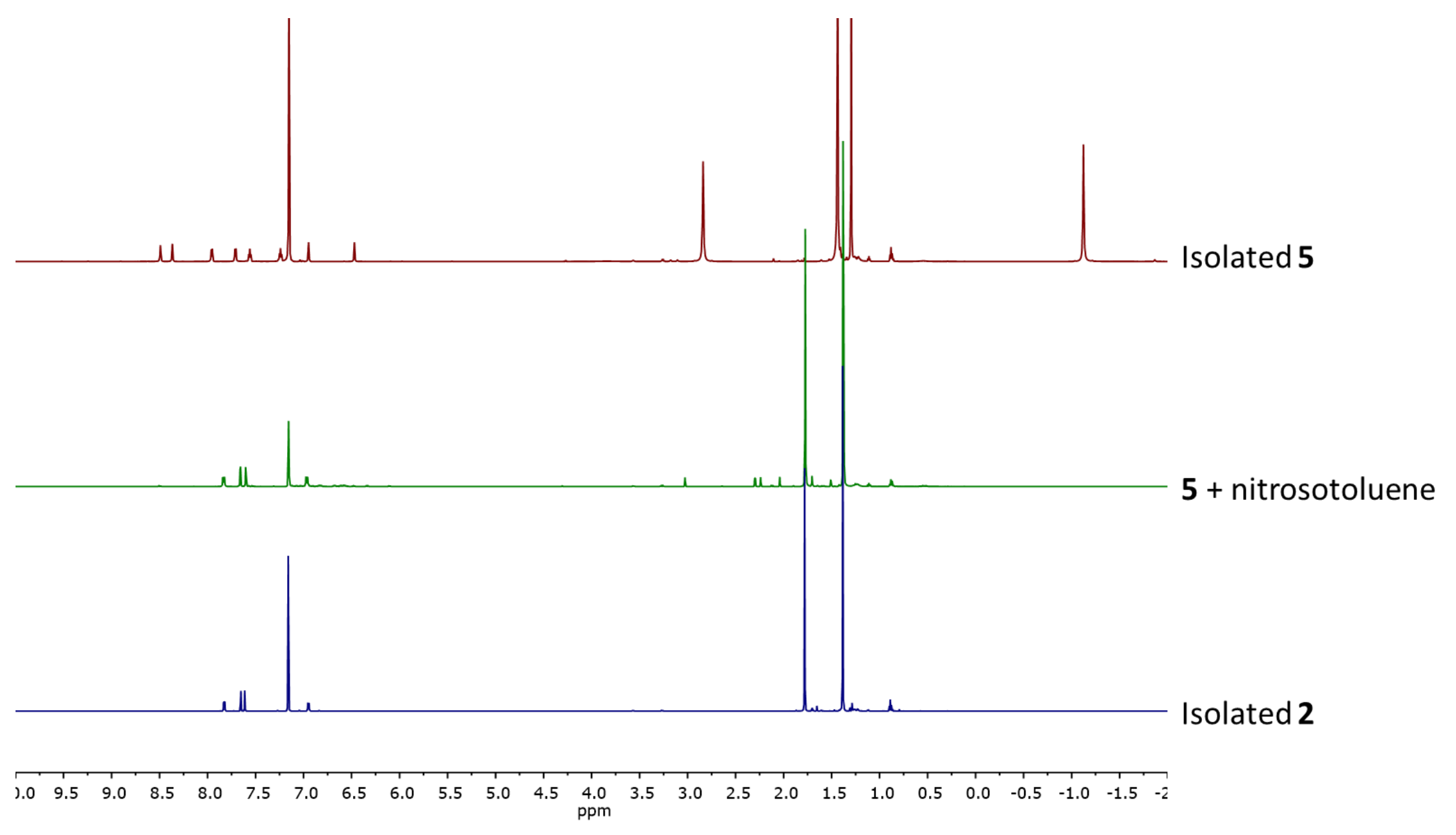

Figure S42: Reaction between $\mathbf{5}$ and $o$-nitrosotoluene at room temperature and isolated $\mathbf{2}$ as the final product of the deoxygenation reaction. 


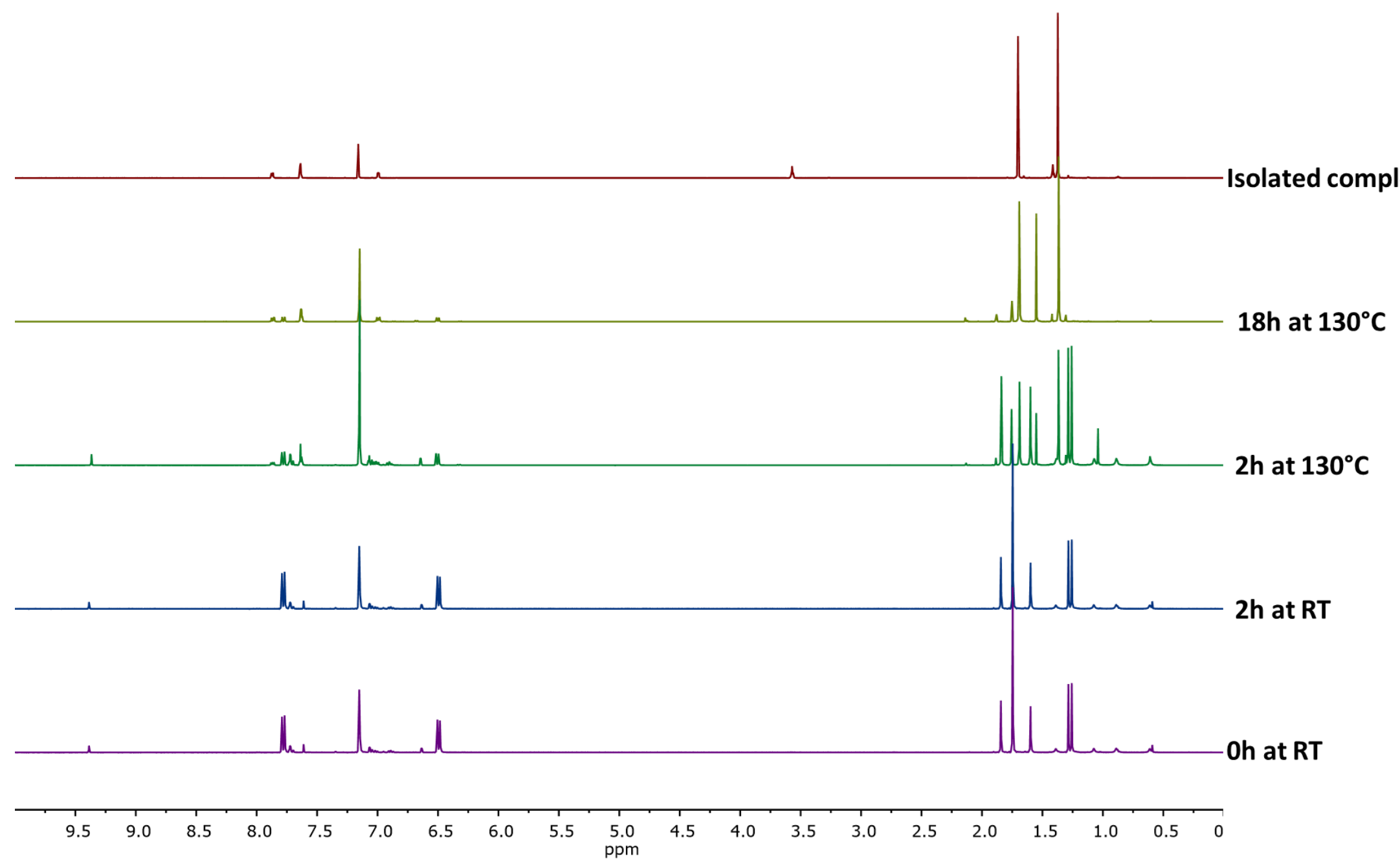

Figure S43: Stoichiometric NMR reaction between complex 6 and p-nitrotoluene. Please note that the peak at 1.55 ppm in the green spectra corresponds to 2 equivalents of acetone, resulting from the oxidative splitting of pinacol bound to complex 6 . 


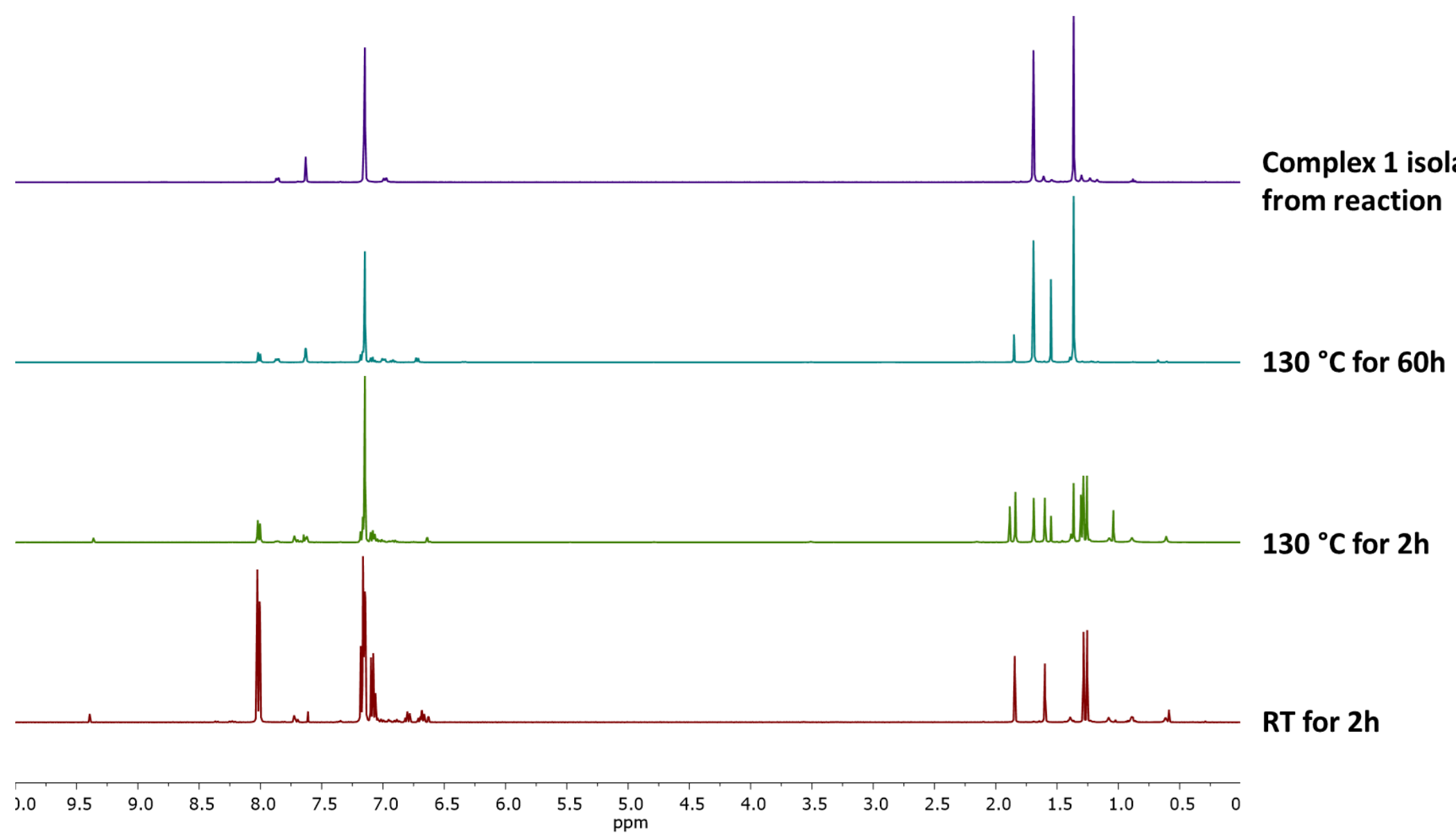

Figure S44: Stoichiometric NMR reaction between complex 6 and azobenzene. Please note that the peak at 1.55 ppm in the turquoise spectra corresponds to 2 equivalents of acetone, resulting from the oxidative splitting of pinacol bound to complex 6 . 


\section{Crystallographic details}

Table S1: Crystallographic details

\begin{tabular}{|c|c|c|c|c|}
\hline & 4 & 5* & 6 & 7 \\
\hline \multirow[t]{2}{*}{ Chemical formula } & $\mathrm{C}_{70} \mathrm{H}_{88} \mathrm{~N}_{4} \mathrm{O}_{7} \mathrm{Mo}_{2}$ & $\mathrm{C}_{78} \mathrm{H}_{106} \mathrm{~N}_{6} \mathrm{O}_{5} \mathrm{Mo}_{2}$ & $\mathrm{C}_{41} \mathrm{H}_{58} \mathrm{~N}_{2} \mathrm{O}_{6} \mathrm{Mo}_{1}$ & $\mathrm{C}_{41} \mathrm{H}_{59} \mathrm{~N}_{2} \mathrm{O}_{5} \mathrm{P}_{1} \mathrm{Mo}$ \\
\hline & $0.5\left(\mathrm{C}_{6} \mathrm{H}_{15} \mathrm{O}_{1} \mathrm{P}_{1}\right)$ & & $2\left(\mathrm{C}_{6} \mathrm{H}_{6}\right)$ & $\mathrm{C}_{7} \mathrm{H}_{8}$ \\
\hline$M r$ & 1356.39 & 1399.56 & 927.05 & 878.94 \\
\hline Crystal system & Monoclinic & Monoclinic & Monoclinic & Monoclinic \\
\hline Space group & $P 2_{1} / n$ & $C 2 / c$ & $C c$ & $P 2_{1} / n$ \\
\hline $\mathrm{a}(\AA)$ & $25.8911(11)$ & $33.500(8)$ & $11.929(4)$ & $11.1269(3)$ \\
\hline$b(\AA)$ & $12.4143(5)$ & $25.214(6)$ & $29.352(13)$ & $16.2135(4)$ \\
\hline$c(\AA)$ & $27.9368(12)$ & $20.917(5)$ & $14.513(6)$ & $25.6393(7)$ \\
\hline$\alpha\left({ }^{\circ}\right)$ & 90 & 90 & 90 & 90 \\
\hline$\beta\left(^{\circ}\right)$ & $112.0440(10)$ & $99.070(6)$ & $96.206(16)$ & $98.5150(10)$ \\
\hline$\gamma\left({ }^{\circ}\right)$ & 90 & 90 & 90 & 90 \\
\hline$V\left(\AA^{3}\right)$ & $8323.0(6)$ & $17447(7)$ & $5052(3)$ & $4574.5(2)$ \\
\hline Z & 4 & 8 & 4 & 4 \\
\hline Densitiy $\left(\mathrm{g} \mathrm{cm}^{-3}\right)$ & 1.082 & 1.066 & 1.219 & 1.276 \\
\hline$F(000)$ & 2852 & 5920 & 1968 & 1864 \\
\hline Radiation Type & MoK $\alpha$ & MoK $\alpha$ & MoK $\alpha$ & MoK $\alpha$ \\
\hline$\mu\left(\mathrm{mm}^{-1}\right)$ & 0.357 & 0.332 & 0.308 & 0.368 \\
\hline Crystal size & $0.08 \times 0.07 \times 0.05$ & $0.15 \times 0.13 \times 0.09$ & $0.25 \times 0.05 \times 0.04$ & $0.15 \times 0.14 \times 0.11$ \\
\hline Meas. Refl. & 132092 & 42816 & 37507 & 146388 \\
\hline Indep. Refl. & 17027 & 4715 & 8604 & 10490 \\
\hline Obsvd. $[I>2 \sigma(I)]$ & 12755 & 3477 & 7831 & 9475 \\
\hline $\mathrm{R}_{\text {int }}$ & 0.0841 & - & 0.0643 & 0.0446 \\
\hline $\mathrm{R}\left[\mathrm{F}^{2}>2 \sigma\left(\mathrm{F}^{2}\right)\right]$ & 0.0562 & - & 0.0308 & 0.0251 \\
\hline$w R\left(F^{2}\right)$ & 0.1727 & & 0.0658 & 0.0662 \\
\hline$S$ & 1.078 & & 1.018 & 1.069 \\
\hline$\Delta \rho_{\max }$ & 2.207 & - & 0.219 & 0.465 \\
\hline$\Delta \rho_{\min }$ & -1.096 & & -0.369 & -0.453 \\
\hline CCDC & 1993054 & - & 2044177 & 1993053 \\
\hline
\end{tabular}

*Due to the low quality of the crystals, we have only been able to integrate the data to a resolution of $1.24 \AA$ Á. Therefore, only the values that can be discussed are given. 
Table S2: $\quad$ Selected Bond lengths and angles

\begin{tabular}{|c|c|c|c|c|c|c|}
\hline & 4 & $4(\text { calc })^{\#}$ & $5 *$ & $5(\mathrm{calc})^{\#}$ & 6 & 7 \\
\hline Mo1-010 & $1.903(3)$ & 1.88 & - & 1.90 & $1.728(3)$ & $1.705(1)$ \\
\hline Mo1A-010 & $1.892(3)$ & 1.88 & - & 1.90 & - & - \\
\hline Mo1-C1 & $2.181(4)$ & 2.18 & - & 2.17 & - & $2.242(1)$ \\
\hline Mo1-011/N40 & $1.674(3)$ & 1.68 & - & 1.72 & $1.711(3)$ & $1.722(1)$ \\
\hline Mo1-01 & $1.977(3)$ & 2.02 & - & 2.04 & $1.982(3)$ & $1.969(1)$ \\
\hline Mo1-O2 & $1.976(3)$ & 2.00 & - & 2.04 & - & $2.000(1)$ \\
\hline Mo1A-C1A & $2.182(4)$ & 2.18 & - & 2.16 & - & - \\
\hline Mo1-011A/N40A & $1.670(3)$ & 1.68 & - & 1.72 & - & - \\
\hline Mo1A-01A & $1.976(3)$ & 2.00 & - & 2.00 & - & - \\
\hline Mo1A-O2A & $1.984(3)$ & 2.01 & - & 2.03 & - & - \\
\hline Mo1-040 & - & & - & & - & $2.252(1)$ \\
\hline Mo1-050 & - & - & - & - & $1.917(3)$ & - \\
\hline Mo1-051 & - & - & - & - & $1.963(3)$ & - \\
\hline O40-P40 & - & - & - & - & - & $1.507(1)$ \\
\hline $\mathrm{N} 1-\mathrm{C} 8$ & $1.437(4)$ & - & - & - & $1.452(5)$ & $1.439(2)$ \\
\hline $\mathrm{C} 8-\mathrm{C} 13$ & $1.400(5)$ & - & - & - & $1.401(6)$ & $1.410(2)$ \\
\hline C13-O1 & $1.341(4)$ & - & - & - & $1.339(5)$ & $1.352(2)$ \\
\hline $\mathrm{N} 2-\mathrm{C} 14$ & $1.430(4)$ & - & - & - & $1.445(5)$ & $1.434(2)$ \\
\hline C14-C19 & $1.398(5)$ & - & - & - & $1.382(5)$ & $1.416(2)$ \\
\hline C19-O2 & $1.341(4)$ & - & - & - & $1.366(5)$ & $1.351(2)$ \\
\hline Mo1-O10-Mo1A & $154.6(2)$ & & - & - & - & - \\
\hline O11-Mo1-010 & $110.1(1)$ & & - & - & $110.9(1)$ & $106.6(1)$ \\
\hline 011A-Mo1A-010 & $111.5(2)$ & & - & - & - & - \\
\hline$\tau_{5} \mathrm{Mo1}$ & 0.10 & & - & - & 0.45 & - \\
\hline$\tau_{5} \mathrm{Mo} 1 \mathrm{~A}$ & 0.03 & & - & - & - & - \\
\hline
\end{tabular}

*Due to the low quality of the crystals, we have only been able to integrate the data to a resolution of $1.24 \AA$ Á, prohibiting any useful discussion of the bnd distances in the molecule.

${ }^{\#}$ Calculated values from DFT calculations (for more information see Section 5 in the SI) 


\section{Computational Details}

Geometry optimizations of the oxo and imido Molybdenum complexes have been performed using the B3PW91 ${ }^{[9,10]}$ hybrid functional without any symmetry restrictions. The Molybdenum atom was treated with its Stuttgart-Köln relativistic effective core potential (RECP) ${ }^{[11]}$ meanwhile for $\mathrm{H}, \mathrm{C}, \mathrm{N}$ and $\mathrm{O}$ atoms with the $6-31 \mathrm{G}(\mathrm{d}, \mathrm{p})$ basis sets ${ }^{[12]}$.

To further investigate the nature of Mo-M (with $\mathrm{M}=\mathrm{C}, \mathrm{N}$ and $\mathrm{O}$ ) interactions in the optimized structures, Wiberg bond indices have been calculated using the natural bond orbital (NBO) scheme ${ }^{[13]}$. In order to analyze the electronic states of Mo-Mo complexes we followed the same procedure as in our previous studies ${ }^{[11,13,14]}$. In the first step, we have determined the optimal sets of molecular orbitals (MOs) for each Molybdenum complex through Restricted Open Shell (ROHF) calculations for different spin values ( $\mathrm{S}=0,1$ and 2 ). In a second stage, using these MOs we have carried out a systematic Complete Active Space Self Consistent Field (CASSCF) study. In both cases (oxo and imido) the complete active space (CAS) has been generated by distributing six electrons in five active orbital. For the oxo complex, HOMO-2, HOMO-1, HOMO, LUMO and LUMO+1 orbitals obtained from the singlet state have been chosen to build a suitable active space. In the other case, when the imido ligand is present, HOMO-3, HOMO-2, SOMO-1 and SOMO and LUMO+12 orbitals from the triplet state were used as an input to perform the multi-configurational SCF calculations. Note that for all complexes considered in this work, CASSCF computations have been carried out to elucidate the nature of the first and the second roots for each spin value aforementioned. All electronic structure calculations were carried out with Gaussian09 software ${ }^{[15]}$.

The supplemental file structures.xyz contains the computed Cartesian coordinates of all of the molecules reported in this study. The file may be opened as a text file to read the coordinates, or opened directly by a molecular modeling program such as Mercury (version 3.3 or later, http://www.ccdc.cam.ac.uk/pages/Home.aspx) for visualization and analysis. 


\section{Influence of the spin state}

Complex 4, singlet state

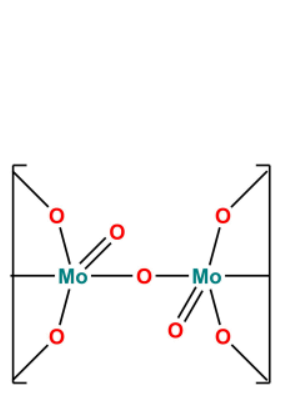

$\Delta \mathrm{H}(\mathrm{kcal} / \mathrm{mol})$
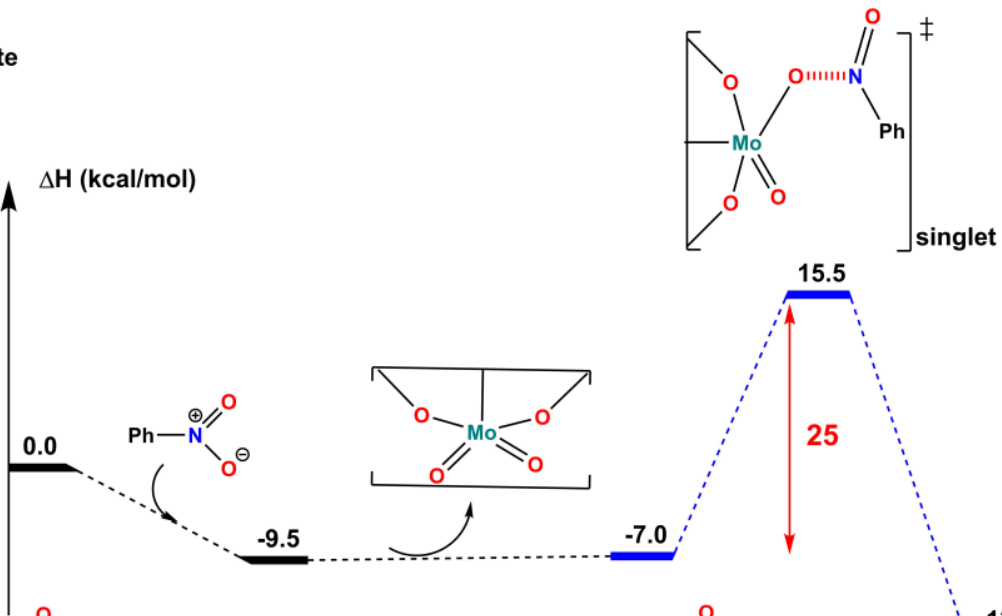

$-9.5$

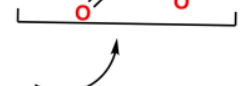

$-7.0 !$
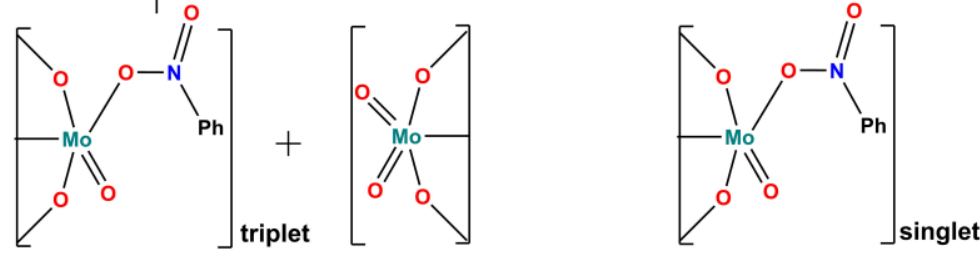

Complex 4, triplet state

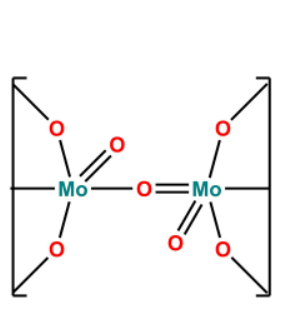

$\Delta \mathrm{H}(\mathrm{kcal} / \mathrm{mol})$
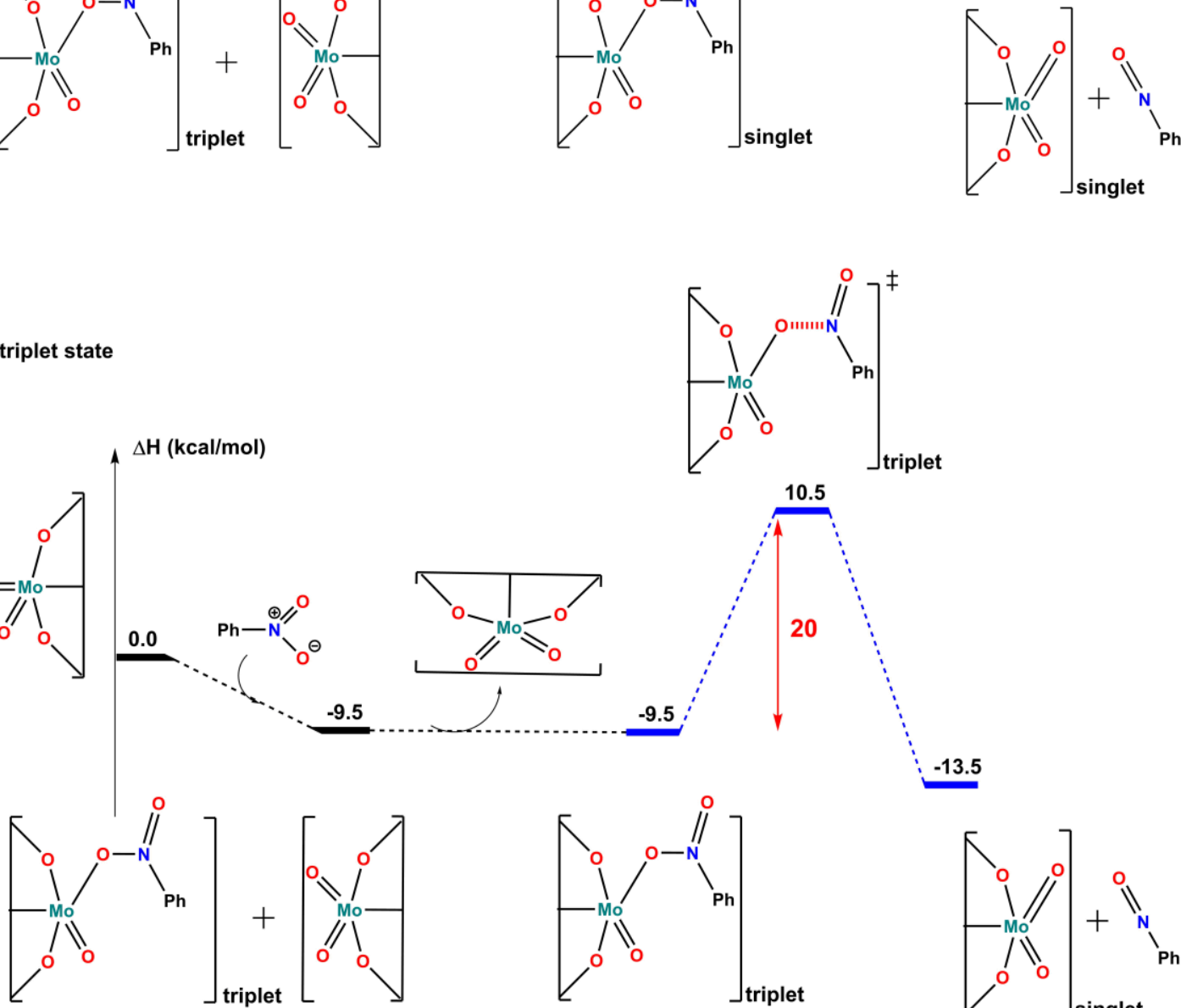

$-13.5$

Figure S45: Reaction coordinate and energy profile of the deoxygenation reaction calculated in dependency of the spin state of complex 4. Top: Energy profile if the catalyst in the singlet state. Bottom: Energy profile if the catalyst is in the triplet state. 


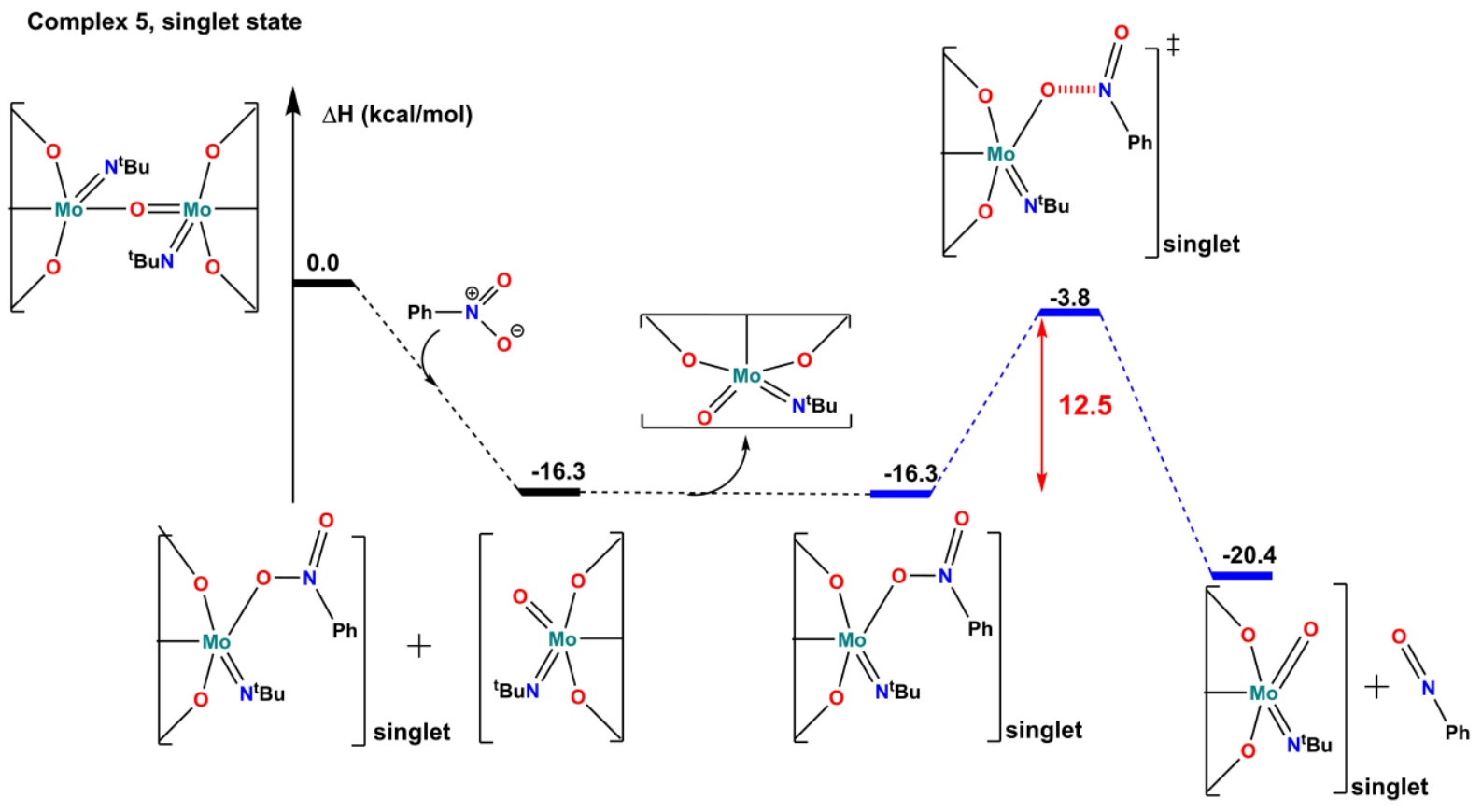

Complex 5, triplet state
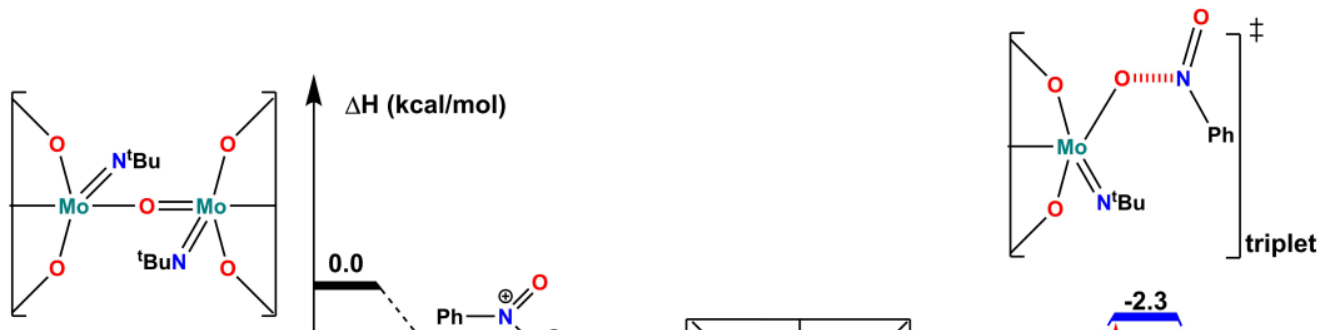

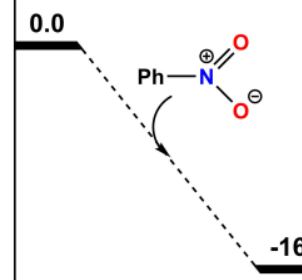
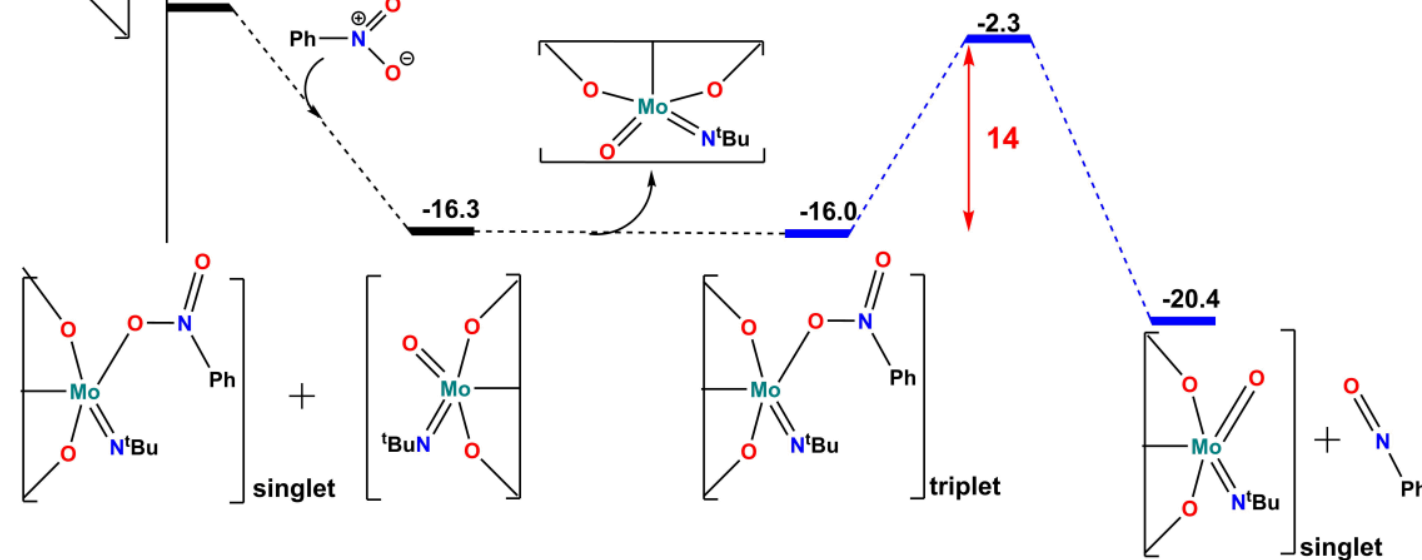

Figure S46: Reaction coordinate and energy profile of the deoxygenation reaction calculated in dependency of the spin state of complex 5. Top: Energy profile if the catalyst in the singlet state. Bottom: Energy profile if the catalyst is in the triplet state. 


\section{Literature}

[1] D.F.Evans, J. Chem. Soc. 1959, 2003.

[2] K.A. Rufanov, D.N. Zarubin, N.A. Ustynyuk, D.N. Gourevitch, J. Sundermeyer, A.V. Churakov, J.A.K. Howard, Polyhedron 2001, 20, 379.

[3] R. Ramnauth, S. Al-Juaid, M. Motevalli, B.C. Parkin, A.C. Sullivan, Inorg. Chem. 2004, 43, 4072.

[4] M. Baltrun, F.A: Watt, R. Schoch, S. Hohloch, Organometallics, 2019, $38,3719$.

[5] a) E. Despagnet-Ayoub, L.M. Henling, J.A. Labinger, J. E. Bercaw, Dalton Trans. 2013, 42, 15544. b) E. Borré, G. Dahm, A. Aliprandi, M. Mauro, S. Dagorne, S. Bellemin-Laponnaz, Organometallics 2014, 33, 4374.

[6] G.M. Sheldrick, Acta cryst. C 2015, 71, 3.

[7] O.V. Dolomanov, L.J. Bourhis, R.J. Gildea, J.A.K. Howard, H. Puschmann, J Appl Crystallogr 2009, 42, 339.

[8] P. van der Sluis, A.L. Spek, Acta Crystallogr A 1990, 46, 194.

[9] A.D. Becke, J. Chem. Phys., 1993, 98, 5648.

[10] J.P. Perdew, Y. Wang, Phys. Rev. B, 1992, 45, 13244.

[11] Stuttgart RSC 1997 ECP Basis Set obtained from "A New Basis Set Exchange: An Open, Up-to-date Resource for the Molecular Sciences Community."

B.P. Pritchard, D. Altarawy, B. Didier, T. D. Gibson and T. L. Windus, J. Chem. Inf. Model. 2019, 59, 4814.

[12] a) A.D. McLean, G.S.J. Chandler, Chem. Phys., 1980, 72, 5639. b) W.J. Hehre, R. Ditchfield, J.A. Pople, J.Chem. Phys., 1972, 56, 2257.

[13] A. E. Reed, L. A. Curtis, F. Weinhold, Chem. Rev., 1998, 88, 899.

[14] R. L. Halbach, G. Nocton, J. I. Amaro-Estrada, L. Maron, C. H. Booth, R. A. Andersen, Inorg. Chem. 2019, 58, 12083.

[15] M. J. Frisch, G. W. Trucks, H. B. Schlegel, G. E. Scuseria, M. A. Robb, J. R. Cheeseman, G. Scalmani, V. Barone, B. Mennucci, G. A. Petersson, et al., gaussian 09, Revision A.01, Gaussian, Inc., Wallingford, CT, 2009, 201. 